University of Louisville

ThinkIR: The University of Louisville's Institutional Repository

8-2014

\title{
A meta-analytic review of the relationships between the therapeutic alliance, empathy, and genuineness in individual adult psychotherapy.
}

Jacob B. Nienhuis

University of Louisville

Follow this and additional works at: https://ir.library.louisville.edu/etd

Part of the Counseling Psychology Commons

\section{Recommended Citation}

Nienhuis, Jacob B., "A meta-analytic review of the relationships between the therapeutic alliance, empathy, and genuineness in individual adult psychotherapy." (2014). Electronic Theses and Dissertations. Paper 1063.

https://doi.org/10.18297/etd/1063

This Doctoral Dissertation is brought to you for free and open access by ThinkIR: The University of Louisville's Institutional Repository. It has been accepted for inclusion in Electronic Theses and Dissertations by an authorized administrator of ThinkIR: The University of Louisville's Institutional Repository. This title appears here courtesy of the author, who has retained all other copyrights. For more information, please contact thinkir@louisville.edu. 


\title{
A META-ANALYTIC REVIEW OF THE RELATIONSHIPS BETWEEN THE THERAPEUTIC ALLIANCE, EMPATHY, AND GENUINENESS IN INDIVIDUAL
}

\section{ADULT PSYCHOTHERAPY}

\author{
By \\ Jacob B. Nienhuis \\ B.A., Calvin College, 2007 \\ M. Ed., University of Louisville, 2011
}

\begin{abstract}
A Dissertation
Submitted to the Faculty of the College of Education and Human Development of the University of Louisville in Partial Fulfillment of the Requirements for the Degree of
\end{abstract}

\author{
Doctor of Philosophy \\ Department of Educational and Counseling Psychology \\ University of Louisville \\ Louisville, Kentucky
}

August 2014 



\title{
ADULT PSYCHOTHERAPY
}

\author{
By \\ Jacob B. Nienhuis \\ B.A., Calvin College, 2007 \\ M. Ed., The University of Louisville, 2011 \\ A Dissertation Approved on
}

December 5, 2013

by the following Dissertation Committee:

\begin{tabular}{|c|}
\hline $\begin{array}{l}\text { Dissertation Director } \\
\text { Jesse Owen, Ph. D. }\end{array}$ \\
\hline $\begin{array}{l}\text { Dissertation Co-Director } \\
\text { Jeffrey Valentine, Ph. D. }\end{array}$ \\
\hline Stephanie Budge, Ph. D. \\
\hline
\end{tabular}




\section{ACKNOWLEDGEMENTS}

I would like to thank my co-chairs for their individual contributions and guidance. Dr. Jesse Owen, thank you for your help exploring the many nuances in the therapeutic relationship literature and helping me apply this work to psychotherapy practice. Our talks helped me see the different facets of the therapeutic relationship and how perception means so much in therapy. I also want to thank you for your insight during advanced practicum and for introducing me to short-term dynamic therapy, which I continue to use and teach to others.

Dr. Jeff Valentine, thank you for your instruction in meta-analysis and guidance that brought this project to completion. You were there at the beginning, when I was still wrestling with translating ideas about therapy relationships into a study-able dissertation question. I really enjoyed our talks, over tea and coffee, as this project gained momentum. Thank you for all your help with the study methodology and showing me how to communicate it in a succinct, meaningful way.

I would also like to thank Dr. Stephanie Budge and Dr. Mark Hilsenroth for their comments and assistance as committee members. Your calm and humorous personalities made an otherwise stressful life event so much more bearable. I never expected to laugh so much during my proposal defense. Special thanks to AC Del Re for his help in creating and providing personal assistance with R-based meta-analysis software.

I want to express my utmost thanks to my wife Miriam for her patience, support, and kind words throughout the full grad school process. You were there before this 
whole process started and you've been strong through all the ups and downs that have come as a result. It's difficult to fully credit Miriam's contribution in such a short space. I'm truly blessed to have you in my life.

Huge thanks to my parents Bob and Jeanne. You've been incredibly supportive through all my education and have provided great insight and comfort during everything that comes with it. From the earliest years, you taught me how to be my genuine, empathic self. Thanks to my brothers Paul and Adam, for all the laughter and fun times that started when we grew up together and continue to the present. Thanks to Kristin, Eva, my grandparents John and Dorothy Nienhuis, and the late Berend and Betty Jonker. Your support through this lengthy process helped me keep focus on the overall goal and your love made the most out of every visit home. Special thanks to the Clasons, who welcomed me into their family. Finally, a silly-but-sincere thanks to Elzee and Murphy, whose pure, tail-wagging affection and walking needs allowed for many much-needed breaks from work. 


\begin{abstract}
A META-ANALYTIC REVIEW OF THE RELATIONSHIPS BETWEEN THE THERAPEUTIC ALLIANCE, EMPATHY, AND GENUINENESS IN INDIVIDUAL ADULT PSYCHOTHERAPY
\end{abstract}

Jacob B. Nienhuis

December 5, 2013

This dissertation explored the relationship between the therapeutic alliance and perceptions of therapist empathy and genuineness through a systematic review and metaanalysis. Alliance, empathy, and genuineness are each integral parts of the therapeutic relationship. Prior meta-analyses demonstrated that alliance, empathy, and genuineness each had a moderate relationship to therapy outcome. No previous analysis has explored how therapist empathy and genuineness contribute to the therapeutic alliance. Studies for this analysis were obtained through a multi-part search strategy. Out of 2,141 obtained abstracts, 46 studies contained enough data for inclusion in the meta-analysis. Thirty-six studies reported alliance/empathy relationships, six studies reported alliance/genuineness relationships, and four studies reported both. Random effects meta-analyses revealed that therapeutic alliance was related to perceptions of therapist empathy with a mean $r(\mathrm{k}=40)$ $=.51(95 \% \mathrm{CI}=0.43-0.59)$. Therapeutic alliance was related to perceptions of therapist genuineness with a mean $r(\mathrm{k}=10)=.53(95 \% \mathrm{CI}=0.40-0.65)$. Tests of publication bias indicated a low likelihood of publication bias affecting the strength and direction of the results. Potential moderating variables were explored. These included: rater perspective 
(client, therapist, and observer), measure of therapeutic relationship variables, client and therapist race/ethnicity, theoretical approach to treatment, publication source, and clientto-therapist ratio. Future directions for study of the therapeutic relationship are discussed. The dissertation concludes with practice implications for clinicians practicing psychotherapy. 


\section{TABLE OF CONTENTS}

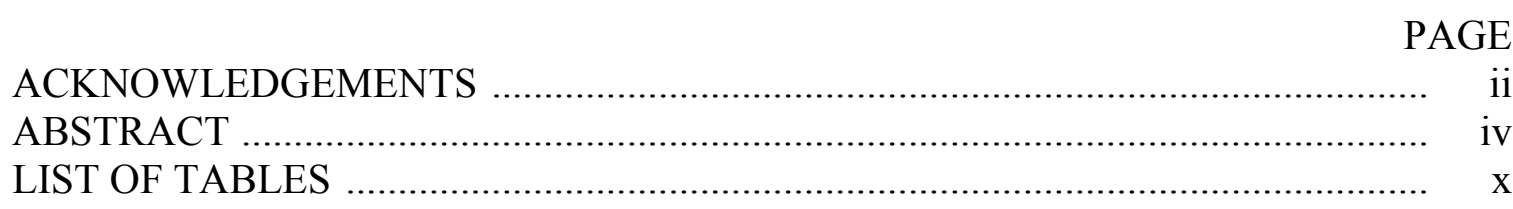

CHAPTER I. INTRODUCTION AND LITERATURE REVIEW ............................ 1

Therapeutic Alliance ..................................................................................... 3

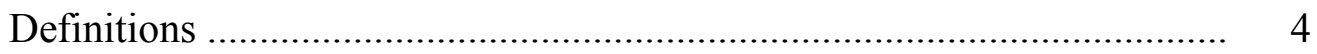

Measures of Alliance .................................................................. 6

Therapeutic Alliance and Outcome ................................................... 8

Therapist Effects on Alliance ..................................................... 10

Nesting ....................................................................... 12

Therapist Characteristics ................................................................... 13

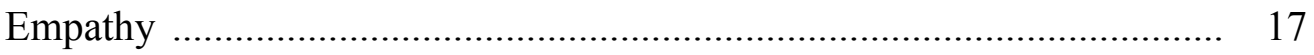

History of Empathy Research .............................................. 17

Definitions of Empathy ...................................................... 18

Empathy and Outcome ..................................................... 20

Potential Moderators ........................................................ 21

Measures of Empathy f........................................................ 22

Genuineness [........................................................................ 23

History of Genuineness Research ........................................... 23

Genuineness and Outcome .................................................... 25 


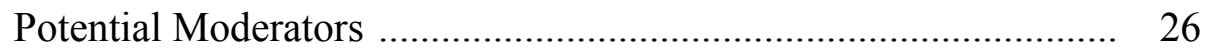

Measures of Genuineness ...................................................... 26

Relationships between Empathy and Genuineness .................................. 28

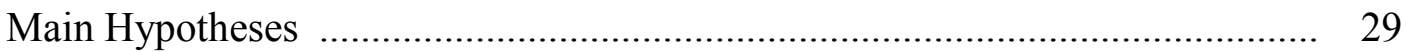

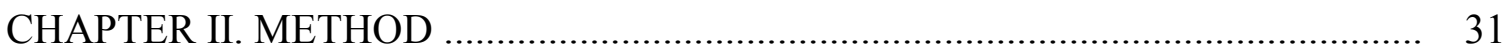

Systematic Review and Meta-Analysis .......................................................... 31

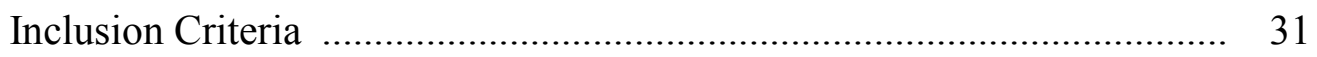

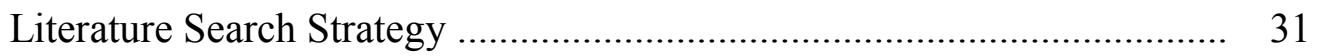

Electronic Databases ............................................................. 32

Searching the Grey Literature ..................................................... 33

Abstract Screening .......................................................................... 34

Coding Process ………................................................................ 34

Statistical Procedures .................................................................... 35

Effect Size Calculation ........................................................... 35

Heterogeneity ………........................................................... 36

Model Choice ……………………....................................... 37

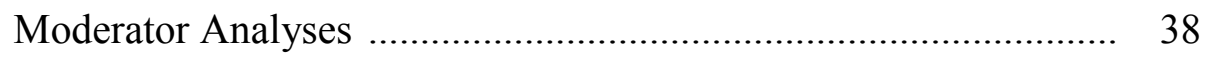

Computer Programs .............................................................. 38

Missing Data .......................................................................... 39

Addressing Publication Bias .................................................... 40

CHAPTER III. RESULTS _.......................................................................... 42

Therapist Empathy and Alliance ……........................................................... 42

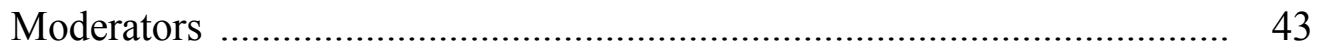




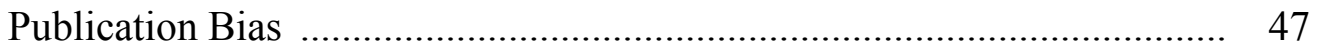

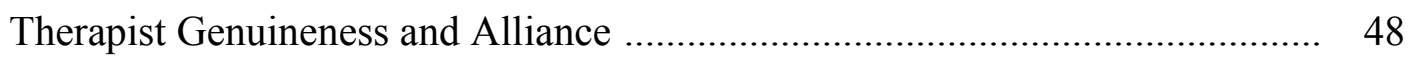

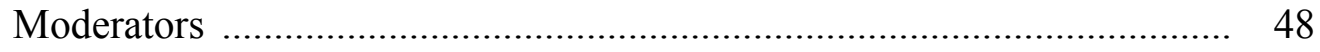

Publication Bias ...................................................................... 50

Therapist Empathy and Genuineness .......................................................... 51

Between-Therapist Effects ........................................................................... 51

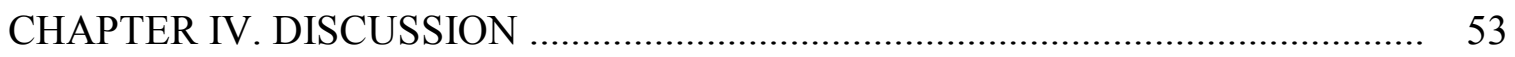

Limitations of the Research ......................................................................... 57

Relationship in Practice and Construct ....................................................... 58

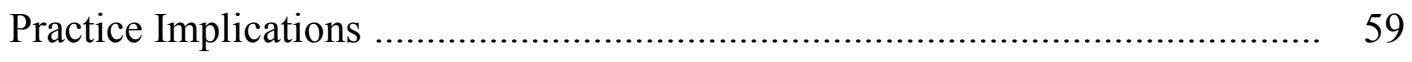

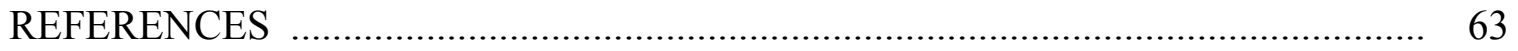

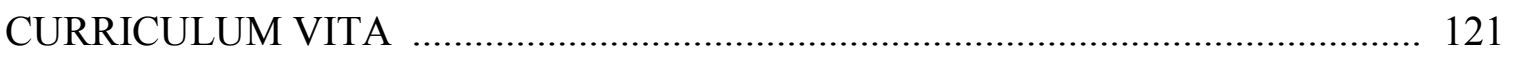




\section{LIST OF TABLES}

TABLE $\quad$ PAGE

1. Database Search Strategy ……………………….......................................... 90

2. List of Authors Contacted for Data ................................................................... 91

3. Abstract Screening Guide …………................................................................ 92

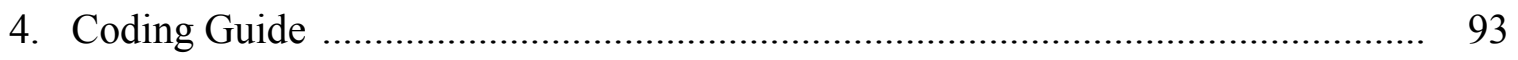

5. Graph of Excluded Studies and Included Studies ................................................. 101

6. Alliance and Therapist Empathy Overall Analysis …............................................. 102

7. Results of Moderator Tests for Therapist Empathy and Alliance .......................... 103

8. Additional Information Regarding the Individual Alliance and Therapist ............. 105

9. Studies of Alliance Related to Empathy by Theoretical Approach to Treatment ... 109

10. Moderator Test of Race/Ethnicity Effects on Alliance/Empathy .......................... 111

11. Funnel Plot of Alliance and Therapist Empathy Studies .................................... 112

12. Trim and Fill Analysis of Alliance Related to Therapist Empathy ....................... 113

13. Alliance and Therapist Genuineness Overall Analysis ........................................ 114

14. Additional Information Regarding the Individual Alliance and Therapist ............ 115

15. Results of Moderator Tests for Therapist Genuineness and Alliance .................... 117

16. Funnel Plot of Alliance and Therapist Genuineness Studies ............................... 119

17. Trim and Fill Analysis of Alliance Related to Therapist Genuineness ................ 120 


\section{CHAPTER I INTRODUCTION AND LITERATURE REVIEW}

Psychotherapy is an effective method for creating behavior change (Smith \& Glass, 1977; Smith, Glass, \& Miller, 1980; Wampold, 2001, 2007, 2010). Understanding why psychotherapy leads to behavior change requires, in part, an investigation of the mechanisms of change (Lambert \& Ogles, 2004; Wampold, 2001). Among these potential mechanisms, the therapeutic relationship (e.g., the relationship between the client and the therapist in individual therapy) has been widely studied as core aspect contributing to the gains made in psychotherapy. Research suggests that the therapeutic relationship and its elements (e.g., alliance, real relationship, empathy, etc.) explain more variance in treatment outcomes than specific treatment modality (Wampold, 2001). The alliance is one of the most prominently studied aspects of the therapeutic relationship in psychotherapy (Grencavage \& Norcross, 1990). Studies have shown that relational aspects, such as the alliance and empathy, account for equal or greater influence on therapy outcome when compared to bona fide methods of treatment (Ahn \& Wampold, 2001; Wampold, 2001; 2007). Wampold (2007) posited that the relational factors inherent in therapy could account for the significant client changes. The present study sought to explore the relationships between some of these relational factors.

As part of the American Psychological Association's (APA) task force to explore Evidence-Based Relationships" (EBR), Norcross (2011) compiled a series of metaanalyses on relationships in psychotherapy. The studies included in this publication reviewed general and specific aspects of the therapeutic relationship associated with 
outcomes. General relational components included the therapeutic alliance (Horvath, Del Re, Flückiger, \& Symonds, 2011), empathy (Elliott, Bohart, Watson, \& Greenberg, 2011), collaboration (Shick Tryon \& Winograd, 2011), genuineness (Kolden, Klein, Wang, \& Austin, 2011), and countertransference management (Hayes, Gelso, \& Hummel, 2011). Further, other general therapeutic processes included stages of change (Norcross, Krebs, \& Prochaska, 2011), culture (Smith, Domenech Rodriguez, \& Bernal, 2011), expectation (Constantino, Glass, Arnkoff, Ametrano, \& Smith, 2011), resistance (Beutler, Harwood, Michelson, Song, \& Holman, 2011), and attachment style (Levy, Ellison, Scott, \& Bernecker, 2011). In the final chapter, Norcross and Wampold (2011) concluded that the evidence-based therapeutic relationship - mlaes substantial and consistent contributions to psychotherapy outcome independent of the specific type of treatment" (p. 423).

The present study used the EBR framework as a guideline for examining relationships between elements of the therapeutic relationship, with the goal of adding to the evidence-based literature on the importance of the therapeutic relationship. The relationship variables of interest were the therapeutic alliance and client perceptions of therapist empathy and genuineness. Several theories of psychotherapy process acknowledge the importance of these relationship variables. For instance, Beck and Freeman (1990) stated that a trusting relationship is needed at the beginning of cognitive therapy. They further highlight the importance of openness and honesty (genuineness), mutual work toward goals and means to those goals (alliance), and sensitivity to the client's needs in therapy (empathy). Moreover, core to the therapeutic relationship, Rogers (1957) theorized that therapist empathy and genuineness acted as primary factors 
for client change. A recent study provided empirical support linking Rogerian conditions to positive treatment outcome (Zuroff, Kelly, Leybman, Blatt, \& Wampold, 2010).

The present study also explored relationships between the different components of the therapeutic relationship as conceptualized by Gelso and Carter (1994). These authors identified three components of the therapeutic relationship: 1) the working alliance, which is the agreement on the tasks and goals for therapy; 2) countertransference management, which is how the therapist manages personal feelings toward the client; and 3) the real relationship, which is the genuine and realistic relationship between client and therapist. The authors posited that these relationship components interacted with each other. Each component of Gelso and Carter's conceptualization of the therapeutic relationship is evident in the present study. Empathy is a facet of countertransference management (Gelso \& Hayes, 2001) and genuineness is an aspect of the real relationship. The present study sought to examine the extent of the relationships between these aspects of the therapeutic relationship.

The following sections provide an overview of the major studies and literature reviews examining the therapeutic alliance, empathy, and genuineness related to psychotherapy outcome. They review definitions, measurement, and effects of measurer perspective on the targeted relationship variables.

\section{Therapeutic Alliance}

This section reviews the history of the alliance in therapy, examines commonly used measures of the alliance, reviews the findings of past meta-analyses of alliance related to treatment outcome, and explores the effects of the therapist on the alliance. 


\section{Definitions}

The therapeutic alliance holds an established and important place in therapy. The concept dates back to Freud's (1913/1958) explanations of the patient-analyst relationship. Freud was trying to understand why the patient continued to return to therapy when the therapeutic content could be frightening. No formal term of alliance" existed; however, Freud referred to this dilemma as exploring transference and allying with the client against the neuroses as a common foe. Although this initial interpretation of the therapeutic alliance was specific to psychoanalysis the therapeutic alliance appeared in different forms in most subsequent theories.

Sterba (1934) was the first to use the term -ego alliance" to describe the relationship between the reasonable parts of the therapist and client. Sterba concluded that this type of relationship originated from the client's ego and identified with the working style of the therapist. Zetzel (1956) was the first to use the label of therapeutic alliance," which, in her definition, represented the client's attachment to, and identification with, the analyst. Greenson (1965) delineated the aspect of conscious collaboration within the alliance. His article also began the tradition of using therapeutic alliance" and working alliance" interchangeably.

Luborsky (1976) extended this concept by outlining two phases of the alliance. The first phase involves the client identifying the therapist as a helper and the therapist providing a warm, supportive relationship for the client. This provides a secure relationship foundation from which the work of therapy can be built. The second phase has the client faithfully investing his or her effort in the process of therapy. Concurrent with the phases of the alliance, Luborsky (1976) also outlined two types of alliance. The 
Type I alliance involves the client's experience of the therapist as helpful and supportive. The Type II alliance involves the client's experience of the therapeutic process as a mutual struggle pitting the client and therapist against the client's presenting problem. Under this model, the therapist's goal should be creating a Type I alliance leading to a Type II alliance with the client.

Bordin (1979) developed a pantheoretical definition of the working alliance that is still used in many studies. This definition outlines three components of the therapeutic alliance: (a) bond between client and therapist; (b) agreement on the tasks directed toward improvement; and (c) agreement on therapeutic goals. Having a broad definition gave the alliance applicability across various therapeutic methodologies, and now most counseling theories include some conceptualization of the therapeutic alliance. Much of the recent research focuses on the alliance in practice, as opposed to the alliance in theory. Some theories of psychotherapy view the therapeutic alliance as one of the strongest mechanisms of change (Barrett-Lennard, 1962; Rogers, 1957; Wampold, 2001), while other theories believe the alliance is necessary for change, but not a primary mechanism of change (Leichsenring, Hiller, Weissberg, \& Leibing, 2006). Bordin's (1979) pantheoretical definition of the alliance receives continued use in recent research (Baldwin, Wampold, \& Imel, 2007; Hauser \& Hays, 2010).

Alliance in individual adult psychotherapy differs from the therapeutic alliance conceptualized in couple, family, child, adolescent, and/or group therapy. Clients' age or developmental level can affect the alliance (Shirk \& Karver, 2011). Likewise, the presence of multiple actors in the therapeutic encounter affects the alliance (Burlingame, McClendon, \& Alonso, 2011; Friedlander et al., 2011). Pinsof et al. (1986; 2008) 
presented the model of Integrative Psychotherapy Alliance, which viewed the alliance across interpersonal domains of self, other, group, and system. These domains accounted for alliance differences based on the number of actors in the therapeutic setting. Norcross (2011) approached these differences by asking the chapter authors to perform different meta-analyses based on the number of persons in therapy and the client age. In keeping with this trend, the present study will focus on the therapeutic alliance in adult individual psychotherapy.

\section{Measures of Alliance}

There are many measures of therapeutic alliance. Recent analyses identified over 30 measures of the therapeutic alliance (Horvath et al., 2011). Some of these measures were previously established while others were used for a small group of studies. For purposes of succinctness, I have detailed only the more commonly used measures.

Alliance research has primarily studied the alliance through four measures. Each of these measures obtained good ( $r=0.90-0.98)$ internal consistency scores (Tichenor \& Hill, 1989). These measures were: the California Psychotherapy Alliance Scale (CALPAS; Gaston \& Marmar, 1994), the Helping Alliance Questionnaires (HAq and HAq-II; Alexander \& Luborsky, 1986; Luborsky et al., 1996), the Vanderbilt Therapeutic Alliance Scale (VTAS; Henry \& Stupp, 1994), and the Working Alliance Inventory (WAI; Horvath \& Greenberg, 1989). The CALPAS measures alliance across four dimensions: therapeutic alliance (client identification and attachment with therapist), working alliance (working partnership between therapist and client), therapist's understanding and involvement, and client/therapist agreement on goals. The CALPAS theoretically differentiates therapeutic alliance from the working alliance. Therapeutic 
alliance was based upon Zetzel's (1956) conceptualization of the alliance whereas the working alliance was based upon Sterba's (1934) ego alliance (Gaston \& Marmar, 1994). The other three measures were based on Bordin's (1979) definition of the alliance. A factor analysis of the HAq-II revealed two distinct factors, referred to as positive and negative alliance (Luborsky et al., 1996). Also based on Bordin's (1979) description, the VTAS contains six factors measuring aspects of the therapeutic relationship: positive therapeutic climate, client resistance, therapist intrusiveness, client motivation, client responsibility, and client anxiety (Henry \& Strupp, 1994). The WAI contains three subscales, each directly tied to an aspect of Bordin's (1979) definition: goal, bond, and task (Horvath \& Greenberg, 1989). Each of these measures has been in use for over 15 years.

Hatcher and Barends (1996) studied the factor structure of the CALPAS, HAq, and WAI, concluding that —Confidiet Collaboration" was a common theme among the measures (p. 1326). A confirmatory factor analysis compared these same three measures' client/therapist agreement on the importance of helpfulness and therapist clarity on tasks and goals (Hatcher, Barends, Hansell, \& Gutfreund, 1995). Tichenor \& Hill (1989) found significant $(r=0.80-0.84)$ correlations between the CALPAS, VTAS, and WAI-O suggesting that the different forms were equivalent measures of the alliance.

Beyond these four core measurements there are several variations of measuring therapeutic alliance measurement. The aforementioned scales have different versions to serve different purposes (e.g., short forms, forms for different raters, and versions for a specific therapeutic context). The relationships between the original forms and the form variations were not always thoroughly documented. 
One potential benefit of this review is determining whether some measures assess therapist characteristics or client perceptions more accurately than others. Horvath et al. (2011) addressed differences between alliance measures in their final meta-analysis. The authors did not find any significant moderator effects between alliance measures. However, they did find that only the effect sizes associated with the CALPAS and Vanderbilt Psychotherapy Process Scale (VPPS) were closely grouped-together, suggesting that raters using the CALPAS and VPPS were measuring the same central construct. Effect sizes obtained from scales used in less than three studies, were grouped together for the moderator analysis.

Another important consideration is the rater of the alliance. Horvath et al. (2011) found a significant moderator in the alliance rater, where the variability between the client-rated alliance and the therapist-rated alliance was greater than expected by chance.

\section{Therapeutic Alliance and Outcome}

Horvath and colleagues (e.g., Horvath et al., 2011; Horvath \& Bedi, 2002; Horvath \& Symonds, 1991) and Martin et al. have conducted meta-analyses examining the therapeutic alliance related to treatment outcome. These reviews, based on 24 to 190 studies, have concluded that alliance and outcome are moderately related $(r=0.21$ 0.275). In general these studies suggest few important moderators of the observed effects (primarily the perspective of the alliance and outcome rater). Authors of the earlier reviews concluded that study effects were homogenous (Martin et al., 2000; Horvath \& Symonds, 1991), but later studies found significant heterogeneity (Horvath et al., 2011; Horvath \& Bedi, 2002). This could be due to the increase in number of studies used in the meta-analysis and methodological differences between the studies. 
In two of the four meta-analyses the alliance-outcome relationship was complicated by between-study heterogeneity. Using the data from Horvath et al. (2011), Flückiger, Del Re, Wampold, Symonds, and Horvath (2011) found that research design (e.g., randomized clinical trial or other), use of disorder-specific manuals, type of therapy (e.g., cognitive, behavioral, or other), and researcher allegiance did not have a moderating effect on the alliance-outcome relationship. The researchers did find a link between allegiance and the alliance-outcome relationship when measured at the beginning of therapy, but this stabilized over time.

Outside of individual psychotherapy with adult clients, the therapeutic alliance continues to be an effective tool for predicting better treatment outcomes. Shirk and Karver (2011) conducted a meta-analysis of working alliance and therapeutic outcome with child and adolescent clients. The alliance was found to be a significant contributor to outcome, although there were significant moderators. Additional analyses showed that the alliance was more closely related to treatment outcome for children than for adolescents. Friedlander et al. (2011) performed a meta-analysis of couple and family therapy alliances and outcomes, again finding a significant relationship between the two variables. Both of the aforementioned reviews noted that maintaining alliances with multiple involved parties (e.g., child and parent, partner and partner) required a delicate balance that kept the focus on treatment goals while addressing the concerns of multiple parties.

One recent review began the work of systematically reviewing the elements of a strong therapeutic alliance. Diener and Monroe (2011) conducted a meta-analysis of 
client attachment style related to the therapeutic alliance and found a positive small to medium sized effect for the association between attachment and alliance $(r=0.17)$.

Although the research base of the therapeutic alliance is strong, several areas still require additional research. Horvath and Luborsky (1993) recommended, -studies aimed at identifying specific therapist actions that facilitate alliance development" (p. 570). This recommendation is nearly 20 years old and there are still many gaps in the research on therapist contributions to the alliance. The present study measured therapist contributors to the therapeutic alliance and thereby addressed comments made in the aforementioned works.

The present study included a systematic review of the research on the therapeutic alliance related to client perceptions of therapist empathy and genuineness. The purpose was to identify additional contributors to the alliance. I conducted a literature search designed to collect all studies of individual adult psychotherapy with sufficient data exploring the relationship between therapeutic alliance and client perceived therapist empathy and genuineness.

\section{Therapist Effects on Alliance}

Therapists have a large impact on the development and strength of the therapeutic alliance. Dinger, Strack, Leichsenring, Wilmers, and Schauenburg (2008) conducted a multilevel regression of therapist effects. They found that therapists accounted for only $3 \%$ of the variance in treatment outcome, but $33 \%$ of the variability on the alliance. Duff and Bedi (2010) questioned recent therapy clients about the behaviors of their therapist and recorded their alliance ratings. Of the 15 presented behaviors, 11 were identified as relating to the alliance. Regression analyses found that three behaviors accounted for 
$62 \%$ of the variance on the alliance score including: 1) making positive comments about the client, 2) using encouraging statements, and 3) greeting the client with a smile. These results suggest that these behaviors may convey interest in clients' wellbeing and encourage clients' strengths, which may be evidence of therapists' empathy and contribute to client's perception of therapist genuineness.

Other studies extend the effects of the therapist to treatment outcome. Baldwin, Wampold, and Imel (2007) studied whether patients and therapist variability affected the alliance-outcome relationship. Their results showed that some therapists tended to have stronger average alliance ratings than others. These differences were also evident in treatment outcomes where therapists who were rated as having strong quality alliances tended to have clients with more positive outcomes than therapists who were rated as having weaker quality alliances. This study showed how the abilities of different therapists could impact the therapeutic relationship.

Given the alliance-outcome relationship and its variance between therapists, it makes sense to examine therapist behaviors related to the alliance. Thomas et al. (2005) compared observer ratings of alliance with therapist behavior, finding that certain therapist behaviors (namely advice-giving and self-disclosure) contributed to the formation of stronger alliances with couples and families. When the behaviors were entered into a hierarchical regression model they were found to be predictors of alliance. However, the therapist behaviors did not predict alliance as strongly as the behaviors of the other partner. Other studies examined therapist behavioral effects on individual therapy, thereby removing the added variance provided by family and partner influence. Watson and McMullen (2005) studied therapist differences based on sessions with high 
and low ratings of the alliance. Their study found the therapists were more supportive than directive in sessions with low alliance ratings. This finding contradicts Duff and Bedi (2010), although it could be attributed to differences in methodologies.

Nesting. There are some inherent concerns with studying therapeutic relationships. In randomized control trials clients are randomly assigned to treatments but are not often randomly assigned to therapists. This can be problematic since, like groups of clients assigned to a particular treatment, groups of clients assigned to a particular therapist may experience different outcomes than another group of clients because of differences between therapists. Client-therapist interactions are nested designs where a group of clients is nested within a single therapist. Nesting occurs in alliance research and threatens the assumption of independence. If multiple clients see a single therapist, then it is difficult to maintain that each relationship measure should be treated as an independent observation. Nesting is a within-therapist and treatment occurrence. In most psychotherapy studies, different therapists provide treatment to multiple clients under a single treatment condition. However, studies do not often account for the within- and between-therapist effects. If some therapists' clients have better average outcome ratings than others', then groups of clients seeing a particular therapist seem to benefit more than clients seeing another therapist regardless of the client characteristics. Similarly, therapists do not often provide more than one treatment to clients, so the problem of nested treatments often occurs.

Marcus, Kashy, and Baldwin (2009) performed a content analysis of two prominent journals (Journal of Consulting and Clinical Psychology and Journal of Counseling Psychology) from 1997-2008 finding only three studies (out of 38) that 
accounted for nesting effects in their designs. The concern about nesting in the present study regarded the abilities of some therapists to form better alliances than other therapists do. For the therapists who form stronger alliances would greater ability to use empathy and genuineness in session follow? And if so, would studies contain enough information about the between-therapist differences to more fully examine these differences? The present study sought to use available between-therapist information to answer this question.

Past reviews acknowledged the flaws in studying the therapeutic relationship. Studies of the relationship are necessary, but basing conclusions solely on the client, therapist, or the therapeutic relationship in any therapeutic dyad ignores the interrelationship of the other variables (Lindgren, Folkesson, \& Almqvist, 2010). Several methodological corrections can address this problem, but many studies ignore these methods. To guard against these effects, Walwyn and Roberts (2010) suggested greater inclusion of therapist variables at the outset of the study, analysis of within-therapist and between-therapist clusters, and multilevel modeling.

\section{Therapist Characteristics}

Thus far, there has been no systematic review analyzing the therapist-based characteristics that contribute to the therapeutic alliance. The most comprehensive reviews of the literature come from Ackerman and Hilsenroth (2001, 2003). They reviewed studies that identified client perceptions of therapist characteristics that positively and negatively impacted the therapeutic alliance. The reviewed characteristics that impacted the alliance included empathy, openness, warmth, confidence, respect, flexibility, honesty, tension, use of self-disclosure, and rigidity. To date, there has yet to 
be a good systematic review and meta-analysis that examine the therapeutic alliance related to client perceptions of therapist empathy and genuineness.

Although reviews of therapist characteristics contributing to the alliance are lacking, other reviews highlight the effects of client perceptions of therapist characteristics on treatment outcome. Beutler, Machado, and Neufeld (1994) created a way to categorize certain therapist variables that can affect the therapeutic relationship. Objective and subjective characteristics appeared on one axis while cross-situational traits and therapy-specific states were on the other axis. Objective, cross-sectional traits included the characteristics more easily observed in the therapist regardless of the environment, such as sex, age, and ethnicity. Subjective, cross-sectional traits were traits that do not vary by situation, but require deeper analysis. These traits included interpersonal style, emotional state, values, and cultural competency. Objective, therapyspecific traits included professional background, technique use, and therapeutic behaviors. Subjective, therapy-specific traits included expectancy, therapeutic orientation, and social influence attributes. These traits were hypothesized to contribute to the working alliance and treatment outcome.

The present study examined traits that are amenable to training. This focus excluded the objective, cross-sectional domain since many of these traits are relatively unalterable. It can be argued that certain traits in the other domains (e.g., cultural values, attitudes, and attribution style) are relatively ingrained. Therefore, this study was concerned only with client perceptions of therapist-based traits/characteristics amenable to change through training and/or that could be ethically used to inform hiring practices. 
Past studies and meta-analyses on outcome and client perceptions of therapist characteristics have included studies that focus on these different trait domains. The literature on cross-sectional, subjective traits included studies of religious belief (Bergin, 1991) and emotional wellbeing (Beutler, Machado, \& Neufeldt, 1994). Other research focused on general personality similarity (Herman, 1998), interpersonal style (Beutler et al., 2004), and type and amount of therapeutic training (Smith, Glass, \& Miller, 1980). Studies and reviews of objective, cross-sectional therapist traits (e.g., sex, age, and ethnicity) related to treatment outcome showed very little effect (Beutler et al., 2004). Other traits have received less research attention.

One of the central controversies in studying therapist traits is the debate of whether observed traits exist between therapists or within therapists. This question arose sporadically in past research literature. Because researchers tended to measure traits based on their perceptions many wondered if assessments based on perceptions gave a measure of: 1) a trait within a therapist, 2) the client's perception of their therapist, or 3) an interaction between the two. If the first option was true, then client-rated measures of therapist characteristics truly assessed the traits they wished to quantify. In that case, there would be no trouble conducting a meta-analysis of therapist traits. If the second option was true, then the client-rated measures actually gave an estimate of how the client perceived the given trait. A way to mediate this problem is to code for therapist nesting and look for consistencies between the clustered participants.

If the third option was true, then the client-therapist interaction influenced the client's rating based on the therapist's level of the trait and how the client perceived this trait through interacting with the therapist. Stiles (2009) explored this third option in an 
essay about therapist responsiveness. He posited that therapists acted more responsively to clients whom they like. The therapist's liking may stem from client personality, engagement in treatment, or fit with the therapist. Through the transference/countertransference aspect of the therapeutic relationship the client would receive this liking and therefore rated their therapist more positively. The basic question amounts to this: Do variations in trait-ratings of the therapist exist as a product of the responsive interactions in the therapeutic relationship or are there true variations in trait levels possessed by different therapists?

A few past studies outlined hypotheses for their results based on this debate. If a group of clients rated their therapists on a given trait, and a graph of the scores showed random scatter across therapists, then I could conclude that clients measured based on their perception of the trait. However, if the therapist's obtained scores appeared in a cluster for each rated therapist, then I could conclude that the client measured a trait possessed by the therapist instead of simply their perception of the therapist.

This dilemma was addressed in the present study through closer analysis of nested designs. The studies that provided enough data to account for between-therapist differences were analyzed separately from all other studies. In addition to the overall relationship between the therapeutic alliance and client-perceived therapist empathy and genuineness, the results also outlined between-therapist effects gleaned from studies with data accounting for nesting. This provided further insight into between-therapist differences and how therapists affect the therapeutic relationship. 


\section{Empathy}

History of Empathy Research. The conceptualization of empathy began in the late 1800 s through the study of aesthetics. Vischer (1873; cited by Listowel, 1934) provided the term - Fnfühlung" to mean one's projections of real psychic feelings into the people and things in their perception. Lipps (1903; cited by Wispe, 1987) believed that, through projection and imitation, people understood and responded to one another through Einfühlung," which then increased the imitation of affect. Einfühlung" was soon translated into an English equivalent of -empathy" (Titchener, 1909). Titchener's (1924) definition of empathy defined it as a -process of humanizing objects, of reading or feeling ourselves into them" (p. 417).

Psychologists picked up the study of empathy emphasizing the self-other differentiation and adding a cognitive component (Deutsch \& Madle, 1975). Empathy has held a central position in the therapeutic relationship since research on therapeutic relations began. Most famously, Rogers' (1957) Person-Centered Therapy holds accurate empathy as a central technique for engendering client change. From the 1960 s to the early 1970 s empathy frequently appeared in the psychotherapy literature as an effective, necessary helping skill included in therapist training. Research during the 1970s and early 1980s scrutinized the sufficiency of empathy as a mechanism of therapeutic change (Elliott et al., 2011). Reviews evidenced the effects of empathy as a core component of the therapeutic relationship (Patterson, 1984; Truax \& Carkhuff, 1967). Watson (2001) recognized a dearth in empathy research from the years 1975 to 1995 as empathy was eclipsed by other helping skills. Since that time, empathy research experienced resurgence with studies examining the biological (Decety \& Ickes, 2009; Preston et al., 
2007), cognitive (Shechtman, 2002), developmental (Eisenberg \& Strayer, 1987;

Hoffman, 2000), and social (Davis, 1994) perspectives on empathy.

Definitions of Empathy. Given the variety of perspectives on empathy, some difficulty followed in defining the construct of empathy. There is no universally agreedupon definition of empathy in psychotherapy (Egan, 2010). Batson (2009) identified eight similar-but-different concepts that referred to as —enpathy." These include: 1) knowing another person's emotional state, thoughts, and feelings, 2) adopting the posture or matching the neural responses of an observed individual, 3) feeling as another person feels, 4) projecting oneself into another person's situation, 5) imagining how another is thinking or feeling, 6) imagining how one would think, feel, or act in the place of another, 7) experiencing distress when witnessing another suffering, and 8) feeling for another who is suffering. Comprehensive empathy definitions often overlaid a handful of these aspects to create a general idea of the term.

Past reviews identified that most empathy definitions fall within specific dyads. These dyads were dispositional vs. state-specific, cognitive vs. affective, and client-rated vs. therapist-rated (Duan \& Hill, 1996; Gladstein, 1987; Ham, 1987). Other works differentiated types of empathy, each with its own utility and focus (Bohart \& Greenberg, 1997). Barrett-Lennard (1981) outlined a five step cycle of empathy occurring in therapy: 1) the therapist attends to the expressive client, 2) the therapist understands the client's experience in a way that makes it vividly salient to the therapist, 3) the therapist communicates awareness of the client's feelings, 4) the client attends to the therapist's response and understands it, and 5) the client continues their expression in a way that either confirms/corrects the therapist's empathic response or shows their understanding of 
the therapeutic relationship, thus continuing the empathy cycle. An empathetic therapeutic relationship involves the therapist and client building on one another's expressions of mutual understanding.

Dispositional and state-specific empathy have been investigated, illuminating different outcomes. The dispositional perspective posited that empathy is a stable trait and implies that some individuals are inherently more empathetic than others. The statespecific definitions supposed that empathy is a relationally based characteristic between two individuals with one taking the perspective of the other. State-specific included aspects of both the empathizer and the empathized along with situational factors. The state-specific perspective implied more trainability in empathy while the dispositional perspective entailed a belief that empathy is a more unchangeable trait. Past research examined empathy as both a dispositional and state-specific construct (Duan \& Hill, 1996). Both dispositional and state-specific empathy can be tested with a nested design. This would account for the therapist- and situation-specific aspects that make up client perceptions of therapist empathy.

The internal definitions therapists use to understand their use of empathy during their practice of psychotherapy tended to be different than literature-based definitions of empathy. It was beneficial to understand how therapists conceptualized empathy because it reflected how they understood their use of empathetic responses in session. Taylor (1996) used phenomenological analysis to identify themes of empathy based on interview transcripts. Therapists identified four themes: Letting Go (of therapist expectations), Connecting (to client experience), Being Responsible and Responsive, and Danger (of misunderstanding). These themes are reflected in most measures of therapist empathy. 
Empathy and Outcome. A few meta-analyses addressed the relationship between empathy and treatment outcome. Bohart, Elliott, Greenberg, and Watson (2002) used 47 studies to perform the first meta-analysis comparing these two variables. They found a relationship of corrected $r=.30$, a medium effect size. Moderating variables of length of therapy, treatment format, measurer perspective, and therapist experience complicated the relationship. Empathy was more predictive of positive outcomes for group therapy over individual therapy. It was less predictive of positive outcomes when treatment was longer and when the therapist had more experience. In terms of rater perspective, although all rater perspectives had positive relationships with treatment outcomes $(r=0.20-0.32)$, client rated empathy had the strongest empathy-outcome relationship $(r=0.32)$. Empathic accuracy did not have a significant moderating effect. Since these moderating variables affected the relationship between therapist empathy and therapy outcome, there could also be moderator effects on the relationship between empathy and alliance. The overall effect size from Bohart et al. (2002) was similar to that of the alliance-outcome association (Horvath et al., 2011). Elliott et al. (2011) performed a follow-up meta-analysis examining therapist empathy and treatment outcome. This most recent synthesis used 59 samples from 57 studies. Again, the researchers found a moderate relationship between the two variables, $r=.30$. Although the results were complicated by heterogeneity, suggesting that additional factors may influence the strength of the relationship between empathy and outcome, the overall relationship showed that therapist empathy had some relationship to psychotherapy outcome. These study results indicated that the therapeutic alliance and client 
perceptions of therapist empathy both contributed to therapy outcome with similar magnitude.

Therapist empathy is conceptualized as a large component of the therapeutic alliance (Feller \& Cottone, 2003). This could work two ways: 1) alliance building is seen as a sign of empathy, or 2) empathy could help build the alliance. A positive relationship would imply that increases in alliance tend to coincide with increases with empathy, and therefore suggest concurrent increases and decreases in multiple areas of the therapeutic relationship. A negative relationship would suggest that, although empathy and alliance impact therapy outcome, they act as opposing aspects of the overall therapeutic relationship. A lack of relationship would imply that, although empathy and alliance impact therapy outcome, they do not have any interrelationship. Understanding the way empathy is related to alliance can help determine the composition of the alliance. Later studies may explore how empathy may covary with the alliance in predicting treatment outcome.

Potential Moderators. In planning moderator analyses for the present study, I examined moderators identified in previous meta-analyses and explored theoretical concerns. Moderating variables are variables secondary to the constructs of interest in a study that affect the direction and/or magnitude of the relations between the constructs of interest. Heterogeneity of study effect sizes indicates the presence of moderating variables.

Bohart et al. (2002) and Elliott et al. (2011) identified some potential moderators in their analyses of empathy related to treatment outcome. In both studies, moderator analyses compared the raters of empathy and outcome (i.e., client, therapist, and 
observer). They found that client ratings of empathy were more strongly related to positive outcomes whereas therapist ratings of empathy were not as strongly related to outcome. Other moderators included theoretical orientation (overall not significant, but significant variability within cognitive-behavioral and -other" perspectives), year of study publication, study $n$, outpatient/inpatient treatment setting, individual/group therapy, length of therapy, client severity, and therapist experience level. For the purposes of moderator analyses, the present study coded for participant and therapist $n$, time of the assessment, therapist experience level, therapist theoretical orientation, and raters of the alliance and therapist characteristics.

Measures of Empathy. There are several scales used to measure empathy. Elliott et al. (2011) categorized measures of empathy into four groups based on the rater. These categories are: 1) client-rated empathy, 2) therapist-rated empathy, 3) observerrated empathy, and 4) empathic accuracy. Empathic accuracy is a measure of congruence between client and therapist empathy ratings. The present study examined measurement type, conducted an overall meta-analysis, and conducted moderator analyses necessitated by tests of heterogeneity.

Client-rated measures of empathy are more commonly used. The most widely used client-rated measure is the Barrett-Lennard Relationship Inventory (BLRI) empathy scale (Hill, Nutt, \& Jackson, 1994). The scale development was based on Rogers' (1957) definition of empathy. Due to its definition, the scale does not adequately measure empathy when observing counseling from an approach other than client centered (Lambert, DeJulio, \& Stein, 1978). Most client-report scales are given to clients at the conclusion of a therapy session (e.g., Bachelor, 1988; Hamilton, 2000; Mercer, Maxwell, 
Heaney, \& Watt, 2004; Truax \& Carkhuff, 1967). As an alternative recollection-based empathy measures, Elliott's (1986) Interpersonal Process Recall required clients to listen to audio recordings of their sessions focusing specifically on their therapists' empathic responses. Previous research suggests that the association between client-rated empathy and outcome is stronger than either therapist or observer rated empathy (Barrett-Lennard, 1981; Bohart et al., 2002; Gurman, 1977; Orlinsky, Grawe, \& Parks, 1994; Orlinsky \& Howard, 1967, 1978).

Therapist-rated empathy measures are less common than client- and observerrated measures. The (BLRI) may have the only well-known empathy scale for therapist rating. This could be because empathy is difficult to honestly assess through a self-report measure. Other self-report measures of empathy seemed to arise as need dictated (e.g., Fields et al., 2004, 2011; Hogan, 1969). Past studies showed that therapist-rated empathy had a lower effect on outcome compared to client- and observer-rated empathy (Bohart et al., 2002).

Observer-rated empathy approaches empathy from a position outside the therapeutic relationship. Similar to client-rated empathy, early observer-rated scales view empathy from a Rogerian perspective (Carkhuff, 1969; Truax \& Carkhuff, 1967). Newer measures base observer ratings on broad understandings of empathic responses (e.g., Response Empathy Rating Scale; Elliott et al., 1982).

\section{Genuineness}

History and Definitions of Genuineness. Similar to empathy, genuineness has strong roots in Person-Centered theory. Along with therapist empathy, client-therapist contact, client vulnerability, client perception, and positive regard, genuineness is one of 
the six necessary and sufficient conditions in therapy (Rogers, 1957). Person-Centered therapy holds that a successful therapeutic relationship entails therapists should being genuine and clients perceiving their therapists as genuine. A later research review supported this claim (Patterson, 1984). Genuineness is defined as 1) therapists being fully themselves, with experience in therapy being an accurate representation of their self, and 2) therapists communicating their in-therapy experience of the client back to the client (Rogers, 1957). This is not to suggest that Rogers believed counselors should share potentially hurtful information to clients, nor did he advocate excessive restraint of feelings. Rather, he stressed the importance of consideration of client's feelings, correct counselor expression of feeling in the therapeutic change process, and appropriate use of the counselor's genuine reactions in addressing barriers to treatment success.

Research on the real relationship expanded on Rogers' views of genuineness. Genuineness in the real relationship is defined as being, and being willing to be, what one truly is in the relationship" (Gelso \& Carter, 1994, p. 297). Beyond this definition, genuineness was associated with terms like honesty, authenticity, transparency, and openness (Gelso \& Hayes, 1998). Watson, Greenberg, and Lietaer (1998) defined two distinct facets of the therapist's experience of genuineness. The two levels were internal and external. Internal referred to the therapist's internal experiencing of their clients whereas the external referred to the therapist's ability to communicate their experience to the client. Newer expanded definitions of genuineness included therapeutic presence and mindful awareness (Geller \& Greenberg, 2002). The most recent comprehensive definition stated that congruent genuineness was the therapist's awareness of their 
internal experience of the session and their ability to appropriately communicate this awareness to the client (Greenberg \& Watson, 2005).

Because congruence and genuineness reflect the same underlying therapist experience, it is important to distinguish between the two constructs while attending to their overall similarity. Both congruence and genuineness reflect the therapist's authentic internal experiencing of the client and session. One distinction is that genuineness can be thought of as openness to oneself, while congruence can be conceptualized of as the extent of therapist transparency (i.e., the correspondence between experience and communication with others; Schmid, 2001). Despite this conceptual distinction, oftentimes congruence and genuineness are studied together (Kolden et al., 2011; Patterson, 1984) and the terms are used interchangeably. For ease of reference, the therapist's use of self in therapy will be referred to as genuineness" for the rest of this review.

Genuineness and Outcome. Several studies and reviews examined the relationship between therapist genuineness and therapy outcome. Thus far, at least 11 reviews examined this relationship (Kiesler, 1973; Klein, Kolden, Michels, \& ChisholmStockard, 2002; Kolden et al., 2011; Lambert, DeJulio, \& Stein, 1978; Luborsky, Chandler, Auerbach, Cohen, \& Bachrach, 1971; Meltzoff \& Kornreich, 1970; Mitchell, Bozarth, \& Krauft, 1977; Orlinsky, Grawe, \& Parks, 1994; Orlinsky \& Howard, 1978, 1986; Orlinsky, Rønnestad, \& Willutzki, 2004; Parloff, Waskow, \& Wolfe, 1978; Truax \& Mitchell, 1971; Watson, 1984). Overall, these reviews provided mixed results with some leaning toward a positive relationship. Kolden et al. (2011) conducted the only meta-analysis comparing genuineness with treatment outcome. Using 16 studies, they 
found a relationship of $r=0.24$ between the two variables, which can be characterized as a medium effect (Cohen, 1988). This corroborated the findings by the then-most recent qualitative review (Klein et al., 2002).

Potential Moderators. Again, it was important to review moderators because of their likely appearance in the study of genuineness and alliance. The Kolden et al. (2011) study had significant heterogeneity and the authors conducted moderator analyses to detect contributors to effect size differences. The moderators identified as significant included: rater perspective, therapist clinical experience, patient variables, and treatment variables. Rater perspective impacted ratings of outcomes where patients rated outcomes higher than therapists. There was a positive relationship between therapist level of experience and the overall effect size. Patient age, gender, and minority status were not significant moderators, but patient educational attainment had a negative relationship on the genuineness-outcome effect size.

Several treatment variables were also associated with effect sizes. Treatment settings had significant differences in effect sizes. School counseling centers had the strongest genuineness-outcome relationship, followed by inpatient settings, mixed ( 2 or more) settings, and outpatient mental health settings (Kolden et al., 2011). Group therapy had a greater moderating effect than individual therapy. Number of sessions had no moderating effect.

Measures of Genuineness. There are three well-known measures of therapist genuineness. These are the Relationship Inventory (BLRI; Barrett-Lennard, 1962), the Truax Relationship Questionnaire (TRQ; Lin, 1973), and the Real Relationship Inventory 
(RRI; Gelso et al., 2005). For purposes of succinctness, I will only detail these three measures.

Along with measuring empathy, the BLRI contains scales measuring genuineness in each of its revisions (Barrett-Lennard, 1962; 1978; 1986). Gurman (1977) performed a review of 24 BLRI studies, finding internal consistency measures gave a mean coefficient of 0.89. Different versions of the BLRI exist. The alternative forms vary in length, were written for different perspectives on the therapeutic relationship, and were translated into different languages. Simmons, Roberge, Kendrick Jr., and Richards (1995) advocated using the BLRI over the TRQ because it had more supportive psychometric data, it is a quick and simple measure, and it is cost effective.

Although most studies using the TRQ were published in the early 1970's it is still considered a prominent measure of genuineness. Mitchell, Bozrath, and Krauft (1977) calculated reliability coefficients for the TRQ. These coefficients ranged from 0.34 to 0.85 with most over 0.65 . The TRQ was revised through item and factor analyses. The revision analysis calculated 0.92 internal reliability coefficient and high to moderate concurrent validities when compared to the BLRI and the Sorenson Relationship Questionnaire (Lin, 1973).

The RRI is a more recently developed measure that includes a subscale examining genuineness. Initial studies of the therapist version of the RRI revealed internal consistency at 0.89 for the total scale and 0.83 for the Genuineness portion (Gelso et al., 2005). It also had good concurrent validity when compared to measures of working alliance and session evaluation. The client version of the RRI also reports higher internal consistency than the therapist version (Kelley, Gelso, Fuertes, Marmarosh, \& Lanier 
2010). The client version also has high test-retest reliability and good discriminant validity.

\section{Relationships between Empathy and Genuineness}

In approaching the study of client perceptions of therapist characteristics, it is important to distinguish the differences between the theoretical conceptualization of therapist characteristics versus how therapist characteristics are measured in practice. The previous sections explained the theoretical constructs of empathy and genuineness. Empathy involves the therapist taking on the client's perspective of the presenting problem whereas genuineness involves the appropriate use of the therapist's internal responses to the client's statements. On a theoretical level, they have separate functions in the therapeutic relationship. In practice, clients' perceptions of therapist empathy and genuineness may be measured in a way that ignores or confirms conceptual differences. Measurement of empathy and genuineness in practice may not reflect their existence as separate relationship constructs, but rather, may serve as a measurement of an overall relationship construct, of which empathy and genuineness are interrelated parts. The present study seeks to explore the relationships between client perceptions of therapist empathy and genuineness in relation to the alliance. This will inform future research on the therapeutic relationship.

Few previous studies have approached the relationship between client perceptions of therapist empathy and genuineness as a study topic. As facilitative conditions of Rogerian therapy these constructs are often studied together (along with therapist warmth). Studies often calculate the relationship between client perceptions of therapist empathy and genuineness, and it is beyond the scope of this literature review to include 
all past correlations. Both the BLRI and TRQ include measures of empathy and genuineness within one questionnaire. Factor analyses show the differences between the constructs (Barrett-Lennard, 1962; 1978; 1986; Lin, 1973; Truax \& Carkhuff, 1967). Analyses of the BLRI showed significant intercorrelations between the empathy and congruence scales (Carkhuff, 1969). Another analysis showed that the BLRI has significant correlations to the RRI Total scale $(r=.71)$ and Genuineness scale $(r=.65)$ (Kelley et al., 2010). Theoretically, the constructs are quite distinct, but this study may find significant covariance when they are measured in practice. This may be due to lack of precision in measurement or lack of knowledge on the part of the measurer. The present study reported intercorrelations in studies that utilized measures of both client perceptions of therapist empathy and genuineness.

\section{Main Hypotheses}

This study sought to explore the relationship between the therapeutic alliance and client perceptions of therapist characteristics of empathy and genuineness. Previously, no research synthesis explored these relationships through a quantitative meta-analysis. This study employed meta-analysis to combine previous research on the therapeutic relationship into a common effect size. The study hypotheses are as follows:

1. There would be a strong positive relationship between therapeutic alliance and therapist empathy without accounting for heterogeneity.

a. The rater of the alliance and therapist empathy would be a significant moderating variable with client-rated empathy and alliance having the strongest relationship as compared to therapist- or observer-rated empathy and alliance. 
b. The relationship between alliance and therapist empathy would remain consistent across theoretical orientations.

c. Time of the study publication would not have a moderating effect on the alliance/empathy relationship.

d. The number of study participants would not have a moderating effect on the alliance/empathy relationship.

2. There would be at least a moderate positive relationship between therapeutic alliance and therapist genuineness without accounting for heterogeneity.

a. The rater of the alliance and therapist genuineness would be a significant moderator with client-rated alliance genuineness having a stronger positive relationship to alliance than other alliance and genuineness from the perspective of other raters.

b. The scale used to measure genuineness would not affect the strength or direction of the alliance/genuineness relationship.

c. The publication date of the study would not significantly affect the strength of the alliance/genuineness relationship.

3. For studies that account for nesting, there would be a strong relationship between therapist alliance strength and therapist use of empathy. Therapists who have stronger mean alliance ratings would also have stronger mean empathy ratings when compared to therapists with lower mean alliance ratings.

4. For studies that account for nesting there would be a strong relationship between therapist alliance strength and therapist use of genuineness. 


\section{CHAPTER II METHOD \\ Systematic Review and Meta-Analysis}

\section{Inclusion Criteria}

Studies included in this review met three criteria: (a) inclusion of a measure of the relationship between alliance and therapist empathy and/or genuineness, (b) publication in English, French, Spanish, or German, and (c) study publication after $1969^{1}$. There were no restrictions on the source of the alliance measure (i.e., client, therapist, or observer). Two researchers working independently screened abstracts from studies identified through the literature search. Disagreements were resolved in conference.

\section{Literature Search Strategy}

I constructed the literature search with intent to limit publication bias. Publication bias occurs when the publication of a report depends on the nature and direction of its results (Dickersin, 1990). This tends to be seen most often in positive effects bias, which is the tendency for researchers to submit manuscripts with positive results and publishers to publish reports that have positive results (Sackett, 1979). This can lead reviewers to overestimate positive effects. All literature reviews can be very susceptible to publication bias. Past content analyses revealed that many published meta-analyses ignored many unpublished studies in their overall analysis (Ferguson \& Brannick, 2012; Hopewell, Clarke, \& Mallett, 2006). Publication bias can be addressed with a strong, diverse search strategy.

${ }^{1}$ The final search was run on Jan 26, 2012 
Studies for the systematic review were obtained through different methods and retrieved from a variety of sources. The initial group of studies came from a search of electronic databases. Additional methods, such as Internet search engines and snowballing, were employed in an attempt to draw in the largest number of relevant studies. Snowballing" entails examining the reference lists of literature reviews for potential missed studies (Rothstein \& Hopewell, 2009). The electronic database search required a list of key terms set to draw potential studies examining the alliance related to empathy and genuineness. This list was created through examination of past literature reviews of therapist characteristics (Beutler et al., 2004; Elliott et al., 2011; Kolden et al., 2011) and working alliance (Horvath et al., 2011). In addition, PsychINFO term suggestions were used. Finally, a forward citation search of the seminal review by Ackerman and Hilsenroth (2003) was conducted with attention to terms used in the titles and abstracts to identify any gaps in the term list. The resulting term list (available in Table 1) was comprised of three categories: (a) alliance terms (e.g., alliance OR rapport OR relationship), (b) therapist terms (i.e., therapist OR counselor OR analyst OR psychotherapist OR social worker OR practitioner), and (c) trait terms (e.g., empathy OR congruence OR genuineness OR real relationship). Additionally, I used this term list in searching Internet and organizational databases.

Electronic databases. Several electronic databases were searched, and the results from these searches were compiled using the citation management program Endnote. I conducted electronic searches of the databases PsychINFO, ProQuest Research Database, ProQuest Digital Dissertations, Social Services Abstracts, Social 
Sciences Citation Index, Applied Social Science Index \& Abstracts, Social Work Abstracts Plus, Medline, PubMed, and ERIC.

Searching the grey literature. With some exceptions (e.g., ProQuest Research Database) electronic databases mainly provide access published studies, but not all relevant studies are published. To obtain the maximum number of relevant studies and to decrease the possibility of publication bias, I employed additional methods to uncover literature. First, I searched Google Scholar. I also targeted the websites of government agencies that are likely to fund related work. These included The National Institute of Mental Health, the National Mental Health Development Unit, and the National Registry of Evidence-based Programs and Practices (NREPP) available through the United States government's Substance Abuse and Mental Health Services Administration (SAMHSA). I also reviewed most recent edition of Bergin and Garfield's (2004) Handbook of Psychotherapy and Behavior Change for additional reviews. In addition, I used the snowballing method with any obtained literature reviews. I performed hand searches of The Journal of Clinical Psychology, Counseling and Psychotherapy Research, American Journal of Psychotherapy, Psychotherapy Research, Psychotherapy, American Psychologist, The Journal of Counseling Psychology, The Journal of Consulting and Clinical Psychology, and Clinical Psychology Review in the years 1970-present. Finally, I contacted prominent authors in the field about any unpublished material or additional information. A list of authors contacted is given in Table 2. This method allowed access to unpublished or conference work that is difficult to obtain through other search means, and served as an additional guard against publication bias. Any potentially relevant studies were obtained and screened for study inclusion. 


\begin{abstract}
Screening
At least two screeners independently reviewed each of the abstracts obtained through the literature search for study relevance. The coding guide used to screen studies for relevance is presented in Table 3. Because the screening guide was based on the inclusion criteria, any question answered as a No" meant that the study was not eligible for this review. Studies that could not clearly be ruled out or in (i.e., studies for which there were no -No" answers) were obtained for further evaluation. The screeners worked independently with periodic meetings to discuss individual decisions and reach a consensus on the inclusion/exclusion of studies.
\end{abstract}

\title{
Coding Process
}

I used a structured coding guide for each study (see Table 4). The guide included coding information for:

- author name(s)

- year of publication

- type of publication (e.g., peer-reviewed journal, dissertation)

- study design (e.g., correlational, experimental, or quasi-experimental

- sample size

- client race/ethnicity, taken from the sample demographic information

- mean age and age range of patients

- number of therapists

- theoretical approach to treatment, obtained by reading about treatments used or inferred by the author-identified theoretical orientation for the therapists 
- assignment method, obtained by scanning methods section for terms like assigned" or randomly"

- therapist trait examined (empathy or genuineness)

- therapist trait measure (e.g., Barrett-Lennard Relationship Inventory)

- rater of the trait (i.e., client, therapist, observer)

- working alliance measure (e.g., Working Alliance Index)

- rater of the alliance

- overall correlation between trait and alliance measures or other effect size data reflective of the relationship between the variables of interest

- if given, correlations between trait and alliance for individual therapists to capture nesting effects.

Similar to the process for the abstract screening, at least two independent coders extracted the data from each study. The coders met intermittently to review their decisions, correct any mistakes, and reach agreement on the extracted data.

\section{Statistical Procedures}

Effect size calculation. An effect size is a statistic representing the magnitude of the relationship between two variables (e.g., the strength of the relationship between the therapeutic alliance and therapist characteristic). Because the research question for this review involves the association between two variables (i.e., therapist traits and either empathy or genuineness), the primary effect size used was the correlation coefficient; meta-analysis was performed on Fisher's $z$ transformed correlations coefficients. Fisher's $z$ transformation is defined as: 


$$
z_{r}=.5 \ln \left(\begin{array}{l}
(1+r) \\
(1-r)
\end{array}\right.
$$

This transformation is used when relevant data are correlational because the variances of correlations follow asymmetrical distributions and this metric stabilizes the variance of $r$ based on the natural logarithm of the correlation coefficient (Borenstein, 2009). For data reporting, the mean Fisher's $z$ scores were back-transformed to $r$ since this is a more familiar metric:

$$
r=\frac{e^{s_{r}}-1}{e^{s_{r}}+1}
$$

Heterogeneity. Due to sampling error we do not expect studies to yield exactly the same effect sizes; heterogeneity is a term that refers to the extent to which study effect sizes differ from one another. One important question is whether differences in study effect sizes are greater than would be expected by chance. To statistically test heterogeneity, used Cochrane's $Q$ to assess presence of heterogeneity and $I^{2}$ to assess its degree.

Cochrane's $Q$ approximately follows a chi-square distribution with the degrees of freedom equal to the number of studies $(k)$ minus one. The formula for testing heterogeneity is:

$$
Q=\sum w_{i}\left(E S_{i}-\overline{E S}\right)
$$

where $E S_{i}$ is each individual effect size, $w_{i}$ is the inverse weight for effect size $i$, and $\overline{E S}$ is the weighted average effect size. The heterogeneity test is a test of between-studies variance where a significant value of $Q$ indicates that the variation between studies is significantly different from zero, often leading researchers to consider a random effects 
model. Considerations for choosing a model based on conceptual concerns include the diversity of study designs, samples, measures, and outcomes. Fixed effect models tend to be more appropriate when studies are highly similar to one another (Valentine et al., 2011).

$I^{2}$ provides an estimate of the extent heterogeneity between the studies, and is defined as:

$$
\digamma^{2}=100 \%\left(\frac{Q-(k-1)}{Q}\right)
$$

Deeks, Higgins, \& Altman (2011) provided approximations for interpreting the $I^{2}$ statistic. Under these approximations $I^{2}=0-40 \%$ might not be important, $I^{2}=30-60 \%$ may represent some moderate heterogeneity, $I^{2}=50-90 \%$ may represent substantial heterogeneity, and $I^{2}=75-100 \%$ indicates considerable heterogeneity.

Model choice. When conducting a meta-analysis, researchers need to decide between a fixed effect and random effects analytic model. In a fixed effect model, one assumes that study effects are estimating a single population value. Error in a fixed effect model is therefore assumed to reflect random sampling error and identifiable covariates. Study effects in a fixed effect model are weighted by the inverse of their large-sample variances while accounting for within study error. In a random effects model, researchers do not assume a single population effect size, and study error is assumed to originate from random sampling error, identifiable covariates, and additional random factors that cannot be easily identified. Another feature of a random effects model is that studies are weighted by their inverse variance while accounting for within-study error and betweenstudy variation (Borenstein, Hedges, Higgins, \& Rothstein, 2009). 
Choosing between a fixed effect model and a random effects model is an important decision in a meta-analysis. Confidence intervals in a random effects model are often larger than those seen in a fixed effect model; this has implications for tests of statistical significance. Choosing between fixed and random effects models can be done empirically (based on the statistical significance of $Q$ ) or conceptually (based on a consideration of the degree of similarity among study characteristics). In the present study, the choice of model was made conceptually. Studies of the therapeutic alliance related to therapist empathy and genuineness employed differing methodologies, measures, samples, and interpretations of the relationships. Additionally, measures of alliance, empathy, and genuineness ask raters to rate a trait based on their perceptions, which are open to response variation. Due to these differences, the present study warranted a random effects model to estimate mean effect sizes and their $95 \%$ confidence intervals.

Moderator analyses. As discussed in the literature review, based on previous studies and theoretical considerations I captured information on several different potential moderators. These included the alliance and therapist characteristic rater perspective (i.e., client, therapist, or observer), treatment differences (i.e., therapist ethnicity, therapist gender, therapist experience level, theoretical orientation, and method of assigning clients to therapists and treatments), and client differences (i.e., ethnicity, gender, mean age, and presenting psychiatric diagnosis).

Computer Programs. To conduct the meta-analyses in this study, I used the program Comprehensive Meta-Analysis (CMA). I chose CMA for this study because past meta-analyses examining the same constructs were complicated by heterogeneity 
and required moderator analyses. CMA was used for the primary analyses and estimates of publication bias.

In conjunction with CMA this study used the R statistical software program $(\mathrm{R}$ Development Core Team, 2009). The present study used the software packages of MAc (Del Re \& Hoyt, 2010) and RcmdrPlugin.MAc (Del Re, 2010). This program was used to calculate moderator analyses in a manner similar to a multiple regression. This allowed comparison of moderator effects and analysis of possible covariates within the moderators. Use of the R programs with CMA allowed for deeper understanding of moderators affecting the relationship between alliance, empathy, and genuineness.

Missing data. Missing data is a problem faced in any systematic review. Missing data includes missing studies (due to lack of publication or access), missing effect sizes, and missing descriptor variables. The most important strategy for addressing missing data is to contact study authors for this information. For studies with a publication date of 2000 or later, I sent email requests (with at least one follow-up reminder, as necessary) to the lead study authors requesting information.

In addition, Pigott (2009) outlined analytical methods of handling missing data. All of these methods were based on assumptions regarding the reasons why the data was missing. These methods work best for data that is missing completely at random. In other words, the data is missing for reasons unrelated to its value or the value of related data. Pigott (2009) determined that making assumptions about why" data would be missing could lead to further bias in reporting and discussing the results. One common approach to missing effect sizes is to assume a study effect size of zero. However, an estimate of zero would bias the tests of heterogeneity, narrow the overall confidence 
interval, and risk misrepresenting the overall effect size. Due to these problems, the present study documented the missing data without conducting further analysis. The number of studies missing relevant data is provided in the results section.

Addressing Publication Bias. The present study sought to minimize publication bias through a variety of means. Methods of assessing publication bias were implemented through the statistical program CMA. One way CMA assesses publication bias is through graphing funnel plots. The funnel plots arrange the studies on a twodimensional graph with study effect size on the $\mathrm{x}$-axis and its standard error on the $\mathrm{y}$-axis. In the absence of publication bias, the funnel plot maintains symmetry regardless of sample size. In the presence of publication bias, the symmetry of the funnel plot decreases and -gaps" appear suggesting that some studies are missing.

I also used Trim and Fill methods with the funnel plots. This method adjusts for publication bias by correcting funnel plot asymmetry. Trim and Fill estimates how many studies would need to be trimmed off the funnel to create symmetry at the center. It does this by repeating a process of assessing funnel plot symmetry, identifying extreme studies, adding extreme effects on the opposite side of the plot, and reassessing symmetry. Once the plot is symmetric the extreme studies are added back into the plot with mirror image studies to maintain symmetry. This method helped assess study-tostudy variability, but had its complications. A Trim and Fill analysis requires a large number of studies; it can be thrown off by a few extreme studies, it assumes a symmetric distribution of study effects, and it assumes that publication bias is at the root of distribution asymmetry. Trim and Fill analysis can also be difficult to interpret in the presence of significant heterogeneity (Peters, Sutton, Jones, Abrams, \& Rushton, 2007; 
Terrin, Schmid, Lau, \& Olkin, 2003). This is of particular concern to the present study, given the heterogeneity found in past meta-analyses of the same topics (Elliot et al., 2011; Horvath et al., 2011; Kolden et al., 2011). As such, the trim and fill analysis is best thought of as a sensitivity analysis, providing possible hints about the presence, nature, and extent of publication bias. 


\section{CHAPTER III RESULTS}

The search strategy outlined in the Methods section identified 2,141 relevant works. Abstract screening reduced the number of relevant works to 153 studies and 31 reviews. Snowballing of the reviews did not produce any new studies. Full text screening revealed 46 studies with sufficient statistics to code. A pyramid graph detailing the number of studies excluded at each point in the abstract screening process is available in Table 5. Thirty-six studies reported alliance/empathy relationships, six studies reported alliance/genuineness relationships, and four studies reported both. Coder agreement was $86.3 \%$ and disagreements were resolved in conference.

\section{Therapist Empathy and Alliance}

The combined effect size for the individual studies examining the relationship between alliance and therapist empathy was $r=0.51$. This effect size used data collected from 40 studies. The standard error (SE) was 0.05 giving the overall effect size a $95 \%$ confidence interval of 0.43 to 0.59 . The magnitude of this relationship indicates a large relationship between the alliance and therapist empathy, suggesting that one's perception of the alliance may influence their perception of a therapist's empathy or vice versa. The data for the overall analysis is displayed in a forest plot in Table 6.

There was a great deal of variability across the studies used in the present analysis. The group of studies cannot be considered homogenous because $Q(39)=$ 287.71, $p<.001$. This statistic indicates that the differences between the study effect

sizes are likely due to more than just random error. The $I^{2}$ statistic for the data indicates a 
.86 ratio of true heterogeneity to total variance across the studies used in this analysis. To explore the sources of heterogeneity I performed additional analyses testing moderating variables and determining any evidence of publication bias.

\section{Moderators}

In the present study, I conducted analyses to test the influence of potential moderator variables. As can be seen in Table 7, the differences in article type (i.e. journal article, dissertation, or thesis), publication year, number of clients, ratio of male to female clients, client mean age, number of therapists, ratio of male to female therapists, therapist race/ethnicity ratios, therapist experience level, theoretical approach to therapy, method of assignment to therapist and/or treatment, average number of sessions, time of measurement, alliance measure, and empathy measure were all statistically nonsignificant moderators. Table 8 details the measures used in each individual study, as well as the treatment type, number of sessions, and rater perspective. It should be noted that the number of studies $(\mathrm{k})$ for many of the moderator analyses does not always equal the total number of studies. This is because some studies did not report certain variables and were therefore excluded, lowering the number of included studies. Other studies used multiple measures and rater perspectives, which increased the number of studies in the analysis.

Theoretical approach to treatment was a significant moderating variable.

Although most studies did not use a single theoretical approach, I was able to compare the effect sizes of studies using a cognitive/behavioral approach $(\mathrm{k}=3)$ to studies that used a psychodynamic approach $(\mathrm{k}=3)$. Theoretical approaches that did not meet the $\mathrm{k}$ $=3$ criteria were not included in this analysis due to the potential for encountering problems inherent in generalizing from a small group of disparate studies. From these 
studies it appeared that a cognitive/behavioral theoretical approach was associated with a stronger alliance/empathy relationship $(r=0.572)$ than a psychodynamic approach $(r=$ 0.279 ) with $Q_{\text {between }}(1)=8.163, p<0.01$. I would caution deeper interpretation of this difference due to the low number of studies involved in the comparison. Further studies will be required to make more definitive conclusions. Details about these studies can be found in Table 9.

The second significant moderator found in this analysis was the ratio of white to nonwhite clients. The unstandardized slope coefficient for the white/nonwhite client ratio $(-0.004)$ indicated that studies with more nonwhite clients tended to have slightly stronger relationships between therapist empathy and alliance. I did a further moderator test where I each coded race variable (i.e. the ratio of each race to the total study sample) as a moderating variable in a regression test. The model of all seven ratios was significant at $\left.Q_{\text {model }}(7)=18.2, p<.05\right)$, but no individual race ratio was a significant moderator. The results of this test are presented in Table 10. I would caution against deeper interpretation of this moderator since this was a supplemental analysis done at the study-level and not the individual client level. We do not have enough information to determine how studies with more White clients may affect the direction and strength of the alliance/empathy relationship. Additional research is required to better explain this moderator.

The scale used to measure empathy was a significant modifying variable, $Q_{\text {between }}(4)=15.925, p<0.01$. The BLRI $(\mathrm{k}=22)$ was the most commonly used empathy measure. The AES, the Burns Empathy Scale (BES), and the Interpersonal Reactivity Index (IRI) were each used in three studies. Other measures that only appeared in one or 
two studies were grouped together in an - Other" category $(\mathrm{k}=14)$. Upon closer inspection, the IRI was associated with a much lower $r$ than the other measures. For IRI $r=0.06$ with $Q_{\mathrm{IRI}}(2)=1.09, p=0.57$, whereas $r$ ranged from 0.41 to 0.62 for the other measures. I performed a subsequent analysis excluding the IRI. This analysis showed that empathy measure neared statistical significance, but was no longer considered a significant moderator $Q_{\text {between }}(3)=6.529, p=0.088$.

I found that the perspective of the rater, for both alliance and therapist empathy, affected the overall alliance/empathy relationship. Alliance rater was a significant moderator with $Q_{\text {between }}(2)=6.372, p=0.041$. The effect sizes for client- $(r=0.54,95 \%$ $\mathrm{CI}=0.45-0.62)$ and observer-rated $(r=0.54,95 \% \mathrm{CI}=0.37-0.68)$ alliance were higher than those for therapist-rated alliance $(r=0.3,95 \% \mathrm{CI}=0.11-0.46)$. This suggests that clients and observers rated alliance closer to how they perceived therapist empathy ratings whereas therapist's rated alliance different than empathy. However, therapist-rated alliance had a lower within-group heterogeneity $\left(I^{2}=58 \%\right)$ compared to the levels obtained by the client- and observer-rated alliance scores related to empathy $\left(I^{2}\right.$ $=85 \%$ and $92 \%$, respectively). This suggests that, although therapist-rated alliance had a weaker relationship to empathy, it had less heterogeneity than client and observer ratings of alliance.

These findings were similar for empathy ratings. For empathy rater, $Q_{\text {between }}(2)=$ 16.32, $p<.001$, indicate significant differences between rater perspectives. Client- and observer-rated empathy had higher alliance/empathy relationships $(r=0.55,95 \% \mathrm{CI}=$ $0.47-0.62$ for client ratings; $r=0.56,95 \% \mathrm{CI}=0.44-0.65$ for observer ratings) than therapist-rated empathy $(r=0.28,95 \% \mathrm{CI}=0.11-0.43)$. This indicated a tendency for 
client and observer empathy ratings to more closely relate to the ratings of alliance, whereas therapist empathy ratings had a comparatively weaker relationship to alliance ratings. Again, therapist ratings had a lower within-group heterogeneity $\left(I^{2}=63 \%\right)$ compared with the heterogeneity observed in client and observer empathy ratings $\left(I^{2}=\right.$ $85 \%$ and $82 \%$ ) respectively.

After seeing the effect size changes related to the raters of alliance and therapist empathy it made sense to explore the effect size of keeping the rater consistent for both aspects of the therapeutic relationship. I tallied the effect sizes associated with clientrated alliance and empathy $(\mathrm{k}=25)$, client-rated alliance related to other-rated empathy $(\mathrm{k}=9)$, therapist-rated alliance and empathy $(\mathrm{k}=8)$, therapist-rated alliance related to other-rated empathy $(\mathrm{k}=8)$, observer-rated alliance and empathy $(\mathrm{k}=7)$, and observerrated alliance related to other-rated empathy $(\mathrm{k}=1)$. This turned out to have a significant moderating influence on the alliance/empathy relationship with $Q_{\text {between }}(1)=28.552, p<$ .001. Having the same person rate alliance and empathy was associated with a much larger effect size $(r=0.562,95 \% \mathrm{CI}=0.5-0.62)$ than having different raters for each trait $(r=0.14,95 \% \mathrm{CI}=0-0.28)$. The heterogeneity for same-rater alliance and empathy was still high $\left(I^{2}=83 \%\right)$, but was low for different-rater ratings $\left(I^{2}=27 \%\right)$.

Although it was not a significant moderating variable, I did a closer examination of the measures used for alliance. The WAI $(\mathrm{k}=31)$ was by far the most commonly used alliance measure. For the studies using the WAI, the overall effect size was similar to that obtained across measures $(r=0.528,95 \% \mathrm{CI}=0.44-0.61)$. The next most commonly used measure was the HAQ $(\mathrm{k}=5)$. Other measures were used in fewer than three studies. 
Occasionally, studies with very large Ns can affect the overall effect size in a direction that runs contrary to the other study data. I ran a test of the relative weights of the studies to see if this affected the outcome. This test systematically eliminated one study from the analysis and recalculated the overall effect size. The test results did not find a single study effect size that, when deleted, significantly changed the overall effect size.

\section{Publication Bias}

I used a funnel plot as the first means of determining the extent of any publication bias. Funnel plots display each study as a point on a graph with risk-ratio as the $\mathrm{X}$-axis and standard error as the Y-axis. Studies with larger N's have smaller standard errors and appear at the top of the plot whereas smaller studies have larger standard errors and appear at the bottom. A meta-analysis affected by publication bias would show asymmetry with a large gap between studies at the top and bottom of the plot. The funnel plot, displayed in Table 11, shows a fairly symmetric distribution of studies. There is some scatter in the plot, which can be attributed to heterogeneity. However, the studies are symmetric despite the scatter. There is also no evidence that sample size relates to different effect, given that the plotted effects tend to be close to the overall effect size.

Trim and Fill analyses supplemented the funnel plot to estimate any publication bias. Using CMA, I conducted Trim and Fill analyses of the data examining the left and right sides of the overall effect size. The results of these tests are in Table 12. The analysis on the left side added one study leaving an adjusted effect size of $r=.498$. This adjusted effect size does not differ much from the original effect size $(r=.511)$. The right side analysis made no adjustments. Since only one study was added and the 
adjusted effect size was close enough to the obtained effect size, based on this Trim and Fill analyses we can conclude that the overall effect size was not influenced by publication bias.

\section{Therapist Genuineness and Alliance}

I found 10 studies examining therapist genuineness related to alliance. The combined effect size was $r=0.53$ with $\mathrm{SE}=0.089$. The $95 \%$ confidence indicated that the true effect size lies between 0.40 and 0.65 . This indicates a strong relationship between therapist genuineness and the therapeutic alliance. The data for the overall analysis is displayed in a forest plot in Table 13.

Similar to empathy, there was significant variability between the studies used in this analysis. In this analysis, $Q(9)=31.79, p<.001$ indicating that differences between the study effect sizes were due to more than random error. To calculate the extent of this error, I calculated $I^{2}=0.72$. This indicates a .72 ratio of true heterogeneity to total variance across the studies used in this analysis. All but one study $(\mathrm{k}=9)$ used the WAI to estimate the alliance. The RRI was most frequently used to measure genuineness ( $\mathrm{k}=$ 7), followed by the BLRI $(\mathrm{k}=4)$, and the Measure of Expressed Empathy $(\mathrm{k}=1)$. Some studies used multiple measures. To analyze this variability I coded each study for the therapy used, participant demographics, time of measurement, alliance and genuineness measures, rater perspectives, and time in therapy for each study for subsequent analysis.

\section{Moderators}

I conducted moderator tests to explore the heterogeneity in the omnibus effect size test of alliance related to genuineness. I was not able to test as many moderators as were tested with therapist empathy due to the low number of alliance/genuineness 
studies, the lack of reporting in the obtained studies, and the lack of diversity in the measures used. The moderators I was unable to test included: diagnosis, theoretical approach, method of assignment, and alliance measure. A display of the individual study data with moderators of measures, measurer perspective, treatment length, and type of therapy is located in Table 14.

Of the moderators that I was able to test several did not have a significant effect on adjusting the alliance/genuineness relationship. These moderators included article type (i.e. journal article, dissertation, or thesis), publication year, number of clients, ratio of male to female clients, client mean age, therapist $n$, ratio of male to female therapists, therapist race/ethnicity ratios, therapist experience level, average number of sessions, time of measurement, genuineness measure, alliance rater perspective, and genuineness rater perspective. The results of these tests are displayed in Table 15.

Similar to the alliance/empathy results, the white/nonwhite ratio for clients was a significant modifying variable. The ratio of white to nonwhite clients had a slope coefficient of -0.013 with $Q_{\text {model }}(1)=5.423, p=.02$. This indicated that studies with more nonwhite clients had a stronger alliance/genuineness relationship than studies with more white clients. There were too few studies examining therapist genuineness to perform a regression using each race ratio as an independent predictor of the alliance/genuineness relationship. Again, I would caution deeper interpretation of this outcome due to the study-level nature of the data. More information is needed to make any definitive conclusion on the influence of client race on the relationship between perceived therapist genuineness and alliance. 
Similar to alliance/empathy, the most powerful moderating influence on the alliance/genuineness relationship was rater constancy. The number of effect sizes by rater consistency are as follows: client-rated alliance and genuineness $(\mathrm{k}=6)$, client-rated alliance related to other-rated genuineness $(\mathrm{k}=4)$, therapist-rated alliance and genuineness $(\mathrm{k}=5)$, therapist-rated alliance related to other-rated genuineness $(\mathrm{k}=3)$, and observer-rated alliance related to other-rated genuineness $(\mathrm{k}=1)$. There were no effect sizes with the observer rating both alliance and genuineness. Having the same person rate alliance and genuineness was associated with a much larger effect size $(r=$ $0.63,95 \% \mathrm{CI}=0.56-0.69)$ than having different raters for each trait $(r=0.26,95 \% \mathrm{CI}=$ $0.14-0.38)$. The heterogeneity for each group was lesser than the overall heterogeneity $\left(I^{2}=55 \%\right.$ for same rater; $51 \%$ for different raters $)$, but still suggests a moderate amount of unexplained heterogeneity.

\section{Publication Bias}

Similar to alliance/empathy, I used a funnel plot and Trim and Fill analysis to test publication bias. The funnel plot, displayed in Table 16, shows a fairly symmetric distribution of studies. The studies that fall outside the lines of the pyramid can be attributed to heterogeneity. However, the studies are symmetric despite the scatter. There is also no evidence that sample size relates to different effect, given that the plotted effects tend to be close to the overall effect size.

The Trim and Fill analyses supplemented the funnel plot. Using CMA, I conducted Trim and Fill analyses of the data examining the left and right sides of the overall effect size. The results of these tests are in Table 17. Neither analysis trimmed 
studies from the overall model. Based on the Trim and Fill analyses, we can conclude that the overall effect size was not influenced by publication bias.

\section{Therapist Empathy and Genuineness}

The relationship between perceptions of therapist empathy and perceptions of therapist genuineness had similarly strong relationship to the therapeutic alliance. Only three studies obtained through the literature search contained relationship data between empathy and genuineness (Fuertes et al., 2007; Gelso et al., 2005; Zuroff \& Blatt, 2006). The average $r$ for these studies was $r=0.80(\mathrm{SE}=0.053)$, suggesting a very strong relationship between perceived empathy and genuineness. This relationship so strong that one may question whether empathy and genuineness reflect separate constructs, or if they are measures that tap a similar core construct. One could argue, based on this data, that perceptions of empathy and genuineness are so similar that raters may be assessing the same construct with different names. The aforementioned statistic had a $Q(2)=18.64$ and $I^{2}=0.57$, so there appears to be some heterogeneity that could be explained with a thorough study of the relationship between empathy and genuineness. Future research will be required to analyze the extent of this relationship.

\section{Between-Therapist Effects}

Too few studies reported mean relationship values for individual therapist, so I was unable to directly compare between-therapist effects. Although I could not test individual therapist differences I was able to test the patient to therapist ratio (PTR) for

therapist effects. This borrows methods from Del Re, Flückiger, Horvath, Symonds, and Wampold (2012) where the effects of the therapist are assessed by the PTR. PTR is 
hypothesized to reflect study designs and capture the variability of alliance related to patient and therapist PTR is explained in the following model:

$$
\mathrm{N}_{\text {patient }} / \mathrm{N}_{\text {therapist }}
$$

where $\mathrm{N}_{\text {patient }}$ equals the number of patients and $\mathrm{N}_{\text {therapist }}$ equals the number of therapists. PTR was not a significant moderator for both the alliance/empathy relationship with $Q_{\text {model }}(27)=2.922, p=0.087$, and the alliance/genuineness relationship with $Q_{\text {model }}(4)=$ $0.126, p=0.723$. Thus, we cannot say that therapist variability affected the relationships between alliance and therapist empathy or genuineness. 


\section{CHAPTER IV DISCUSSION}

Recent meta-analyses of the therapeutic relationship linked therapy outcome to the therapeutic alliance (Horvath et al., 2011), therapist empathy (Elliott et al., 2011), and therapist genuineness Kolden et al., 2011). Each of these studies showed a moderatesized relationship between the chosen relationship variable and outcome. However, no systematic review or meta-analysis has explored the therapeutic alliance related to therapist empathy and genuineness. In doing so, this meta-analysis fills a gap in the literature, which is important because research thus far has focused more on the effects of the therapeutic relationship on outcome rather than the make-up of the therapeutic relationship and its inter-related components. Based on the study results, there is a strong, positive relationship between both the alliance and perceptions of therapist empathy and alliance and perceptions of therapist genuineness. Indeed, three prominent findings emerged that affect our conception of the alliance and perceived therapist traits of empathy and genuineness as distinct aspects of the therapeutic relationship.

First, there was a strong relationship between the therapeutic alliance and therapist empathy $(r=.51)$. However, there was notable variability among the studies, suggesting influence of other variables on the alliance/empathy relationship. In part, this variability was addressed by understanding both the alliance and empathy raters. Interestingly, client and observer ratings of both alliance and therapist empathy were similar. Observer- and client-rated alliance and empathy had very strong relationships ( $r$ $=0.544-0.559)$. This was nearly twice the effect size of therapist-rated alliance and 
empathy ( $r=0.275$ for both), suggesting that clients and observers tend to perceive alliance and therapist empathy similarly.

The discrepancy between client, therapist, and observer ratings leads to some therapeutically important insights. Alliance and empathy go hand in hand from the perspective of clients and observers, suggesting that the constructs are closely aligned and potentially could suggest that the emotional connection between clients and therapists are essential for alliance ratings (or vice versa). For example, from the observer's perspective, it could reflect an appreciation for the therapist's extension of the therapeutic relationship. However, from therapists' perspective the expression of empathy and alliance are more distinct, suggesting that some therapists may see their ability to form alliance as distinct from their expression of empathy. It could be therapists tend of have a better understanding of the constructs and understand the nuances that distinguish alliance and their use of empathy.

Clinically, the discrepancies between therapists and client ratings of alliance and empathy may indicate a mismatch in the therapeutic relationship. Following the conclusions of Hannan et al. (2005), therapists' perceptions of the therapeutic process may not be consistent with clients. The degree to which this could be helpful or not is not fully known, but it may represent opportunities for the therapeutic dyad to engage in conversations about their relationship in the here and now to promote new insights or help bridge gaps in the interpersonal connection.

Second, there was a strong relationship between the therapeutic alliance and perceptions of therapist genuineness $(r=0.534)$. This suggests that use of genuine responses in therapy can help build the alliance, or that a strong alliance can enhance 
client receptivity to genuine responses. The moderator testing did not reveal significant differences due to rater perspective like those seen in the alliance/empathy relationship. This could be due to the lower number of studies relating therapist genuineness to the alliance. It could also stem from the lack of observer ratings gleaned from the literature on perceptions of therapist genuineness.

Both empathy and genuineness analyses had client race as a significant moderator. I believe this moderating influence indicates at least two possibilities. First, it could also be that, in order to remain in therapy, racial/ethnic minorities require their therapist to display higher degrees of alliance, empathy, and genuineness. The majority of the studies in this analysis obtained data from clients who attended therapy past three sessions. Second, multicultural competency might be a therapeutic relationship skill entwined with other aspects of the therapeutic relationship, such that a more multiculturally competent therapist presents as more empathic, more genuine, and better at alliance-building. This could be explained by employing measures exploring cultural competence and adherence. Some studies included in the analysis used the CrossCultural Counseling Inventory - Revised (LaFramboise, Coleman, \& Hernandez, 1991) and scales measuring adherence to specific cultural values. In this study I did not have the raw data and could not calculate whether scores on these scales mediated the effects of the race/ethnicity moderator. Future studies can assess for any mediating effects.

Unintentional bias affects all areas of life for racial/ethnic minorities and Vasquez (2007) addresses potential impacts in psychotherapy. Biased comments from the therapist, however unintended, would impede development of an alliance and impact client perceptions of therapist empathy. Through this lens, therapists with greater 
awareness and restraint of their internal biases would be form stronger therapeutic relationships.

The last finding was that few articles and dissertations report statistics for individual therapists. This makes it difficult to determine whether characteristics of empathy and genuineness vary based on the preceptor or if they are internal traits that are static across situations. This review sought to separately examine studies that accounted for between-therapist effects, supporting the research begun by Marcus, Kashy, \& Baldwin (2009). The review did not obtain the desired cutoff number of studies $(\mathrm{k}=3)$ for analyzing the effects of an individual therapist on the therapeutic relationship. Only the dataset provided by Karlinska-Nehrebecka and Pokorny (2012) provided betweentherapist data. Therefore, this analysis could not examine the relationship between average alliance strength and empathy or genuineness for individual therapist.

Future research is needed to better understand the relationship between the alliance and therapist empathy and genuineness. The effect sizes obtained in the present analysis showed that alliance was highly related to both empathy and genuineness, suggesting that raters might not be assessing separate constructs. I would posit that raters of relationship constructs are actually assessing an underlying relationship trait that influences the constructs that comprise the therapeutic relationship as it is currently studied. This means that raters of alliance are also accounting for therapist empathy, genuineness, and other relationship factors that are not theoretically part of the alliance. This calls for further assessment of how the therapeutic relationship is understood in theory and how it appears in practice. 


\section{Limitations of the Research}

This dissertation is based upon the research available at the time of its writing. While I have done my best to assure a comprehensive review of the literature on alliance, empathy, and genuineness, no meta-analysis is fully comprehensive. Some studies may have escaped the search strategies of this analysis or may have been disseminated after the writing of this dissertation. Nonetheless, this dissertation details the only effort thus far to systematically review and analyze the relationship between the therapeutic alliance and therapist empathy and genuineness.

To make any inferences about the nature of the relationship between the therapeutic alliance and perceptions of therapist empathy and genuineness, one must account for the methodological limitations of the included studies. As with all correlational studies one cannot infer causation. We cannot say that higher perceptions of therapist empathy or genuineness lead to a higher alliance rating or vice versa. We also cannot infer the direction of influence. One can also question the perception-based nature of the therapeutic relationship. Previous studies have demonstrated the ceiling effects seen in ratings of the therapeutic relationship. Thus, it is possible the study only analyzed a restricted range of alliance strength running from good therapeutic relationships to great therapeutic relationships.

Meta-analyses are very useful in analyzing quantitative data from a variety of sources, but there remain a number of factors to consider when combining effects from different studies. These factors include: study quality, similarity between studies, and the perspectives of the relationship raters. Combining these factors can introduce -noise" into the overall findings of a meta-analysis. However, Orlinsky and Howard (1978, pp. 
288-289) stated, If study after flawed study seemed to point in the same general direction, we could not help believing that somewhere in all that variance there must be a reliable effect." The pattern of strong relationships between alliance, empathy, and genuineness is not likely to be dismissed because of study flaws.

\section{Relationship in Practice and Construct}

Because this analysis showed such close relationships between alliance, empathy, and genuineness, it might be important to consider how these might appear similarly and differently in practice. Psychotherapy research treats these relationship variables as very distinct constructs. However, these constructs may appear very similar to raters when presented with statements in a therapy session. It can be difficult to preserve the distinctness of these constructs in a therapy session. Therapist statements that appear conceptually distinct would include: Eet's see what we want to work on in therapy" (alliance) and $\Psi$ felt sad when you were talking about that" (genuineness).

This becomes complicated when these constructs overlap. An easy argument could be made that one cannot give an empathic response that does not draw on the therapist's genuine concern. A statement like + would feel very upset if I were in your place" can be said without being genuine. The therapist may say the statement while their genuine feelings toward the client are feelings of frustration. This may or may not be perceived by the client. Is the client more likely to rate high empathy with low genuineness, or are will they internalize a message that they don't like their therapist? The conceptual distinctness is also complicated in situations when the empathic response matches a therapist's genuine feeling. One would see high ratings of both, blurring the conceptual lines between empathy and genuineness. 
At a scale-level, it makes sense that alliance, empathy, and genuineness appear to be very similar constructs. The whole aforementioned analysis can be seen as a study of construct validity. At a level of content validity, some of the scales have very similar items to measure distinct constructs. The WAI has an item +feel really understood" (Horvath, 1981, p. 227) and the BLRI empathy subscale has a similar item understands me" (Horvath, 1981, p. 236). Similarly, the WAI contains the item $\Psi$ feel that is not totally honest with me about his/her feelings toward me" (Horvath, 1981, p. 228) and the Genuineness scale of the RRI has the item 4 felt there was a significant holding back in our relationship" (Kelley, 2002, p. 128). From a content validity standpoint, it looks like some overlap between alliance, empathy, and genuineness is to be expected given the similarity in the sample items.

\section{Practice Implications}

To conclude, I have outlined some ways practitioners can recognize and utilize the alliance, empathy, and genuineness in the therapy setting. Past research has linked alliance, empathy, and genuineness to treatment outcome (Elliott et al., 2011; Horvath et al., 2011; Kolden et al., 2011) and this analysis showed the relationships between these relationship variables. The therapeutic relationship appears as a necessary, and sometimes sufficient, condition for change in most theories of psychotherapy. It is therefore important for therapists to understand and recognize the different aspects of the therapeutic relationship as it appears in treatment.

Conceptually, engendering alliance, expressing empathy, and using genuine responses may appear different when used in therapy. Alliance work usually involves discussion of therapy goals and means of achieving those goals. Empathy expression 
involves the therapist accounting for the client's behaviors, emotions, and words, and then reflecting this understanding back to the client. Use of genuineness occurs when the therapist recognizes a gut-level" reaction to the client, determines the therapeutic merit of mentioning this reaction, and, if appropriate, divulging this response to the client. The conceptual distinctions between the alliance, empathy, and genuineness are conceptually distinct, that does not prohibit any overlap. At this point we do not know about the directionality of the relationships between alliance, empathy, and genuineness. There is a high potential for overlap. Examples of overlap can include: 1) use of empathy and genuineness can build the bond aspect of the therapeutic alliance, 2) empathizing with client frustrations over any perceived barriers to therapeutic goals, 3) expressing genuine frustration when a client consistently ignores their task work, etc.

While the alliance, empathy, and genuineness are key components of the therapeutic relationship, they do not fully comprise that relationship. Other aspects of the therapeutic relationship include creation of a safe environment, responsiveness, liking, etc. Beutler et al. (2004) identified several areas where therapist variables were underresearched. These areas provide direction for future research on the inner workings of the therapeutic relationship.

The therapeutic relationship should be understood as a fluid entity in psychotherapy. Therapists can intentionally or unintentionally create an alliance rupture, thereby damaging the therapeutic relationship. Therapists should not personalize or internalize these shifts, but do their best to work with the client at their current comfort level. That being said, therapists need to recognize their influence on the therapeutic relationship. If the therapist does something harmful to the relationship, they should 
accept their responsibility and openly discuss any thoughts or feelings that led to the negative event. Alliance ruptures could result from the differences in client and therapist perceptions. An example would be $\mathrm{Idid}$ not mean to upset you by my statement. I was feeling frustrated that we often spend so much time talking about your job, which is just one area of your life. I realize that it must be a very important area and I've wondered if there are other areas we're not getting to talk about when we're spending a lot of talking about work."

As seen in the present analysis, therapists and clients perceive the therapeutic relationship differently. This is a meaningful finding in that disagreement on the therapeutic relationship could have an impact on the progress of therapy. Each perceiver of the relationship appears to have their own consistent viewpoint across relationship variables, but this does not always reflect the viewpoint of a different perceiver. In order to monitor progress in the therapeutic relationship, therapists should solicit and acknowledge their client's perceptions of the therapeutic relationship. Oftentimes, one party (usually the therapist) will believe that the goals of therapy are clear while the other party will be uncertain about the direction of therapy. Incorrect judgment of the strength of the relationship can impede the progress of therapy. Therapists should elicit client feedback about the process of therapy. This can be done with verbal check-ins (e.g. Was my understanding of your feelings accurate?") and/or with questionnaires. Feedback should be accepted in a non-defensive manner.

In conclusion, the meta-analysis described in this work shows that the therapeutic alliance is very closely related to perceptions of therapist empathy and genuineness. A variety of factors affect the strength of this relationship, including rater perspective, client 
race/ethnicity, and empathy measure. This relationship is especially strong when a client or an observer rate both alliance and perceptions of therapist traits. Future studies can expand upon interrelations within the overall therapeutic relationship. 


\section{REFERENCES}

References marked with an asterisk indicate studies included in the metaanalyses.

Ackerman, S. J., \& Hilsenroth, M. J. (2001). A review of therapist characteristics and techniques negatively impacting the therapeutic alliance. Psychotherapy, 38(3), 171-185. doi: 10.1037/0033-3204.38.2.171

Ackerman, S. J., \& Hilsenroth, M. J. (2003). A review of therapist characteristics and techniques positively impacting the therapeutic alliance. Clinical Psychology Review, 23, 1-33. doi: 10.1016/S0272-7358(02)00146-0

*Adler, J. V. (1988). A study of the working alliance in psychotherapy. Retrieved from Proquest Digital Dissertations. (AAT NL47090).

Ahn, H., \& Wampold, B. E. (2001). Where oh where are the specific ingredients? A meta-analysis of component studies in counseling and psychology. Journal of Counseling Psychology, 48(3), 251-257. doi: 10.1037/0022-0167.48.3.251

Alexander, L. B., \& Luborsky, L. (1986). The Penn Helping Alliance Scales. In L. S. Greenberg \& W. M. Pinsof (Eds.), The psychotherapeutic process: A research handbook (pp. 325-356). New York: Guilford.

*Allen, J. G., Coyne, L., Colson, D. B., Horwitz, L., Gabbard, G. O., Frieswyk, S. H., \& Newson, G. (1996). Pattern of therapist interventions associated with patient collaboration. Psychotherapy, 33(2), 254-261. doi: 10.1037/0033-3204.33.2.254 
Bachelor, A. (1988). How clients perceive therapist empathy: A content analysis of received" empathy. Psychotherapy, 25, 227-240. doi: 10.1037/h0085337

Baldwin, S. A., Wampold, B. E., \& Imel, Z. E. (2007). Untangling the alliance-outcome correlation: Exploring the relative importance of therapist and patient variability in the alliance. Journal of Consulting and Clinical Psychology, 75(6), 842-852. doi: $10.1037 / 0022-006 x .75 .6 .842$

Barrett-Lennard, G. T. (1962). Dimensions of therapist response as a causal factor in therapeutic change. Psychological Monographs, 76, 1-36.

Barrett-Lennard, G. T. (1978). The relationship inventory: Later development and adaptations: American Psychological Association, Journal Supplement Abstract Service.

Barrett-Lennard, G. T. (1981). The empathy cycle: Refinement of a nuclear concept. Journal of Counseling Psychology, 28(2), 91-100. doi: 10.1037/00220167.28 .2 .91

Barrett-Lennard, G. T. (1986). The Relationship Inventory now: Issues and advances in theory, method, and use. In L. S. Greenberg \& W. M. Pinsof (Eds.), The psychotherapeutic process (pp. 439-477). New York: Guilford.

Barrett-Lennard, G. T. (1998). Carl Rogers' helping system: Journey and substance. Beverly Hills, CA: Sage.

Batson, C. D. (2009). These things called empathy: Eight related but distinct phenomena. In J. Decety \& W. Ickes (Eds.), The social neuroscience of empathy (pp. 3-15). Cambridge, MA: The MIT Press. 
Beck, A. T., \& Freeman, A. (1990). Cognitive therapy of personality disorders. New York: Guilford.

Bergin, A. E. (1991). Values and religious issues in psychotherapy and mental health. American Psychologist, 46, 394-403. doi: 10.1037/0003-066X.46.4.394

Beutler, L. E., Harwood, T. M., Michelson, A., Song, X., \& Holman, J. (2011). Reactance/resistance level. In J. C. Norcross (Ed.), Psychotherapy relationships that work: Evidence-based responsiveness (2nd ed., pp. 261-278). New York: Oxford University Press.

Beutler, L. E., Malik, M., Alimohamed, S., Harwood, T. M., Talebi, H., Noble, S., \& Wong, E. (2004). Therapist variables. In M. J. Lambert (Ed.), Bergin and Garfield's handbook of psychotherapy and change (5th ed., pp. 227-306). New York: John Wiley \& Sons.

Beutler, L. E., Machado, P.P.P., \& Neufeldt, S. (1994). Therapist variables. In S. L. Garfield \& A. E. Bergin (Eds.), Handbook of psychotherapy and behavior change (4th ed., pp. 259-269). New York: John Wiley \& Sons.

Bohart, A. C., Elliott, R., Greenberg, L. S., \& Watson, J. C. (2002). Empathy. In J. Norcross (Ed.), Psychotherapy relationships that work (pp. 89-108). New York: Oxford University Press.

Bohart, A. C., \& Greenberg, L. S. (1997). Empathy and psychotherapy: An introductory overview. In A. C. Bohart \& L. S. Greenberg (Eds.), Empathy reconsidered: New directions in psychotherapy (pp. 3-31). Washington, DC: American Psychological Association. doi: 10.1037/10226-000 
Bordin, E. S. (1979). The generalizability of the psychoanalytic concept of the working alliance. Psychotherapy: Theory, Research, and Practice, 16, 252-260. doi: $10.1037 / \mathrm{h} 0085885$

Borenstein, M. (2009). Effect sizes for continuous data. In H. Cooper, L. V. Hedges, \& J. C. Valentine (Eds.), The handbook of research synthesis and meta-analysis (2nd ed., pp. 221-236). New York: The Russell Sage Foundation.

Borenstein, M., Hedges, L. V., Higgins, J. P. T., \& Rothstein, H. R. (2009). Introduction to meta-analysis. Chichester, England: Wiley. doi: 10.1002/9780470743386

*Burchard, P. (1991). The relationship of four dimensions of therapist empathy to two measures of the therapeutic alliance. (Unpublished doctoral dissertation). Adelphi University, Garden City, NY.

Burlingame, G. M., McClendon, D. T., \& Alonso, J. (2011). Cohesion in group therapy. Psychotherapy, 48(1), 34-42.

Carkhuff, R. P. (1969). Helping and human relations (Vols. 1 and 2). New York: Holt, Rinehart, \& Winston.

Cohen, J. (1988). Statistical power analysis for the behavioral sciences (2nd ed.). Hillsdale, NJ: Lawrence Erlbaum.

Constantino, M. J., Glass, C. R., Arnkoff, D. B., Ametrano, R. M., \& Smith, J. Z. (2011). Expectations. In J. C. Norcross (Ed.), Psychotherapy relationships that work: Evidence-based responsiveness (2nd ed., pp. 354-376). New York: Oxford University Press.

*Constantino, M. J., Marnell, M. E., Haile, A. J., Kanther-Sista, S. N., Wolman, K., Zappert, L., \& Arnow, B. A. (2008). Integrative cognitive therapy for depression: 
A randomized pilot comparison. Psychotherapy: Theory, Research, Practice, Training, 45(2), 122-134. doi: 10.1037/0033-3204.45.2.122

Cooper, H. (2009). Research synthesis and meta-analysis: A step-by-step approach. Thousand Oaks, CA: Sage Publications.

Cooper, H, \& Hedges, L. V. (2009). Research synthesis as a scientific process. In H. Cooper, L. V. Hedges, \& J. C. Valentine (Eds.), The handbook of research synthesis and meta-analysis (2nd ed., pp. 3-16). New York: The Russell Sage Foundation.

Cramer, D. (1986). An item factor analysis of the revised Barrett-Lennard Relationship Inventory. British Journal of Guidance and Counselling, 14(3), 314-325. doi: $10.1080 / 03069888600760321$

${ }^{*}$ Crowley, M. J. (2000). Patient and therapist pre-treatment characteristics as predictors of the therapeutic alliance. Retrieved from Proquest Digital Dissertations. (AAT 9989107).

*Daniels, H. (1993). Predicting the strength of the therapeutic alliance: Selfobject transference, empathy, psychopathology. (Unpublished doctoral dissertation). Adelphi University, Garden City, NY.

Davis, M. H. (1994). Empathy: A social psychological approach. Madison, WI: Brown \& Benchmark Publishers.

*Daw, B., \& Joseph, S. (2010). Psychological mindedness and therapist attributes. Counselling \& Psychotherapy Research, 10(3), 233-236. doi: $10.1080 / 14733140903226982$ 
Decety, J., \& Ickes, W. (Eds.). (2009). The social neuroscience of empathy. Cambridge, MA: MIT Press.

Deeks, J. J., Higgins, J. P. T., \& Altman, D. G. (eds.). Chapter 9: Analysing data and undertaking meta-analyses. In Higgins, J. P. T., \& Green, S. (eds.). Cochrane handbook for systematic reviews of interventions Version 5.1.0. The Cochrane Collaboration, 2011. Retrieved from www.cochrane-handbook.org.

*DeGeorge, J. (2008). Empathy and the therapeutic alliance: Their relationship to each other and to outcome in cognitive-behavioral therapy for generalized anxiety disorder. (Unpublished masters thesis). University of Massachusetts, Amherst, MA.

Del Re, A. C. (2010). RcmdrPlugin.MAc: Meta-Analysis with Correlations (MAc) Rcmdr Plug-in. R package version 1.1. http://CRAN.Rproject.org/package=RcmdrPlugin.MAc.

Del Re, A. C., Flückiger, C., Horvath, A. O., Symonds, D., \& Wampold, B. E. (2012). Therapist effects in the therapeutic alliance-outcome relationship: A restrictedmaximum likelihood meta-analysis. Clinical Psychology Review, 32, 642-649. http://dx.doi.org/10.1016/j.cpr.2012.07.002

Del Re, A. C., \& Hoyt, W. T. (2010). MAc: Meta-Analysis with Correlations. R package version 1.1. http://CRAN.R-project.org/package=MAc.

Deutsch, F., \& Madle, R. A. (1975). Empathy: Historic and current conceptualizations, measurement, and a cognitive theoretical perspective. Human Development, 18 , 267-287. doi: $10.1159 / 000271488$ 
Dickersin, K. (1990). The existence of publication bias and risk factors for its occurrence. Journal of the American Medical Association, 263(10), 1385-1389. doi: 10.1001/jama.1990.03440100097014

Diener, M. J., \& Monroe, J. M. (2011). The relationship between adult attachment style and therapeutic alliance in individual psychotherapy: A meta-analytic review. Psychotherapy, 48(3), 237-248. doi: 10.1037/a0022425

Dinger, U., Strack, M., Leichsenring, F., Wilmers, F., \& Schauenburg, H. (2008). Therapist effects on outcome and alliance in inpatient psychotherapy. Journal of Clinical Psychology, 64(3), 344-354. doi: 10.1002/jclp.20443

Duan, C., \& Hill, C. E. (1996). The current state of empathy research. Journal of Counseling Psychology, 43(3), 261-274. doi: 10.1037/0022-0167.43.3.261

Duff, C. T., \& Bedi, R. P. (2010). Counsellor behaviours that predict therapeutic alliance: From the client's perspective. Counselling Psychology Quarterly, 23(1), 91-110. doi: $10.1080 / 09515071003688165$

Egan, G. (2010). The skilled helper: A problem management and opportunity development approach to helping (9th ed.). Belmont, CA: Brooks/Cole, Cengage Learning.

Eisenberg, N., \& Strayer, J. (Eds.). (1987). Empathy and its development. New York: Cambridge University Press.

Elliott, R. (1986). Interpersonal Process Recall (IPR) as a psychotherapy process research method. In L. S. Greenberg \& W. M. Pinsof (Eds.), The psychotherapeutic process (pp. 503-528). New York: Guilford. 
Elliott, R., Bohart, A. C., Watson, J. C., \& Greenberg, L. S. (2011). Empathy. In J. C. Norcross (Ed.), Psychotherapy relationships that work: Evidence-based responsiveness (2nd ed., pp. 132-152). New York: Oxford University Press.

Elliott, R., Filipovich, H., Harrigan, L., Gaynor, J., Reimschuessel, C., \& Zapadka, J. K. (1982). Measuring response empathy: The development of a multi-component rating scale. Journal of Counseling Psychology, 29(4), 379-387.

*Evans-Jones, C., Peters, E., \& Barker, C. (2009). The therapeutic relationship in CBT for psychosis: Client, therapist and therapy factors. Behavioural and Cognitive Psychotherapy, 37(5), 527-540. doi: 10.1017/s1352465809990269

Feller, C. P., \& Cottone, R. R. (2003). The importance of empathy in the therapeutic alliance. Journal of Humanistic Counseling, Education and Development, 42, 5361.

Ferguson, C. J., \& Brannick, M. T. (2012). Publication bias in psychological science: Prevalence, methods for identifying and controlling, and implications for the use of meta-analyses. Psychological Methods, 17(1), 120-128. doi: 10.1037/a0024445

Fields, S. K., Hojat, M., Gonnella, J. S., Mangione, S., Kane, G., \& Magee, M. (2004). Comparisons of nurses and physicians on an operational measure of empathy. Evaluation \& the Health Professions, 27, 80-94. doi: 10.1177/ 0163278703261206

Fields, S. K., Mahan, P., Tillman, P., Harris, J., Maxwell, K., \& Hojat, M. (2011). Measuring empathy in healthcare profession students using the Jefferson Scale of Physician Empathy: Health provider - student version. Journal of Interprofessional Care, 25, 287-293. doi: 10.3109/13561820.2011.566648 
*Fitch, J. (2008). Counselors as caregivers: The validation of the Counselor Caregiving Questionnaire (CCQ). Retrieved from Proquest Digital Dissertations. (AAT 3418690).

Flückiger, C., Del Re, A. C., Wampold, B. E., Symonds, D., \& Horvath, A. O. (2011). How central is the alliance in psychotherapy? A multilevel longitudinal metaanalysis. Journal of Counseling Psychology, 59(1), 10-17. doi: 10.1037/a0025749

*Forman, N. W. (1990). The nature of trait empathy in clients with chronic pain and their counselors and its impact on the development of the working alliance and outcome. Retrieved from Proquest Digital Dissertations. (AAT 9022497).

Friedlander, M. L., Escudero, V., Heatherington, L., \& Diamond, G. M. (2011). Alliance in couple and family therapy. In J. C. Norcross (Ed.), Psychotherapy relationships that work: Evidence-based responsiveness (2nd ed., pp. 92-109). New York:

Oxford University Press. doi: 10.1093/acprof:oso/9780199737208.003.0004

Freud, S. (1958). On the beginning of treatment: Further recommendations on the technique of psychoanalysis. London: Hogarth Press (Original work published 1913).

*Fuertes, J. N., Boylan, L. S., \& Fontanella, J. A. (2009). Behavioral indices in medical care outcome: The working alliance, adherence, and related factors. Journal of General Internal Medicine, 24(1), 80-85. doi: 10.1007/s11606-008-0841-4

*Fuertes, J. N., Stracuzzi, T. I., Bennett, J., Scheinholtz, J., Mislowack, A., Hersh, M., \& Cheng, D. (2006). Therapist multicultural competency: A study of therapy dyads. Psychotherapy: Theory, Research, Practice, Training, 43(4), 480-490. doi: $10.1037 / 0033-3204.43 .4 .480$ 
*Fuertes, J. N., Stracuzzi, T. I., Bennett, J., Scheinholz, J., Mislowack, A., Hersh, M., \& Cheng, D. (2007). 'Therapist Multicultural Competency: A Study of Therapy Dyads': Correction. Psychotherapy: Theory, Research, Practice, Training, 44(1). doi: $10.1037 / 0033-3204.44 .1 .13$

Gaston, L., \& Marmar, C. (1994). The California Psychotherapy Alliance Scales. In A. O. Horvath \& L. S. Greenberg (Eds.), The working alliance: Theory, research, and practice. New York: Wiley.

Geller, S., \& Greenberg, L. S. (2002). Therapeutic presence: Therapists experience of presence in the psychotherapy encounter in psychotherapy. Person Centered \& Experiential Psychotherapies, 1, 71-86. doi: 10.1080/14779757.2002.9688279

Gelso, C. J., \& Carter, J. A. (1985). The relationship in counseling and psychotherapy: Components, consequences, and theoretical antecedents. Journal of Counseling Psychology, 13(2), 155-194.

Gelso, C. J., \& Carter, J. A. (1994). Components of the psychotherapy relationship: Their interaction and unfolding during treatment. Journal of Counseling Psychology, 41(3), 296-306. doi: 10.1037/0022-0167.41.3.296

Gelso, C. J., \& Hayes, J. A. (1998). The psychotherapy relationship: Theory, research, and practice. New York: Wiley.

*Gelso, C. J., Kelley, F. A., Fuertes, J. N., Marmarosh, C., Holmes, S. E., Costa, C., \& Hancock, G. R. (2005). Measuring the real relationship in psychotherapy: Initial validation of the therapist form. Journal of Counseling Psychology, 52(4), 640649. doi:10.1037/0022-0167.52.4.640 
Gladstein, G. A. (1987). The role of empathy in counseling: Theoretical considerations. In G. A. Gladstein and Associates (Eds.), Empathy and counseling: Explorations in theory and research (pp. 1-20). New York: Springer-Verlag.

Grencavage, L. M., \& Norcross, J. C. (1990). Where are the commonalities among the therapeutic factors? Professional psychology: Research and practice, 21(5), 372378.

Greenberg, L. S., \& Watson, J. (2005). Emotion-focused therapy of depression. Washington, DC: American Psychological Association Press.

Greenson, R. R. (1965). The working alliance and the transference neuroses. Psychoanalysis quarterly, 34, 155-181.

Gurman, A. S. (1977). The patient's perception of the therapeutic relationship. In A. S. Gurman \& A. M. Razin (Eds.), Effective psychotherapy: A handbook of research (pp. 503-543). New York: Pergamon.

Ham, M. A. (1987). Counselor empathy. In G. A. Gladstein and Associates (Eds.), Empathy and counseling: Explorations in theory and research (pp. 21-29). New York: Springer-Verlag.

Hamilton, J. C. (2000). Construct validity of the core conditions and factor structure of the Client Evaluation of Counselor Scale. The Person-Centered Journal, 7, 40-51.

Hannan, C., Lambert, M. J., Harmon, C., Nielsen, S. L., Smart, D. W., Shimokawa, K. and Sutton, S. W. (2005). A lab test and algorithms for identifying clients at risk for treatment failure. Journal of Clinical Psychology: In Session, 61, 155-163. doi: 10.1002/jclp.20108

Hatcher, R. L., \& Barends, A. W. (1996). Patient's view of the alliance in psychotherapy: 
Exploratory factor analysis of three alliance measures. Journal of Clinical and Consulting Psychology, 64, 1326-1336. doi: 10.1037/0022-006X.64.6.1326

Hatcher, R. L., Barends, A., Hansell, J., \& Gutfreund, M. J. (1995). Patients' and therapists' shared and unique views of the therapeutic alliance: An investigation using confirmatory factor analysis in a nested design. Journal of Consulting and Clinical Psychology, 63(4), 636-643. doi: 10.1037/0022-006X.63.4.636

Hauser, M., \& Hays, D. G. (2010). The slaying of a beautiful hypothesis: The efficacy of counseling and the therapeutic process. Journal of Humanistic Counseling, Education and Development, 49, 32-44.

Hayes, J. A., Gelso, C. J., \& Hummel, A. M. (2011). Managing countertransference. In J. C. Norcross (Ed.), Psychotherapy relationships that work: Evidence-based responsiveness (2nd ed., pp. 239-258). New York: Oxford University Press.

*Hayes, J. A., Yeh, Y.-J., \& Eisenberg, A. (2007). Good grief and not-so-good grief: Countertransference in bereavement therapy. Journal of Clinical Psychology, 63(4), 345-355. doi: $10.1002 /$ jclp.20353

Henry, W. P., \& Strupp, H. A. (1994). Therapeutic alliances as interpersonal process. In A. O. Horvath \& L. S. Greenberg (Eds.), The working alliance: Theory, research, and practice, (pp. 51-84). New York: John Wiley \& Sons.

Herman, S. M. (1998). The relationship between therapist-client modality similarity and psychotherapy outcome. Journal of Psychotherapy Practice and Research, 7, 5664.

Hill, C. E., Nutt, E., \& Jackson, S. (1994). Trends in psychotherapy process research: Samples, measures, researchers, and classic publications. Journal of Counseling 
Psychology, 41, 364-377. doi: 10.1037/0022-0167.41.3.364

*Hoffart, A., Borge, F.-M., Sexton, H., \& Clark, D. M. (2009). The role of common factors in residential cognitive and interpersonal therapy for social phobia: A process-outcome study. Psychotherapy Research, 19(1), 54-67. doi: $10.1080 / 10503300802369343$

Hoffman, M. L. (2000). Empathy and moral development: Implications for caring and justice. New York: Cambridge University Press.

Hogan, R. (1969). Development of an empathy scale. Journal of Consulting and Clinical Psychology, 33(3), 307-316. doi: 10.1037/h0027580

Hopewell, S., Clarke, M. and Mallett, S. (2006) Grey literature and systematic reviews. In H. R. Rothstein, A. J. Sutton, \& M. Borenstein (Eds.), Publication bias in meta-analysis: Prevention, assessment and adjustments (pp. 49-72). Chichester, UK: John Wiley \& Sons, Ltd. doi: 10.1002/0470870168.ch4

*Horvath, A. O. (1981). An exploratory study of the working alliance: Its measurement and relationship to therapy outcome. Retrieved from Proquest Digital Dissertations. (AAT NK55037).

Horvath, A. O., \& Bedi, R. P. (2002). The alliance. In J. C. Norcross (Ed.), Psychotherapy relationships that work: Therapist contributions and responsiveness to patients (pp. 37-70). New York: Oxford University Press.

Horvath, A. O., Del Re, A. C., Flückiger, C., \& Symonds, D. (2011). Alliance in individual psychotherapy. In J. C. Norcross (Ed.), Psychotherapy relationships that work: Evidence-based responsiveness (2nd ed., pp. 25-69). New York: Oxford University Press. doi: 10.1093/acprof:oso/9780199737208.003.0002 
Horvath, A. O., \& Greenberg, L. S. (1989). Development and validation of the Working Alliance Inventory. Journal of Counseling Psychology, 36(2), 223-233.

Horvath, A. O., \& Luborsky, L. (1993). The role of the therapeutic alliance in psychotherapy. Journal of Consulting and Clinical Psychology, 61(4), 561-573. doi: 10.1037/0022-006X.61.4.561

Horvath, A. O., \& Symonds, B. D. (1991). Relation between working alliance and outcome in psychotherapy: A meta-analysis. Journal of Counseling Psychology, 38, 139-149. doi:10.1037/0022-0167.38.2.139

*James, E. B. (1986). Measuring concurrent effects of psychotherapy: Domains of session impact. (Unpublished doctoral dissertation). The University of Toledo, Toledo, $\mathrm{OH}$.

*Jang, Y. J. (2009). The influence of Korean counselors' personal wellness on clientperceived counseling effectiveness: The moderating effects of empathy. (Unpublished doctoral dissertation). The University of Iowa, University Heights, IA.

*Karlinska-Nehrebecka, M., \& Pokorny, D. (2012). Prognostic factors of remaining in the psychotherapy and finding solution. Paper presented at the 3rd Annual Meeting of the SPR European and UK Chapters, Porto, Portugal.

*Kelley, F. A. (2002). Development and psychometric investigation of the Real Relationship Inventory. Retrieved from Proquest Digital Dissertations. (AAT 3070533).

Kelley, F. A., Gelso, C. J., Fuertes, J. N., Marmarosh, C., \& Lanier, S. (2010). The Real Relationship Inventory: Development and psychometric investigation of the client 
form. Psychotherapy: Theory, Research \& Practice, 47(4), 540-553. doi: $10.1037 / \mathrm{a} 0022082$

Kiesler, D. J. (1973). The process of psychotherapy: Empirical foundations and systems of analysis. Chicago: Aldine.

*Kim, B. S. K., Li, L. C., \& Liang, C. T. H. (2002). Effects of Asian American client adherence to Asian cultural values, session goal, and counselor emphasis of client expression on career counseling process. Journal of Counseling Psychology, 49(3), 342-354. doi: 10.1037//0022-0167.49.3.342

*Kim, B. S. K., Ng, G. F., \& Ahn, A. J. (2005). Effects of client expectation for counseling success, client-counselor worldview match, and client adherence to Asian and European American cultural values on counseling process with Asian Americans. Journal of Counseling Psychology, 52(1), 67-76. doi: 10.1037/00220167.52 .1 .67

* Kim, B. S. K., Ng, G. F., \& Ahn, A. J. (2009). Client adherence to Asian cultural values, common factors in counseling, and session outcome with Asian American clients at a university counseling center. Journal of Counseling \& Development, 87, 131-142. doi: 10.1002/j.1556-6678.2009.tb00560.x

Klein, M. H., Kolden, G. G., Michels, J., \& Chisholm-Stockard, S. (2002). Congruence. In J. C. Norcross (Ed.), Psychotherapy relationships that work: Therapist contributions and responsiveness to patients (pp. 195-215). New York: Oxford Press.

Kolden, G. G., Klein, M. H., Wang, C.-C., \& Austin, S. B. (2011). Congruence/genuineness. In J. C. Norcross (Ed.), Psychotherapy relationships 
that work: Evidence-based responsiveness (2nd ed., pp. 187-202). New York: Oxford University Press. doi: 10.1093/acprof:oso/9780199737208.003.0009 Lafferty, P., Beutler, L. E., \& Crago, M. (1989). Differences between more and less effective psychotherapists: A study of select therapist variables. Journal of Consulting and Clinical Psychology, 57(1), 76-80. doi: 10.1037/0022006X.57.1.76

LaFramboise, T. D., Coleman, H. L. K., \& Hernandez, A. (1991). Development and factor structure of the Cross-Cultural Counseling Inventory-Revised. Professional Psychology: Research and Practice, 22, 380-388.

Lambert, M. J. (Ed.) (2004). Bergin and Garfield's handbook of psychotherapy and behavior change (5th ed.). New York: Wiley.

Lambert, M. J., DeJulio, S. J., \& Stein, D. M. (1978). Therapist interpersonal skills: Process, outcome, methodological considerations, and recommendations for future research. Psychological Bulletin, 85, 467-489. doi: 10.1037/00332909.85.3.467

Lambert, M. J., \& Ogles, B. M. (2004). The efficacy and effectiveness of psychotherapy. In M. J. Lambert (Ed.), Bergin and Garfield's handbook of psychotherapy and behavior change (5th ed., pp. 139-193). New York: Wiley.

*Lampropoulos, G. K. (2006). Thinking styles, treatment preferences, and early counseling process and outcome. (Unpublished doctoral dissertation). Ball State University, Muncie, IN.

Leichsenring, F., Hiller, W., Weissberg, M., \& Leibing, E. (2006). Cognitive-behavioral therapy and psychodynamic psychotherapy: Techniques, efficacy, and indications. 
American Journal of Psychotherapy, 60(3), 233-259.

Levy, K. N., Ellison, W. D., Scott, L. N., \& Bernecker, S. L. (2011). Attachment style. In J. C. Norcross (Ed.), Psychotherapy relationships that work: Evidence-based responsiveness (2nd ed., pp. 377-401). New York: Oxford University Press.

*Li, L. C., \& Kim, B. S. K. (2004). Effects of counseling style and client adherence to Asian cultural values on counseling process with Asian American college students. Journal of Counseling Psychology, 51(2), 158-167. doi: 10.1037/00220167.51.2.158

Lin, T. (1973). Revision and validation of the Truax-Carkhuff Relationship Questionnaire. Measurement \& Evaluation in Guidance, 6(2), 82-86.

Lindgren, O., Folkesson, P., \& Almqvist, K. (2010). On the importance of the therapist in psychotherapy: A summary of current research. International Forum of Psychoanalysis, 19, 224-229. doi: 10.1080/08037060903536047

*Linley, P. A., \& Joseph, S. (2007). Therapy work and therapists' positive and negative well-being. Journal of Social and Clinical Psychology, 26(3), 385-403. doi: $10.1521 /$ jscp.2007.26.3.385

Listowel, E. (1934). A critical history of aesthetics. London: G. Allen \& Unwin. *Lo Coco, G., Gullo, S., Prestano, C., \& Gelso, C. J. (2011). Relation of the real relationship and the working alliance to the outcome of brief psychotherapy. Psychotherapy, 48(4), 359-367. doi: 10.1037/a0022426

Luborsky, L. (1976). Helping alliances in psychotherapy. In J. L. Cleghhorn (Ed.), Successful psychotherapy (pp. 92-116). New York: Brunner/Mazel.

Luborsky, L., Barber, J. P., Siqueland, L., Johnson, S., Najavits, L. M., Frank, A., \& 
Daley, D. (1996). The revised Helping Alliance Questionnaire (HAq-II):

Psychometric properties. Journal of Psychotherapy Practice and Research, 5(3), 260-271.

Luborsky, L., Chandler, M., Auerbach, A. H., Cohen, J., \& Bachrach, H. M. (1971). Factors influencing the outcome of psychotherapy: A review of quantitative research. Psychological Bulletin, 75, 145-185. doi: 10.1037/h0030480

*Macauley, H. L. (2005). What are the qualities of therapists' empathic responses? (Unpublished masters thesis). York University, Toronto, ON.

Marcus, D. K., Kashy, D. A., \& Baldwin, S. A. (2009). Studying psychotherapy using the one-with-many design: The therapeutic alliance as an exemplar. Journal of Counseling Psychology, 56(4), 537-548. doi: 10.1037/a0017291

*Marmarosh, C. L., Gelso, C. J., Markin, R. D., Majors, R., Mallery, C., \& Choi, J. (2009). The real relationship in psychotherapy: Relationships to adult attachments, working alliance, transference, and therapy outcome. Journal of Counseling Psychology, 56(3), 337-350. doi: 10.1037/a0015169

Martin, D. J., Garske, J. P., \& Davis, M. K. (2000). Relation of the therapeutic alliance with outcome and other variables: A meta-analytic review. Journal of Consulting and Clinical Psychology, 68, 438-450. doi:10.1037/0022-006X.68.3.438

Meltzoff, J., \& Kornreich, M. (1970). Research in psychotherapy. New York: Atherton.

Mercer, S. W., Maxwell, M., Heaney, D., \& Watt, G. C. M. (2004). The consultation and relational empathy (CARE) measure: Development and preliminary validation and reliability of an empathy-based consultation process measure. Family Practice, 21(6), 699-705. doi: 10.1093/fampra/cmh621 
Mitchell, K. M., Bozrath, J. D., \& Krauft, C. C. (1977). A reappraisal of the therapeutic effectiveness of accurate empathy, nonpossessive warmth, and genuineness. In A. S. Gurman \& A. M. Razin, (Eds.), Effective psychotherapy: A handbook of research (pp. 503-543). Oxford, UK: Pergamon.

*Moseley, D. (1983). The therapeutic relationship and its association with outcome. (Unpublished doctoral dissertation). University of British Columbia, Vancouver, Canada.

*Murphy, C. L. (1988). The relationship between cognitive and affective empathy and the quality of the working alliance in psychotherapy. (Unpublished doctoral dissertation). University of Maryland, College Park, MD.

Norcross, J. C. (2010). The therapeutic relationship. In B. L. Duncan, S. D. Miller, B. E. Wampold, \& M. A. Hubble (Eds.), The heart and soul of change (2nd ed., pp. 113-141). Washington, DC: American Psychological Association.

Norcross, J. C. (Ed.). (2011). Psychotherapy relationships that work: Evidence-based responsiveness (2nd ed.). New York: Oxford University Press.

Norcross, J. C., Krebs, P. M., \& Prochaska, J. O. (2011). Stages of change. In J. C. Norcross (Ed.), Psychotherapy relationships that work: Evidence-based responsiveness (2nd ed., pp. 279-300). New York: Oxford University Press.

Norcross, J. C., \& Wampold, B. E. (2011). Evidence-based therapy relationships: Research conclusions and clinical practices. In J. C. Norcross (Ed.), Psychotherapy relationships that work: Evidence-based responsiveness (2nd ed., pp. 423-430). New York: Oxford University Press. doi:

10.1093/acprof:oso/9780199737208.001.0001 
Orlinsky, D. E., Grawe, K., \& Parks, B. K. (1994). Process and outcome in psychotherapy—noch einmal. In A. E. Bergin \& S. L. Garfield (Eds.), Handbook of psychotherapy and behavior change (4th ed., pp. 270-376). New York: Wiley.

Orlinsky, D. E., \& Howard, K. I. (1967). The good therapy hour: Experiential correlates of patients' and therapists' evaluations of therapy sessions. Archives of General Psychiatry, 12, 621-632.

Orlinsky, D. E., \& Howard, K. I. (1978). The relation of process to outcome in psychotherapy. In S. L. Garfield \& A. E. Bergin (Eds.), Handbook of psychotherapy and behavior change (2nd ed., pp.283-330). New York: Wiley.

Orlinsky, D. E., \& Howard, K. I. (1986). Process and outcome in psychotherapy. In S. L. Garfield \& A. E. Bergin (Eds.), Handbook of psychotherapy and behavior change (3rd ed.) (pp. 311-384). New York: Wiley.

Orlinsky, D. E., Rønnestad, M. H., \& Willutzki, U. (2004). Fifty years of psychotherapy process-outcome research: Continuity and change. In M. J. Lambert (Ed.), Bergin and Garfield's handbook of psychotherapy and behavior change (5th ed.) (pp. 307-389). New York: John Wiley \& Sons.

Orwin, R. G. (1983). A fail-safe $\mathrm{n}$ for effect size in meta-analysis. Journal of Educational Statistics, 8(2), 157-159. doi: 10.2307/1164923

*Owen, J. J., Tao, K., Leach, M. M., \& Rodolfa, E. (2011). Clients' perceptions of their psychotherapists' multicultural orientation. Psychotherapy, 48(3), 274-282. doi: $10.1037 / \mathrm{a} 0022065$

*Pantalon, M. V., Chawarski, M. C., Falcioni, J., Pakes, J., \& Schottenfeld, R. S. (2004). Linking process and outcome in the community reinforcement approach for 
treating cocaine dependence: A preliminary report. The American Journal of Drug and Alcohol Abuse, 30(2), 353-367. doi: 10.1081/ada-120037382

Parloff, M. B., Waskow, I. E., \& Wolfe, B. E. (1978). Research on client variables in psychotherapy. In S. L. Garfield \& A. E. Bergin (Eds.), Handbook of psychotherapy and behavior change (2nd ed.) (pp. 233-282). New York: Wiley.

Patterson, C. H. (1984). Empathy, warmth, and genuineness in psychotherapy: A review of reviews. Psychotherapy, 21(4), 431-438. doi: 10.1037/h0085985

Peters, J. L., Sutton, A. J., Jones, D. R., Abrams, K. R., \& Rushton, L. (2007).

Performance of the trim and fill method in the presence of publication bias and between-study heterogeneity. Statistics in Medicine, 26, 4544-4562.

Pigott, T. D. (2009). Handling missing data. In H. Cooper, L. V. Hedges, \& J. C. Valentine (Eds.), The handbook of research synthesis and meta-analysis (2nd ed., pp. 399-416). New York: The Russell Sage Foundation.

Pinsof, W. M., \& Catherall, D. R. (1986). The integrative psychotherapy alliance: Family, couple, and individual therapy scales. Journal of Marital and Family Therapy, 12, 137-151.

Pinsof, W. M., Zinbarg, R., \& Knobloch-Fedders, L. M. (2008). Factorial and construct validity of the Revised Short Form Integrative Psychotherapy Alliance Scales for family, couple, and individual therapy. Family Process, 47(3), 281-301.

Preston, S. D., Bechara, A., Damasio, H., Grabowski, T. J., Stansfield, R. B., Mehta, S., \& Damasio, A. R. (2007). The neural substrates of cognitive empathy. Social Neuroscience, 2(3-4), 254-275. doi: 10.1080/17470910701376902

R Development Core Team (2009). R: A language and environment for statistical 
computing. R Foundation for Statistical Computing. Vienna: Austria. ISBN 3900051-07-0, http://www.R-project.org.

Rogers, C. R. (1957). The necessary and sufficient conditions of therapeutic personality change. Journal of Consulting Psychology, 21(2), 95-103. doi:10.1037/h0045357

*Rossi, P. R. (2012). Categorization of the fourth session of successful and unsuccessful psychotherapies. (Unpublished masters thesis). Universidade de Sao Paulo, Sao Paulo, Brazil.

*Rothman, D. (2007). The role of the therapeutic alliance in psychotherapy with sexual offenders. Retrieved from Proquest Digital Dissertations. (AAT NR26309).

Rothstein, H. R., \& Hopewell, S. (2009). Grey literature. In H. Cooper, L. V. Hedges, \& J. C. Valentine (Eds.), The handbook of research synthesis and meta-analysis (2nd ed., pp. 103-125). New York: The Russell Sage Foundation.

Rosenthal, R. (1979). The file drawer problem and tolerance for null results. Psychological Bulletin, 86(3), 638-641. doi: 10.1037/0033-2909.86.3.638

Sackett, D. L. (1979). Bias in analytic research. Journal of Chronic Diseases, 32(1-2), 51-63. doi: doi:10.1016/0021-9681(79)90012-2

*Saunders, S. M. (2001). Pretreatment correlates of the therapeutic bond. Journal of Clinical Psychology, 57(12), 1339-1352. doi: 10.1002/jclp.1101

Schmid, P. F. (2001). Authenticity: The person as his or her own author: Dialogical and ethical perspectives on therapy as an encounter relationship. And beyond. In Wyatt, G. (Ed.), Rogers' Therapeutic Conditions Evolution, Theory and Practice. Volume 1: Congruence (pp. 217-232). Ross- on-Wye, UK: PCCS Books.

Shechtman, Z. (2002). Cognitive and affective empathy in aggressive boys: Implications 
for counseling. International Journal for the Advancement of Counselling, 24(4), 211-222. doi: 10.1023/a:1023316712331

Shick Tryon, G., \& Winograd, G. (2011). Goal consensus and collaboration. In J. C. Norcross (Ed.), Psychotherapy relationships that work: Evidence-based responsiveness (2nd ed., pp. 153-152). New York: Oxford University Press.

Shirk, S. R., \& Karver, M. S. (2011). Alliance in child and adolescent psychotherapy. In J. C. Norcross (Ed.), Psychotherapy relationships that work: Evidence-based responsiveness (2nd ed., pp. 70-91). New York: Oxford University Press. doi: 10.1093/acprof:oso/9780199737208.003.0003

Simmons, J., Roberge, L., Kenrick Jr., S. B., \& Richards, B. (1995). The interpersonal relationship in clinical practice: The Barrett-Lennard Relationship Inventory as an assessment instrument. Evaluation \& the Health Professions, 18(1), 103-112. doi: $10.1177 / 016327879501800108$

Smith, M. L., \& Glass, G. V. (1977). Meta-analysis of psychotherapy outcome studies. American Psychologist, 32, 752-760. doi: 10.1037/0003-066X.32.9.752

Smith, M. L., Glass, G. V., \& Miller, T. I. (1980). The benefits of psychotherapy. Baltimore: Johns Hopkins University Press.

Smith, T. B., Domenech Rodriguez, M., \& Bernal, G. (2011). Culture. In J. C. Norcross (Ed.), Psychotherapy relationships that work: Evidence-based responsiveness (2nd ed., pp. 316-335). New York: Oxford University Press.

*Spigelman, A. (2011). The contribution of empathy to early alliance building and emotional processing during experiential treatment of depression. Retrieved from Proquest Digital Dissertations. (AAT MR80456). 
Sterba, R. (1934). The fate of the ego in analytic therapy. International Journal of Psychoanalysis, 15, 117-126.

Stiles, W. B. (2009). Responsiveness as an obstacle for psychotherapy outcome research: It's worse than you think. Clinical Psychology: Science and Practice, 16(1), 8691. doi: $10.1111 / j .1468-2850.2009 .01148 . x$

Taylor, B. L. (1995). Psychotherapists' experiences of empathy: A phenomenological inquiry. (Unpublished doctoral dissertation). University of Tennessee, Knoxville.

Thomas, S. E. G., Werner-Wilson, R. J., \& Murphy, M. J. (2005). Influence of therapist and client behaviors on therapy alliance. Contemporary Family Therapy, 27(1), 19-35. doi: 10.1007/s10591-004-1968-z

Tichoner, V., \& Hill, C. E. (1989). A comparison of six measures of working alliance. Psychotherapy, 26(2), 195-199.

Titchener, E. (1909). Experimental psychology of the thought processes. New York: Macmillan. doi: 10.1037/10877-000

Titchener, E. (1924). A textbook of psychology. New York: Macmillan.

Terrin, N., Schmid, C. H., Lau, J., \& Olkin, I. (2003). Adjusting for publication bias in the presence of heterogeneity. Statistics in Medicine, 22, 2113-2126.

*Tresky, S. (2010). Gender Sensitive Counseling, Gender Role Values Conflict and Session Evaluation Among Female College Students in Rural Hawaii. Retrieved from Proquest Digital Dissertations. (AAT 1487435).

Truax, C. B., \& Carkhuff, R. R. (1967). Toward effective counseling and psychotherapy: Training and practice. Chicago: Aldine Publishing Company. 
Truax, C. B., \& Mitchell, K. M. (1971). Research on certain therapist interpersonal skills in relation to process and outcome. In A. E. Bergin \& S. L. Garfield (Eds.), Handbook of psychotherapy and behavior change (pp. 299-344). New York: Wiley.

Walwyn, R., \& Roberts, C. (2010). Therapist variation within randomised trials of psychotherapy: implications for precision, internal and external validity. Statistical Methods in Medical Research, 19, 291-315. doi: $10.1177 / 0962280209105017$

Wampold, B. E. (2001). The great psychotherapy debate: Models, methods, and findings. Mahwah, NJ: Lawrence Erlbaum Associates.

Wampold, B. E. (2007). Psychotherapy: The humanistic (and effective) treatment. American Psychologist, 62, 857-873. doi: 10.1037/0003-066X.62.8.857

Wampold, B. E. (2010). The research evidence for the common factor models: A historically situated perspective. In B. L. Duncan, S. D. Miller, B. E. Wampold, \& M. A. Hubble (Eds.), The heart and soul of change: Delivering what works in therapy (2nd ed., pp. 49-81). Washington, DC: American Psychological Association. doi: 10.1037/12075-002

*Wang, S., \& Kim, B. S. K. (2010). Therapist multicultural competence, Asian American participants' cultural values, and counseling process. Journal of Counseling Psychology, 57(4), 394-401.

Watson, J. C. (2001). Re-visioning empathy. In D. Cain \& J. Seeman (Eds.), Humanistic psychotherapies: Handbook of research and practice (pp. 445-471). Washington: American Psychological Association. 
Watson, J. C., Greenberg, L. S., \& Lietaer, G. (1998). The experiential paradigm unfolding: Relationship and experiencing in therapy. In L. S. Greenberg, J. C. Watson, \& G. Lietaer (Eds.), Handbook of experiential psychotherapy (pp. 3-27). New York: Guilford.

Watson, J. C., \& McMullen, E. J. (2005). An examination of therapist and client behavior in high- and low- alliance sessions in cognitive-behavioral therapy and process experiential therapy. Psychotherapy: Theory, Research, Practice, Training, 42(3), 297-310. doi: 10.1037/0033-3204.42.3.297

Watson, N. (1984). The empirical status of Rogers' hypotheses of the necessary and sufficient conditions for effective psychotherapy. In R. F. Levant \& J. M. Schlein (Eds.), Client-centered therapy and the person centered approach: New directions in theory, research, and practice (pp. 17-40). New York: Praeger.

*Wing, E., Jr. (2010). The relationship between therapist empathy, the working alliance, and therapy outcome: A test of a partial mediation model. Retrieved from Proquest Digital Dissertations. (AAT 3398120).

Wispe, L. (1987). History of the concept of empathy. In N. Eisenberg \& J. Strayer (Eds.), Empathy and its development (pp. 17-37). New York: Cambridge University Press.

*Wolff, M. C., \& Hayes, J. A. (2009). Therapist variables: Predictors of process in the treatment of alcohol and other drug problems. Alcoholism Treatment Quarterly, 27(1), 51-65. doi: 10.1080/07347320802586791 
*Young, S. (2007). Effect of counselor self-disclosure of religious similarity on client perception of empathy within the therapeutic relationship: An analogue study. Retrieved from Proquest Digital Dissertations. (AAT 1446138).

*Young, S. (2011). Effects of an analogue counselor's religious or financial selfdisclosure and observer characteristics on therapeutic processes. Retrieved from Proquest Digital Dissertations. (AAT 3473295).

Zetzel, E. R. (1956). Current concepts of transference. International Journal of Psychoanalysis, 37, 369-376.

*Zuroff, D. C., Kelly, A. C., Leybman, M. J., Blatt, S. J., \& Wampold, B. E. (2010). Between-therapist and within-therapist differences in the quality of the therapeutic relationship: Effects on maladjustment and self-critical perfectionism. Journal of Clinical Psychology, 66(7), 681-697. doi: 10.1002/jclp.20683 
Table 1: Database Search Strategy

1: alliance OR "therapeutic relationship" OR rapport OR "therapeutic bond" OR "client engagement" OR partnership OR "client relationship" OR "client therapist relationship" OR "relationship quality"

2: therapist OR counselor OR analyst OR psychotherapist OR "social worker" OR practitioner

3: empathy OR empathic OR genuine OR genuineness OR congruence OR acceptance OR honesty OR openness OR "real relationship"

4: 1 AND 2 AND 3 
Table 2: List of Authors Contacted for Data

Chris Barker

Michael Constantino

Telsie A. Davis

Irene Elkin

Adam Fenske

Jairo N. Fuertes

Asle Hoffart

Milena Karlinska-Nehrebecka

Gregory G. Kolden

Alex Linley

Daniel Rothman

George Silberschatz

Jeanne C. Watson

David C. Zuroff

And the Psychotherapyresearch.org listserv 
Table 3: Abstract Screening Guide

\begin{tabular}{|c|c|}
\hline $\begin{array}{l}\text { Study Inclusion Criteria: Relationship between } \\
\text { Therapist Characteristics and the Therapeutic } \\
\text { Alliance }\end{array}$ & \\
\hline 1. Does the document report on a research study? & $\begin{array}{l}\text { 0. No } \\
\text { 1. Yes, but a review } \\
\text { 2. Yes } \\
\text { 3. Can't tell/not sure } \\
\text { IF NO THEN STOP } \\
\text { IF REVIEW THEN SKIP TO } \\
\text { QUESTION } 3\end{array}$ \\
\hline 2. If yes, is this a quantitative research study? & \begin{tabular}{|ll} 
0. & No \\
1. & Yes \\
2. & Can't tell/not sure \\
IF NO & THEN STOP
\end{tabular} \\
\hline $\begin{array}{l}\text { 3. Does this document report on therapist empathy } \\
\text { and/or genuineness? } \\
\text { If the study only looks at client characteristics, then put } \\
\text { NO. }\end{array}$ & \begin{tabular}{|ll} 
0. & No \\
1. & Yes \\
2. & Can't tell/not sure \\
IF NO & THEN STOP
\end{tabular} \\
\hline $\begin{array}{l}\text { 4. Does the document measure/examine the therapeutic } \\
\text { alliance/relationship/partnership? } \\
\text { If the study only looks at the supervisory working } \\
\text { alliance (between therapist trainee and supervisor), then } \\
\text { put NO. }\end{array}$ & \begin{tabular}{|ll} 
0. & No \\
1. & Yes \\
2. & Can't tell/not sure \\
IF NO & THEN STOP
\end{tabular} \\
\hline $\begin{array}{l}\text { 5. Does this study/review examine individual therapy? } \\
\text { (One client and one therapist) }\end{array}$ & \begin{tabular}{|ll} 
0. & No \\
1. & Yes \\
2. & Can't tell/not sure \\
IF NO & THEN STOP
\end{tabular} \\
\hline
\end{tabular}


Table 4: Coding Guide

A Meta-Analytic Review of the Relationships between the Therapeutic Alliance, Empathy, and Genuineness

Coding Guide 1.0

Study Level

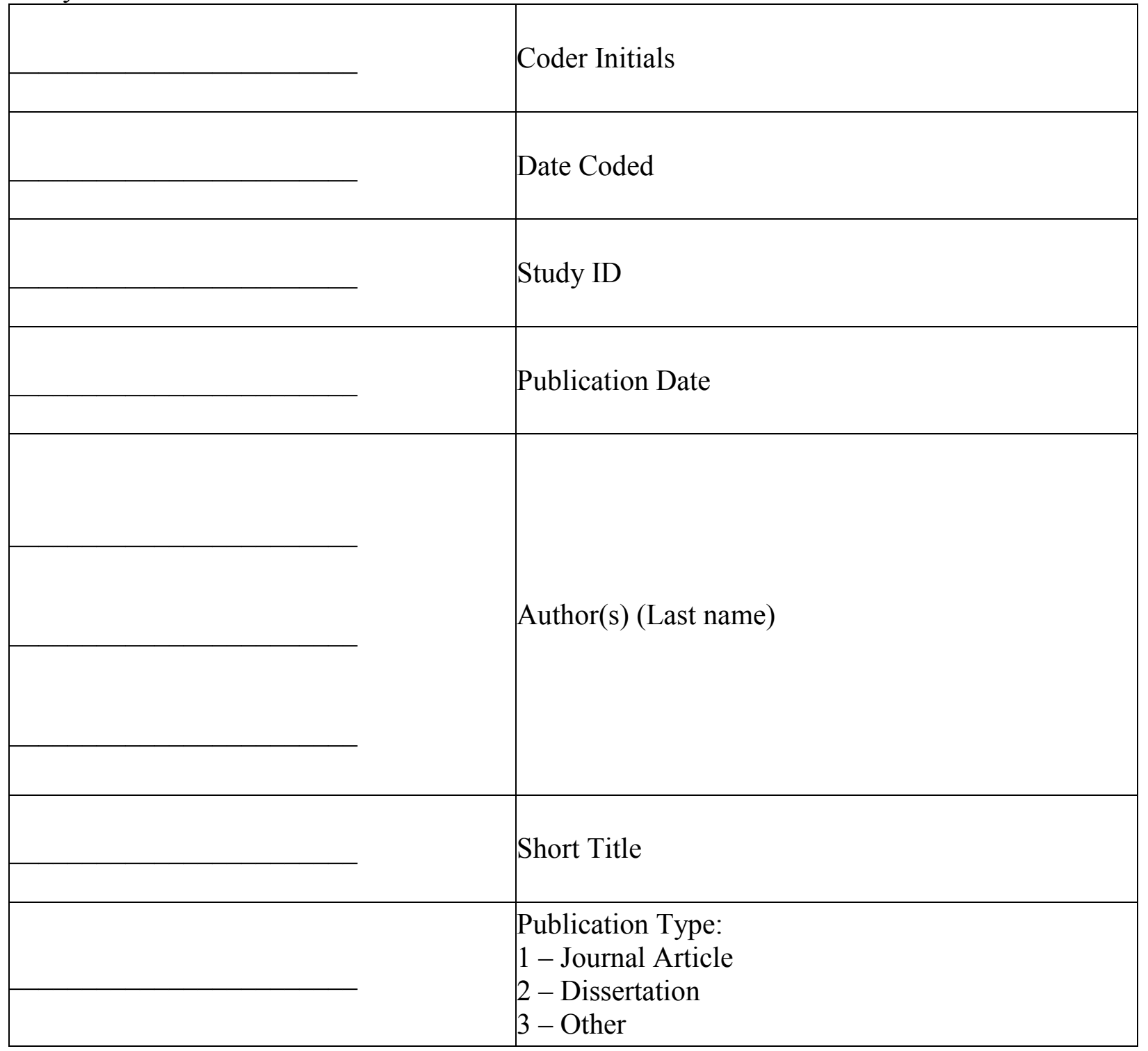


Sample Level

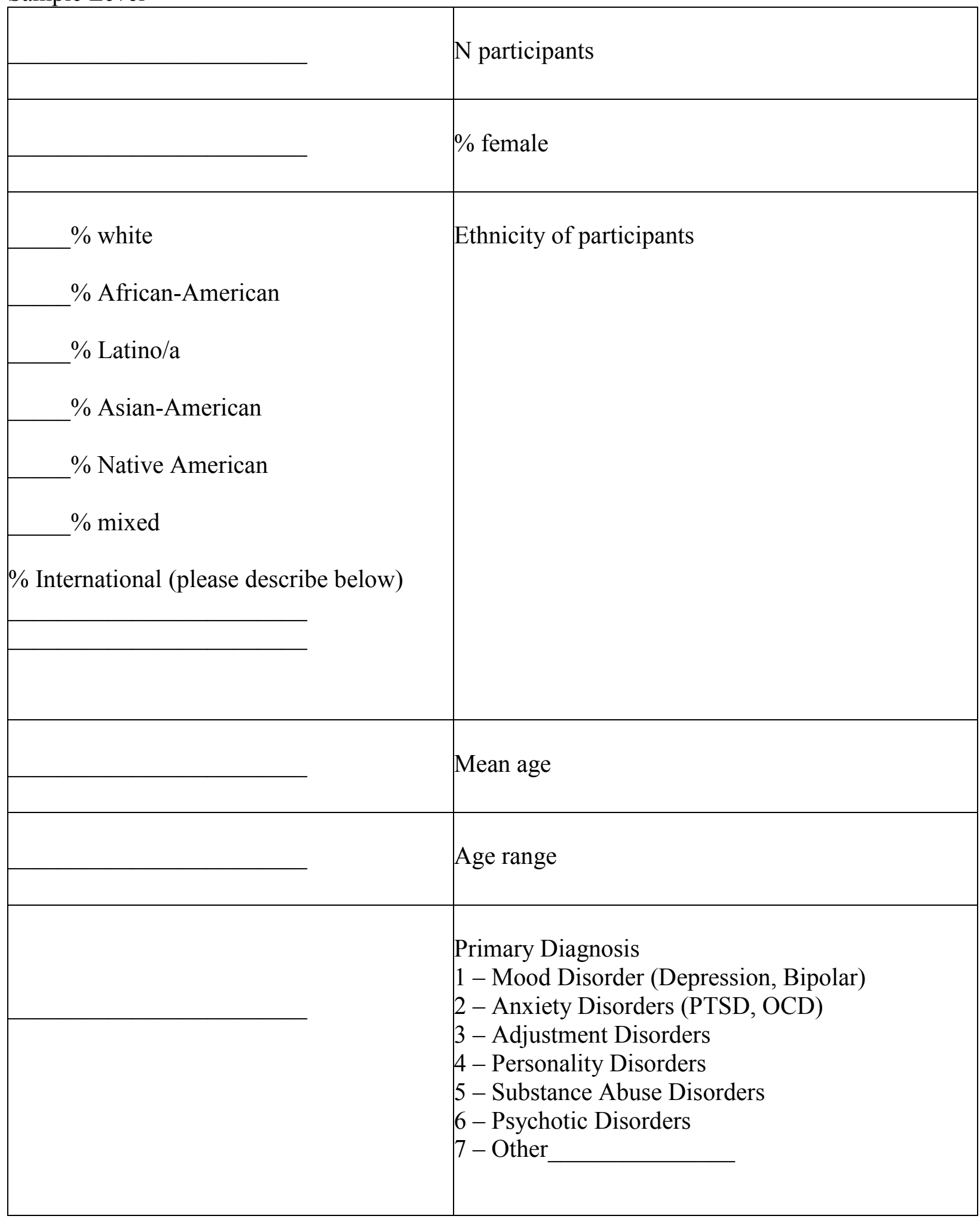


Therapist Level

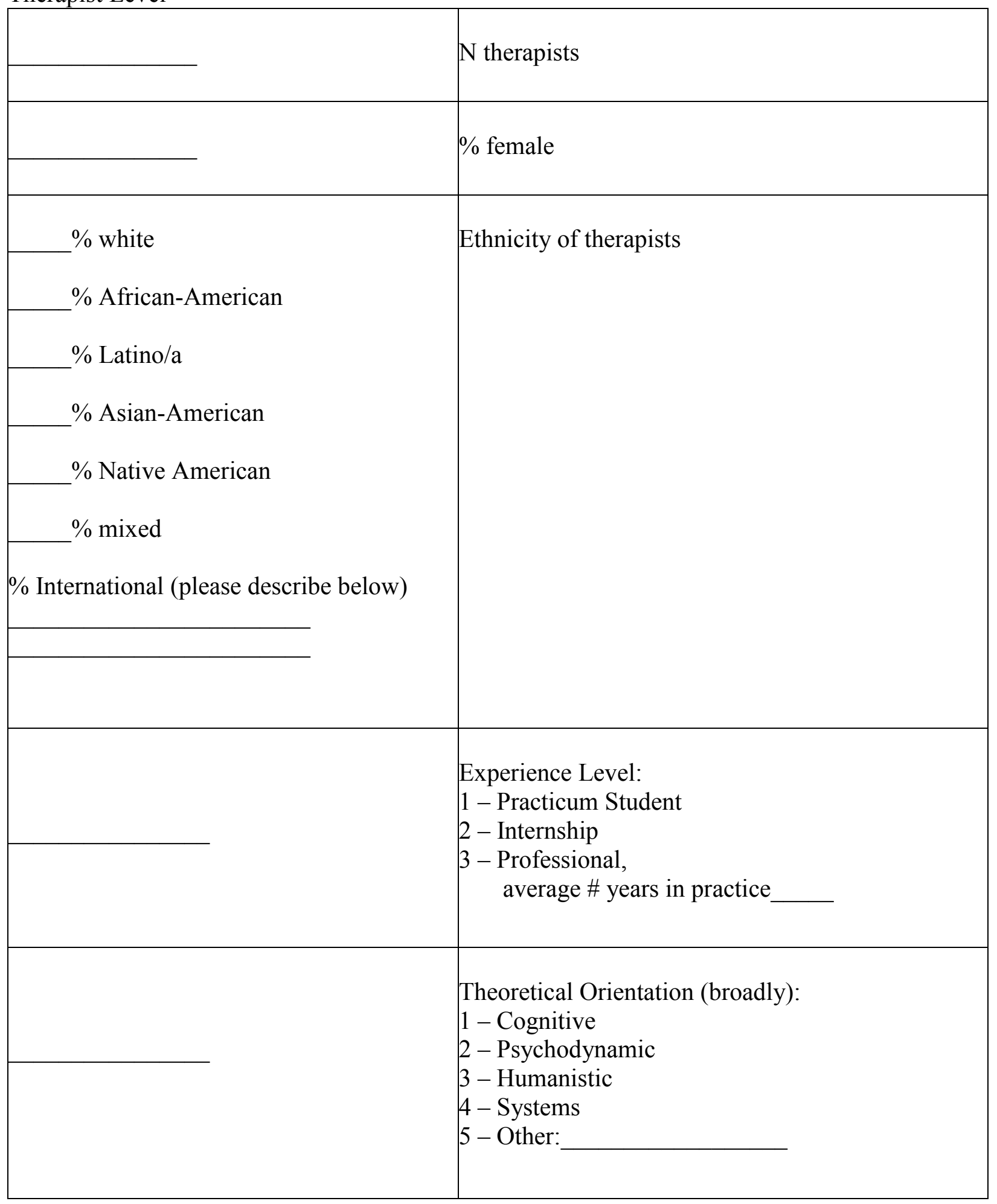




\begin{tabular}{|l|l|}
\hline & $\begin{array}{l}\text { Method of assigning participants to therapists: } \\
1 \text { - Randomly to tx and therapist } \\
2-\text { Randomly to tx only } \\
3-\text { Randomly to therapist only } \\
4-\text { Nonrandom assignment }\end{array}$ \\
\hline$\quad$ & $\begin{array}{l}\text { Are between therapist measures provided? } \\
0-\text { No } \\
1-\text { Yes (If yes, provide detail on page } 8)\end{array}$ \\
\hline
\end{tabular}




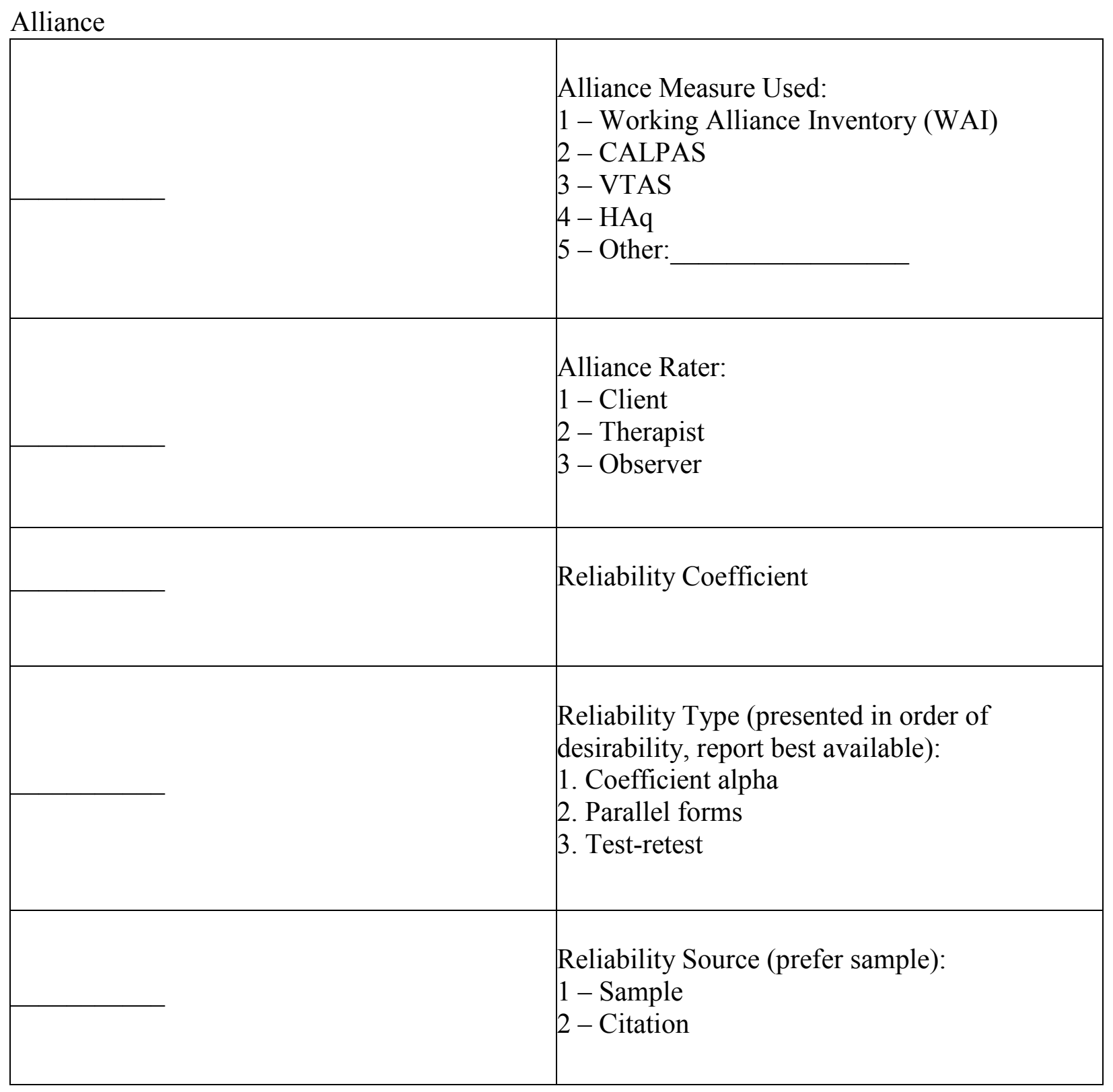




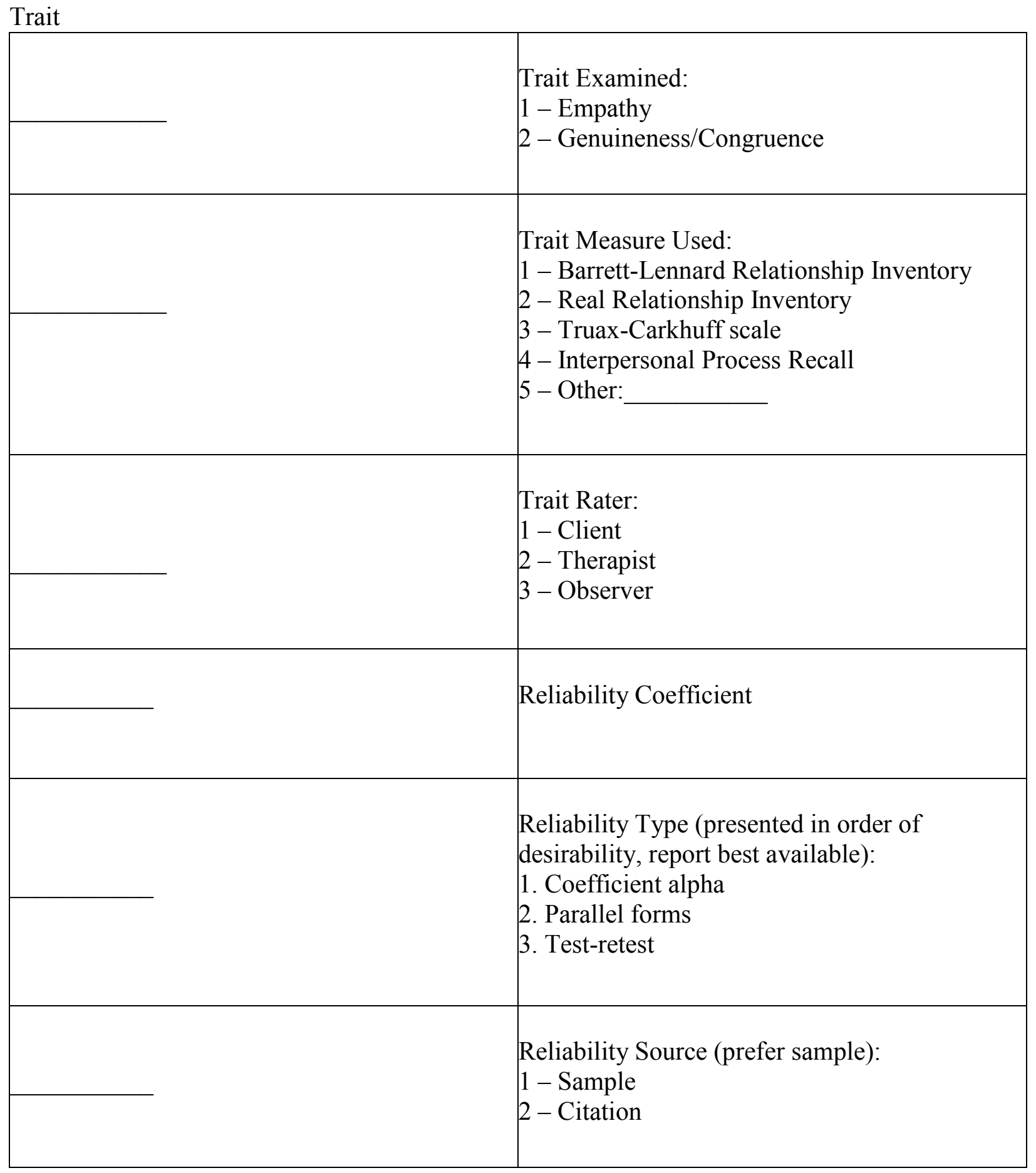


Time of Measurement

\begin{tabular}{|l|l|}
\hline & Length of treatment \\
\hline & $1-$ PreIntervention \\
& $2-1 / 4$ of the way through \\
$3-1 / 3$ of the way through \\
$4-$ Halfway through \\
\hline $5-2 / 3$ of the way through \\
$6-3 / 4$ of the way through \\
$7-$ At termination \\
$8-$ Follow-up, time since termination \\
$9-$ Other: \\
\hline
\end{tabular}

Effect Size

\begin{tabular}{|l|l|}
\hline & Correlation $n$ \\
\hline & Correlation $(r)$ between alliance and trait \\
\hline & \\
\hline
\end{tabular}


If between-therapist measures are provided, detail them in the space below: 
Table 5: Graph of Excluded Studies and Included Studies

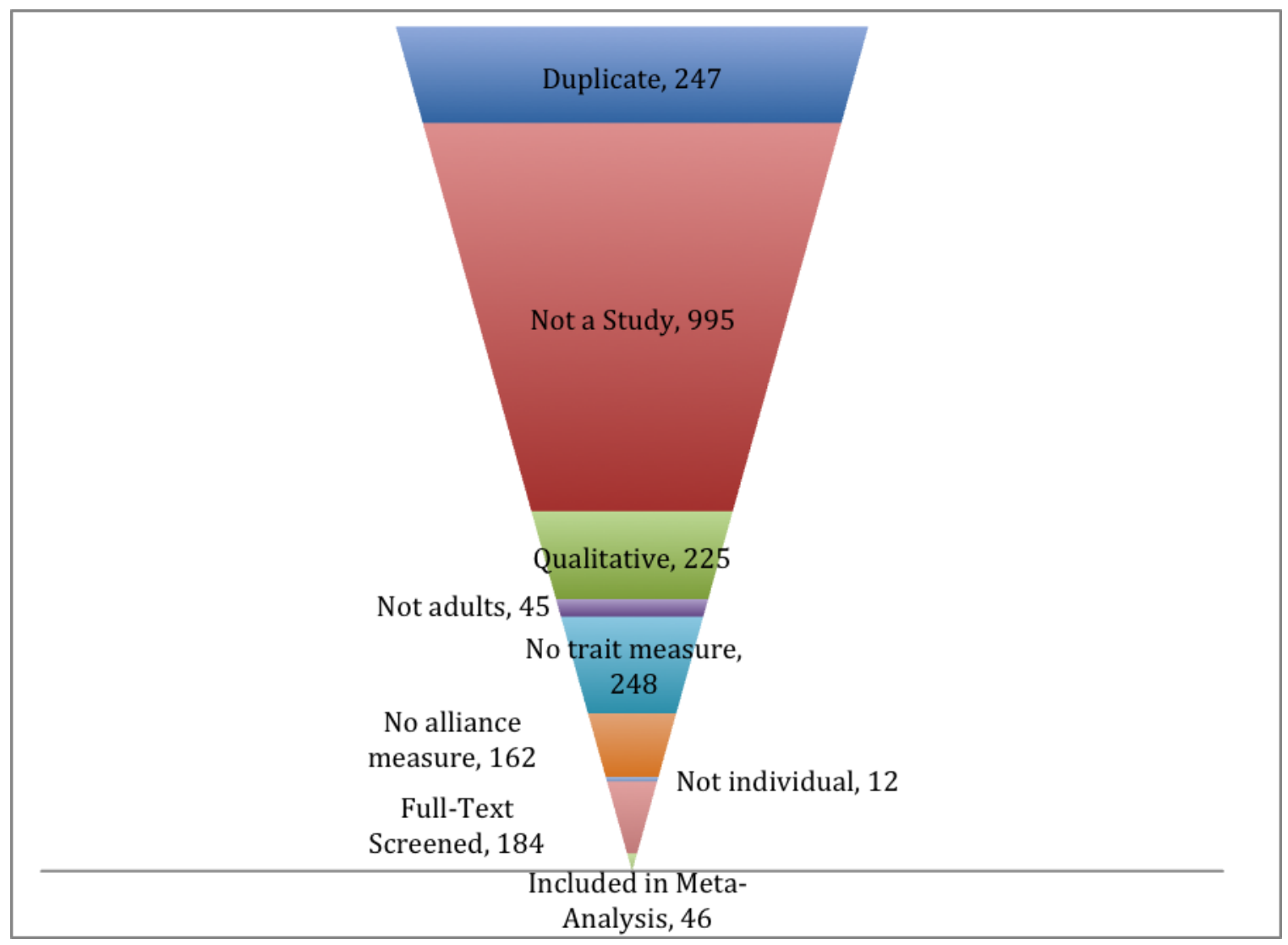


Table 6: Alliance and Therapist Empathy Overall Analysis

\section{Aliance and Empathy}

\begin{tabular}{|c|c|c|c|c|c|c|c|}
\hline \multirow[t]{2}{*}{ sludunan: } & \multicolumn{7}{|c|}{ Stititio for ench thidy } \\
\hline & $\begin{array}{l}\text { Fishers } \\
z\end{array}$ & $\begin{array}{c}\text { Sandad } \\
\text { enor }\end{array}$ & Variancs & $\begin{array}{l}\text { Lowg } \\
\text { limit }\end{array}$ & $\begin{array}{l}\text { Yper } \\
\text { linit }\end{array}$ & Z-Vive & plation \\
\hline Ader 1980 & 0611 & $Q 158$ & 0004 & 035 & 0917 & 392 & $0, \infty$ \\
\hline 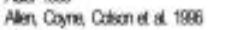 & $a+a$ & 0.167 & 0008 & -0203 & 0.51 & 074 & 0.67 \\
\hline Bunderd 1980 & 0.35 & $a 154$ & 0004 & 0000 & $a 660$ & 2450 & 004 \\
\hline Oretartion a a a & 0.00 & 0.28 & 0001 & 0.28 & 1.28 & 300 & 0,000 \\
\hline Orovey aw & $Q 10$ & Q.154 & 0094 & 2.190 & 0.413 & 076 & 0.474 \\
\hline Dankt & 0208 & 0.140 & 0000 & 0.013 & a西 & 2064 & 0000 \\
\hline Daw 8 ksegh 2010 & 0.51 & a.129 & 0002 & 4131 & 0.564 & 1083 & 0.29 \\
\hline Deceorgs 2009 & 0618 & 0,130 & 0017 & a.fG & 0.804 & $4 \pi$ & 000 \\
\hline Evarovons Pairs 8 Barker 2009 & 9065 & 0218 & 0068 & $a 20$ & 1.065 & 290 & 0006 \\
\hline Farmen 1980 & -0009 & Q 130 & 0017 & -203 & $a 206$ & +010 & 0880 \\
\hline Furstes at a 2008 & 0.534 & Q. 144 & 001 & 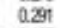 & 0.60 & 397 & 0000 \\
\hline Firres a d a 20 ? & 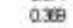 & a.134 & 0018 & 0.00 & aE⿴囗十 & $2 \pi 1$ & 000 \\
\hline Furtes of a $\mathrm{aII}$ & 0908 & acke & $000 \mathrm{~T}$ & a 70 & 1. 070 & now & $0 \infty 0$ \\
\hline Hadps 1984 & 030 & 咊 & 0004 & aOE2 & atent & 223 & 0,02 \\
\hline Haye Yeh Ecerbarg 2017 & $a \in B$ & $\mathrm{a} 123$ & 0015 & $0<02$ & 0.964 & 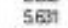 & 000 \\
\hline Heffot a a 2ans & 0715 & $0+114$ & 000 & 000 & 0.968 & 6204 & 0000 \\
\hline Fowath 1981 & 0806 & Q 196 & 0008 & $a \notin$ & t. 198 & 420 & 0000 \\
\hline Janes 1980 & 0472 & 0.008 & 000 & a.m & 0600 & 5745 & 0,00 \\
\hline $\operatorname{san} 200$ & 000 & Q.098 & 000 & 0.112 & $a z 0$ & $\cos$ & 0.450 \\
\hline 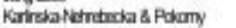 & 1.061 & Q. 10 & 0011 & ases & 1.20 & nos4 & 0000 \\
\hline Kom L \& L Ling ZmL & $0 \sigma 8$ & $a+15$ & 0013 & Quent & 0.504 & 509 & $a \omega$ \\
\hline $\mathrm{Km} N \mathrm{Ng} \& \mathrm{Am} 2 \mathrm{aI5}$ & asv3 & 0,108 & 0012 & $a \pi 0$ & 1.116 & 890 & 000 \\
\hline $\mathrm{Km} N \mathrm{~kg} 8 \mathrm{Am} 20 \mathrm{~g}$ & 0,08 & a. 131 & 0017 & $a \in(\mathbb{0})$ & 1. 俩 & 690 & 000 \\
\hline Limproubs 2008 & 1071 & 0,160 & 0006 & $a>30$ & 1.365 & 6007 & 0000 \\
\hline $58 \mathrm{~km} 200 \mathrm{~A}$ & ant & Q.148 & 0000 & 0.531 & 1.001 & $56 \% 5$ & 0000 \\
\hline Liney a dooph 2018? & a.21 & a.ent & 0000 & a.162 & 0.09 & 3906 & 000 \\
\hline Mravey III & 0.517 & Q.164 & ow & a.194 & 0.000 & $3 \times 2$ & acoe \\
\hline Mradsy 19 G & 0910 & 0.213 & 0045 & a 40 & 1.329 & 42五 & 000 \\
\hline Murhy 1978 & 0.28 & 0.12 & 0005 & $-0,000$ & 0.56 & 145 & 0.100 \\
\hline Pritikn af a 2004 & $0 \%$ & Q.या & $00 \mathrm{w}$ & 0.306 & $1 . x 8$ & 3054 & 000 \\
\hline Possi (undited) & 0280 & a333 & 0111 & $-0 \times 19$ & 0.903 & $0 \pi 5$ & $0+63$ \\
\hline Putimen 2005 & asce & $a, 150$ & 0004 & 0.586 & 1.206 & $5 \pi 6$ & 0000 \\
\hline Sanders 200 & 0.192 & 0.086 & 000 & 0,00 & a.300 & 2008 & 0006 \\
\hline Spopinan 2011 & 0604 & Q1958 & 000 & azw & 0981 & $3 \pi$ & 000 \\
\hline Treky zyo & 0,00 & a. 1 田 & 0008 & a.100 & 0.894 & $2 \pi 41$ & acow \\
\hline Wang \& Kom 2010 & 1009 & $a 006$ & 0009 & 0912 & 1.26 & 1192 & 0000 \\
\hline Why $x, 2010$ & 0.50 & $a+18$ & 003 & a.153 & 0.57 & $2 \pi 34$ & 0006 \\
\hline Wedil \& Hayes 2009 & 082 & a.164 & $0 \propto 7$ & $05 \mathrm{II}$ & 1. 151 & 5000 & 0000 \\
\hline Yarg 2007 & 0466 & 0003 & 0005 & 0.322 & 0.610 & 635 & 0000 \\
\hline Vary 2001 & $\alpha \times 1$ & 0000 & 000 & a624 & 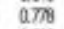 & 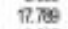 & 0000 \\
\hline Zndif \& Eant 206 & 0.188 & 0,000 & 0006 & Q018 & 0.20 & 2228 & 0,05 \\
\hline & 0.503 & $a, 00$ & 0003 & a 406 & $a \in 2$ & $11 \%$ & 0000 \\
\hline
\end{tabular}

Elingrizandoro

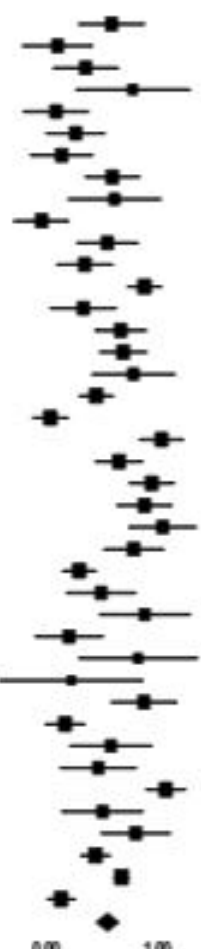

200 
Table 7: Results of Moderator Tests for Therapist Empathy and Alliance

Categorical

\begin{tabular}{|c|c|c|c|c|}
\hline Moderator & $k$ & $Q_{\mathrm{b}}$ & $p$ & $r$ \\
\hline Article Type & 40 & 1.252 & 0.263 & \\
\hline Published & 18 & & & 0.56 \\
\hline Unpublished & 22 & & & 0.474 \\
\hline Therapist Experience & 31 & 0.971 & 0.324 & \\
\hline Practicum Student & 8 & & & 0.608 \\
\hline Professional & 10 & & & 0.51 \\
\hline Theoretical Approach** & 16 & 8.163 & 0.004 & \\
\hline Cognitive/Behavioral & 3 & & & 0.572 \\
\hline Psychodynamic & 3 & & & 0.278 \\
\hline Method of Assignment & 30 & 0.908 & 0.319 & \\
\hline Random assignment & 6 & & & 0.583 \\
\hline Nonrandom & 24 & & & 0.47 \\
\hline Alliance Measure & 41 & 0.52 & 0.771 & \\
\hline WAI & 31 & & & 0.528 \\
\hline HAQ & 4 & & & 0.443 \\
\hline Other & 6 & & & 0.553 \\
\hline Alliance Rater** & 40 & 6.372 & 0.041 & \\
\hline Client & 30 & & & 0.543 \\
\hline Therapist & 11 & & & 0.303 \\
\hline Observer & 9 & & & 0.544 \\
\hline Empathy Measure** & 45 & $\begin{array}{c}15.925 \\
(\text { Without IRI = } \\
6.529)\end{array}$ & $\begin{array}{c}<0.01 \\
(\text { Without IRI }= \\
0.088)\end{array}$ & \\
\hline BLRI & 22 & & & 0.588 \\
\hline AES & 3 & & & 0.527 \\
\hline IRI & 3 & & & 0.063 \\
\hline BES & 3 & & & 0.62 \\
\hline Other & 14 & & & 0.404 \\
\hline Empathy Rater** & 49 & 11.33 & $<0.01$ & \\
\hline Client & 25 & & & 0.555 \\
\hline Therapist & 10 & & & 0.275 \\
\hline Observer & 14 & & & 0.559 \\
\hline Rater Constancy** & 60 & 34.243 & $<0.001$ & \\
\hline
\end{tabular}




\begin{tabular}{|l|c|l|l|c|}
\hline Rater Constant & 42 & & & 0.562 \\
\hline Rater Not Constant & 18 & & & 0.14 \\
\hline
\end{tabular}

Continuous

\begin{tabular}{|l|c|c|c|c|}
\hline Moderator & $\mathrm{k}$ & Coefficient Value & $Q_{\text {model }}$ & $p_{\text {model }}$ \\
\hline Publication/Defense Year & 38 & 0.009 & 2.159 & 0.142 \\
\hline Male/Female Client Ratio & 36 & -0.002 & 1.007 & 0.315 \\
\hline Number of Clients & 40 & $1.13 \times 10^{-5}$ & 0.000 & 0.98 \\
\hline White/Nonwhite Client Ratio* & 28 & -0.004 & 6.21 & 0.01 \\
\hline Client Mean Age & 28 & 0.003 & 0.192 & 0.661 \\
\hline Male/Female Therapist Ratio & 27 & 0.002 & 0.528 & 0.467 \\
\hline Number of Therapists & 30 & -0.002 & 2.695 & 0.101 \\
\hline White/Nonwhite Therapist Ratio & 21 & 0.003 & 1.384 & 0.239 \\
\hline Average Number of Sessions & 28 & $1.33 \times 10^{-4}$ & $6 \times 10^{-4}$ & 0.98 \\
\hline
\end{tabular}

Note: $\mathrm{k}=$ number of studies

$Q_{\mathrm{b}}=$ Heterogeneity between categorical variables

$Q_{\text {model }}=$ Model fit $Q$ statistic

$P_{\text {model }}=\mathrm{p}$-value (significance level) of model

*Significant at the $p<.05$ level

$* *$ Significant at the $p<.01$ level 
Table 8: Additional Information Regarding the Individual Alliance and Therapist

Empathy Studies

\begin{tabular}{|c|c|c|c|c|c|c|c|c|}
\hline & & & & Alliance & & Empathy & Outc & come \\
\hline Study & \begin{tabular}{|l|} 
Sessio \\
ns
\end{tabular} & Type & Rater & Measure & Rater & Measure & $\mathrm{N}$ & ES \\
\hline Adler 1988 & 12 & $\begin{array}{l}\text { Study of alliance } \\
\text { in psychotherapy }\end{array}$ & $\mathrm{C}, \mathrm{T}$ & WAI, HAQ & C & BLRI & 44 & .611 \\
\hline $\begin{array}{l}\text { Allen et al. } \\
1996\end{array}$ & Varied & $\begin{array}{l}\text { Therapist } \\
\text { interventions and } \\
\text { collaboration }\end{array}$ & $\mathrm{O}$ & $\begin{array}{l}\text { Luborsky } \\
\text { helping } \\
\text { alliance } \\
\text { scales, } \\
\text { Menninger } \\
\text { global } \\
\text { collaboration } \\
\text { scale }\end{array}$ & $\mathrm{O}$ & $\begin{array}{l}\text { Observed } \\
\text { intervention }\end{array}$ & 39 & .124 \\
\hline $\begin{array}{l}\text { Burchard } \\
1991\end{array}$ & $\mathrm{nr}$ & Psychodynamic & $\mathrm{C}$ & HAQ & $C, T$ & BLRI, IRI & 45 & 378 \\
\hline $\begin{array}{l}\text { Constantino et } \\
\text { al. } 2008\end{array}$ & 16 & $\begin{array}{l}\text { Cognitive therapy } \\
\text { for depression }\end{array}$ & C & WAI & C & BES & 17 & .802 \\
\hline Crowley 2000 & 13 & \begin{tabular}{|} 
Pretreatment \\
characteristics as \\
alliance predictors
\end{tabular} & C & WAI & C & $\begin{array}{l}\text { California } \\
\text { Psychological } \\
\text { Inventory - } \\
\text { Empathy Scale }\end{array}$ & 45 & .110 \\
\hline Daniels 1993 & $\mathrm{nr}$ & \begin{tabular}{|l|} 
Predicting \\
alliance strength
\end{tabular} & C & HAQ & C & BLRI & 54 & .288 \\
\hline $\begin{array}{l}\text { Daw \& Joseph } \\
2010\end{array}$ & $n \mathrm{nr}$ & \begin{tabular}{|l|} 
Psychological \\
mindedness and \\
therapist attributes
\end{tabular} & T & WAI & $T$ & JSPE & 48 & .161 \\
\hline $\begin{array}{l}\text { DeGeorge } \\
2008\end{array}$ & 14 & $\begin{array}{l}\text { Empathy and the } \\
\text { therapeutic } \\
\text { alliance }\end{array}$ & C & WAI & C & BLRI & 62 & .618 \\
\hline $\begin{array}{l}\text { Evans-Jones } \\
\text { et al. } 2009\end{array}$ & $n r$ & CBT in psychosis & $\mathrm{C}, \mathrm{T}$ & WAI & $\mathrm{C}, \mathrm{T}$ & BLRI & 24 & .637 \\
\hline Forman 1990 & \begin{tabular}{|l|}
6 \\
weeks
\end{tabular} & $\begin{array}{l}\text { Trait empathy in } \\
\text { patients with } \\
\text { chronic pain }\end{array}$ & $\mathrm{C}, \mathrm{T}$ & WAI & $\mathrm{C}, \mathrm{T}$ & IRI & $\begin{array}{l}\mathrm{C}= \\
96, \mathrm{~T} \\
=29\end{array}$ & -.019 \\
\hline
\end{tabular}




\begin{tabular}{|c|c|c|c|c|c|c|c|c|}
\hline $\begin{array}{l}\text { Fuertes et al. } \\
2006\end{array}$ & $\mathrm{nr}$ & $\begin{array}{l}\text { Therapist } \\
\text { multicultural } \\
\text { competency }\end{array}$ & $\mathrm{C}, \mathrm{T}$ & WAI & $\mathrm{C}$ & BLRI & 51 & .574 \\
\hline $\begin{array}{l}\text { Fuertes et al. } \\
2007\end{array}$ & $\begin{array}{l}16 \\
\text { (media } \\
\text { n) }\end{array}$ & $\begin{array}{l}\text { Correlates of real } \\
\text { relationship }\end{array}$ & $\mathrm{C}, \mathrm{T}$ & WAI & $\mathrm{C}$ & BLRI & 59 & .369 \\
\hline $\begin{array}{l}\text { Fuertes et al. } \\
2009\end{array}$ & $\mathrm{nr}$ & $\begin{array}{l}\text { Behavioral } \\
\text { indices in medical } \\
\text { care outcome }\end{array}$ & C & $\begin{array}{l}\text { Physician- } \\
\text { Patient } \\
\text { Working } \\
\text { Alliance Scale }\end{array}$ & $\mathrm{C}$ & $\begin{array}{l}\text { Physician } \\
\text { Empathy } \\
\text { Questionnaire }\end{array}$ & 152 & .908 \\
\hline $\begin{array}{l}\text { Hayes et al. } \\
2007\end{array}$ & 24 & $\begin{array}{l}\text { Countertransferen } \\
\text { ce in behavioral } \\
\text { therapy }\end{array}$ & C & WAI & $\mathrm{C}$ & BLRI & 69 & .693 \\
\hline $\begin{array}{l}\text { Hoffart et al. } \\
2009\end{array}$ & $\begin{array}{l}10 \\
\text { weeks }\end{array}$ & $\begin{array}{l}\text { Residential } \\
\text { cognitive and } \\
\text { interpersonal } \\
\text { treatment of } \\
\text { social phobia }\end{array}$ & $\mathrm{C}, \mathrm{T}$ & WAI & $\mathrm{C}, \mathrm{T}$ & BES & 80 & .715 \\
\hline Horvath 1981 & 10 & $\begin{array}{l}\text { Validation of the } \\
\text { WAI }\end{array}$ & $\mathrm{C}, \mathrm{T}$ & WAI & $\mathrm{C}, \mathrm{T}$ & BLRI & 29 & .808 \\
\hline James 1986 & $\mathrm{nr}$ & $\begin{array}{l}\text { Concurrent effects } \\
\text { in therapy }\end{array}$ & $\mathrm{SC}$ & HAQ & $\mathrm{C}$ & $\begin{array}{l}\text { Session Impacts } \\
\text { Questionnaire }\end{array}$ & 151 & .44 \\
\hline Jang 2009 & $\begin{array}{l}3 \text { or } \\
\text { more }\end{array}$ & \begin{tabular}{|l|} 
Korean \\
counselors' \\
personal wellness \\
effects
\end{tabular} & $\mathrm{C}$ & WAI & $\mathrm{T}$ & IRI & 133 & .06 \\
\hline $\begin{array}{l}\text { Karlinska- } \\
\text { Nehrebecka } \\
\text { (undated) } \\
\end{array}$ & 1 & $\begin{array}{l}\text { Prognostic factors } \\
\text { of remaining in } \\
\text { psychotherapy }\end{array}$ & $\mathrm{O}$ & $\begin{array}{l}\text { Competencies } \\
\text { Rating Scale }\end{array}$ & $\mathrm{O}$ & $\begin{array}{l}\text { Competencies } \\
\text { Rating Scale }\end{array}$ & 93 & 1.061 \\
\hline $\begin{array}{l}\text { Kim et al. } \\
2002\end{array}$ & 1 & $\begin{array}{l}\text { Asian American } \\
\text { cultural adherence }\end{array}$ & C & WAI & $\mathrm{C}$ & BLRI & 78 & .678 \\
\hline $\begin{array}{l}\text { Kim et al. } \\
2005\end{array}$ & 1 & $\begin{array}{l}\text { Expectation, } \\
\text { worldview match, } \\
\text { and value } \\
\text { adherence }\end{array}$ & $\mathrm{C}$ & WAI & $\mathrm{C}$ & BLRI & 88 & .973 \\
\hline $\begin{array}{l}\text { Kim et al. } \\
2009\end{array}$ & 1 & $\begin{array}{l}\text { Adherence to } \\
\text { Asian cultural } \\
\text { values }\end{array}$ & $\mathrm{C}$ & WAI & $\mathrm{C}$ & BLRI & 61 & .908 \\
\hline $\begin{array}{l}\text { Lampropoulos } \\
2006\end{array}$ & $\mathrm{nr}$ & $\begin{array}{l}\text { Thinking styles, } \\
\text { treatment } \\
\text { preferences, } \\
\text { process, and } \\
\text { outcome }\end{array}$ & $\mathrm{C}$ & WAI & C & BLRI & 42 & 1.071 \\
\hline
\end{tabular}




\begin{tabular}{|c|c|c|c|c|c|c|c|c|}
\hline $\begin{array}{l}\text { Li \& Kim } \\
2004\end{array}$ & 1 & $\begin{array}{l}\text { Counseling style } \\
\text { and adherence to } \\
\text { Asian American } \\
\text { culture }\end{array}$ & $\mathrm{C}$ & WAI & C & BLRI & 52 & .811 \\
\hline \begin{tabular}{|l} 
Linley \& \\
Joseph 2007
\end{tabular} & $\mathrm{nr}$ & $\begin{array}{l}\text { Therapist work } \\
\text { and well-being }\end{array}$ & T & WAI & $T$ & JSPE & 156 & .321 \\
\hline $\begin{array}{l}\text { Macauley } \\
2005\end{array}$ & $\mathrm{nr}$ & $\begin{array}{l}\text { Qualities of } \\
\text { therapeutic } \\
\text { relationship }\end{array}$ & $\mathrm{O}$ & WAI & $\mathrm{O}$ & BLRI & 40 & .517 \\
\hline Moseley 1983 & 14 & $\begin{array}{l}\text { Therapeutic } \\
\text { relationship and } \\
\text { outcome }\end{array}$ & $\mathrm{C}$ & WAI & C & BLRI & 25 & .91 \\
\hline Murphy 1988 & $\mathrm{nr}$ & $\begin{array}{l}\text { Cognitive and } \\
\text { affective empathy } \\
\text { and the alliance }\end{array}$ & C, T & WAI & C, T & $\begin{array}{l}\text { Cognitive } \\
\text { Empathy Scale, } \\
\text { Affective } \\
\text { Empathy Scale }\end{array}$ & 41 & .228 \\
\hline $\begin{array}{l}\text { Pantalon et al. } \\
2004\end{array}$ & $\begin{array}{l}19 \\
\text { weeks } \\
\text { (mean) }\end{array}$ & $\begin{array}{l}\text { Linking process } \\
\text { to outcome }\end{array}$ & $\mathrm{O}$ & $\begin{array}{l}\text { Interpersonal } \\
\text { Variables } \\
\text { Rating Scale - } \\
\text { Alliance } \\
\text { Subscale }\end{array}$ & $\mathrm{O}$ & \begin{tabular}{|l|} 
Interpersonal \\
Variables \\
Rating Scale - \\
Empathy \\
Subscale
\end{tabular} & 16 & .85 \\
\hline Rossi 2012 & $5-32$ & $\begin{array}{l}\text { Successful vs. } \\
\text { unsuccessful } \\
\text { psychotherapies }\end{array}$ & $\mathrm{C}, \mathrm{T}$ & WAI & $\mathrm{O}$ & $\mid \begin{array}{l}\text { Not reported - } \\
\text { observer coding }\end{array}$ & 12 & .25 \\
\hline Rothman 2007 & $1-120$ & $\begin{array}{l}\text { Therapeutic } \\
\text { alliance with } \\
\text { sexual offenders }\end{array}$ & C & WAI & C & BLRI & 44 & .902 \\
\hline Saunders 2000 & 17 & $\begin{array}{l}\text { Association of } \\
\text { bond and outcome }\end{array}$ & C & $\begin{array}{l}\text { Therapeutic } \\
\text { Bond Scale - } \\
\text { Role } \\
\text { Investment } \\
\text { Subscale }\end{array}$ & C & $\begin{array}{l}\text { Therapeutic } \\
\text { Bond Scale- } \\
\text { Empathic } \\
\text { Resonance } \\
\text { Subscale }\end{array}$ & 114 & .192 \\
\hline $\begin{array}{l}\text { Spigelman } \\
2011\end{array}$ & $16-20$ & $\begin{array}{l}\text { Contribution of } \\
\text { empathy to early } \\
\text { alliance }\end{array}$ & C & WAI & $\mathrm{O}$ & MEE & 30 & .604 \\
\hline Tresky 2010 & 1 & $\begin{array}{l}\text { Gender sensitive } \\
\text { counseling }\end{array}$ & C & WAI & $\mathrm{O}$ & BLRI & 34 & .492 \\
\hline $\begin{array}{l}\text { Wang \& Kim } \\
2010\end{array}$ & 1 & $\begin{array}{l}\text { Therapist } \\
\text { multicultural } \\
\text { competency, } \\
\text { Asian American } \\
\text { culture, and } \\
\text { process }\end{array}$ & $\mathrm{O}$ & WAI & $\mathrm{O}$ & BLRI & 113 & 1.099 \\
\hline
\end{tabular}




\begin{tabular}{|l|l|l|l|l|l|l|l|l|}
\hline Wing Jr. 2010 & $\begin{array}{l}5 \text { or } \\
\text { more }\end{array}$ & $\begin{array}{l}\text { Relationship } \\
\text { between alliance, } \\
\text { therapist empath, } \\
\text { and outcome }\end{array}$ & O & $\begin{array}{l}\text { WAI, Global } \\
\text { Alliance } \\
\text { Rating }\end{array}$ & O & AES, MEE & 30 & .53 \\
\hline $\begin{array}{l}\text { Wolff \& } \\
\text { Hayes 2009 }\end{array}$ & $\mathrm{nr}$ & $\begin{array}{l}\text { Substance abuse } \\
\text { therapy }\end{array}$ & $\mathrm{C}$ & WAI & C & BLRI & 40 & .829 \\
\hline Young 2007 & 2 & $\begin{array}{l}\text { Counselor self- } \\
\text { disclosure of } \\
\text { religious } \\
\text { similarities }\end{array}$ & O & WAI & O & AES, BLRI & 189 & .466 \\
\hline Young 2011 & 1 & $\begin{array}{l}\text { Counselor } \\
\text { religious or } \\
\text { financial self- } \\
\text { disclosure }\end{array}$ & O & WAI & O & AES, BES & 647 & .701 \\
\hline $\begin{array}{l}\text { Zuroff \& Blatt } \\
2006\end{array}$ & $\begin{array}{l}\text { Therapist } \\
\text { contributions to } \\
\text { brief therapy for } \\
\text { depression }\end{array}$ & O & VTAS & C & BLRI & 209 & .155 \\
\hline
\end{tabular}

Abbreviations

Rater:

$\mathrm{C}=$ Client

$\mathrm{O}=$ Observer

$\mathrm{T}=$ Therapist

Measures:

AES $=$ Accurate Empathy Scale

BES = Burns Empathy Scale

BLRI = Barrett-Lennard Relationship Inventory

$\mathrm{HAQ}=$ Helping Alliance Questionnaire

IRI = Interpersonal Reactivity Index

JSPE $=$ Jefferson Scale of Physician Empathy

MEE = Measure of Expressed Empathy

VTAS $=$ Vanderbilt Therapeutic Alliance Scale

$\mathrm{WAI}=$ Working Alliance Inventory 
Table 9: Studies of Alliance Related to Empathy by Theoretical Approach to Treatment

\begin{tabular}{|c|c|c|c|c|c|c|c|}
\hline Author & Year & Theory & \begin{tabular}{|l} 
Study \\
Purpose
\end{tabular} & Sample & \begin{tabular}{|l} 
Alliance \\
Measure
\end{tabular} & $\begin{array}{l}\text { Empathy } \\
\text { Measure }\end{array}$ & $(r)$ \\
\hline Burchard & 1991 & PD & $\begin{array}{l}\text { Dimensions } \\
\text { of empathy } \\
\text { related to } \\
\text { alliance }\end{array}$ & $\begin{array}{l}45 \text { volunteer } \\
\text { participants } \\
\text { from mental } \\
\text { health clinics }\end{array}$ & HAQ & $\begin{array}{l}\text { BLRI } \\
\text { and IRI }\end{array}$ & 0.35 \\
\hline $\begin{array}{l}\text { Constantino } \\
\text { et al. }\end{array}$ & 2008 & C & $\begin{array}{l}\text { Integrative } \\
\text { cognitive } \\
\text { therapy vs. } \\
\text { traditional } \\
\text { cognitive } \\
\text { therapy }\end{array}$ & $\begin{array}{l}22 \\
\text { participants } \\
\text { in a } \\
\text { university } \\
\text { medical } \\
\text { clinic } \\
\end{array}$ & WAI & BES & 0.665 \\
\hline DeGeorge & 2008 & $\mathrm{C}$ & $\begin{array}{l}\text { Empathy, } \\
\text { alliance, and } \\
\text { treatment } \\
\text { outcome for } \\
\text { CBT with } \\
\text { Generalized } \\
\text { Anxiety }\end{array}$ & $\begin{array}{l}69 \\
\text { participants } \\
\text { referred from } \\
\text { local } \\
\text { practitioners } \\
\text { or recruited } \\
\text { through } \\
\text { advertising } \\
\end{array}$ & WAI & BLRI & 0.55 \\
\hline $\begin{array}{l}\text { Evans- } \\
\text { Jones et al. }\end{array}$ & 2009 & $\mathrm{C}$ & $\begin{array}{l}\text { CBT for } \\
\text { psychosis }\end{array}$ & \begin{tabular}{|l|}
24 \\
participants \\
seeking \\
community \\
mental \\
health \\
services
\end{tabular} & WAI & BLRI & 0.563 \\
\hline Saunders & 2000 & PD & $\begin{array}{l}\text { Relationship } \\
\text { between } \\
\text { therapeutic } \\
\text { bond and } \\
\text { outcome }\end{array}$ & $\begin{array}{l}114 \\
\text { participants } \\
\text { from the } \\
\text { Long Term } \\
\text { Psychotherap } \\
\text { y Research } \\
\text { Project }\end{array}$ & TBS & TBS & 0.19 \\
\hline Wing & 2010 & PD & $\begin{array}{l}\text { Empathy, } \\
\text { alliance, and } \\
\text { outcome }\end{array}$ & $\begin{array}{l}30 \text { clients } \\
\text { from the } \\
\text { Vanderbilt } \\
\text { video } \\
\text { archive }\end{array}$ & WAI & MEE & 0.55 \\
\hline
\end{tabular}

Abbreviations

Theory:

$\mathrm{C}=$ Cognitive approach

$\mathrm{PD}=$ Psychodynamic approach 
Measures:

BLRI = Barrett-Lennard Relationship Inventory

MEE $=$ Measure of Expressed Empathy

TBS $=$ Therapeutic Bond Scale

$\mathrm{WAI}=$ Working Alliance Inventory 
Table 10: Moderator Test of Race/Ethnicity Effects on Alliance/Empathy

\begin{tabular}{|l|l|l|}
\hline Race/Ethnicity & Coefficient Value & $p$-value \\
\hline White & -0.007 & 0.515 \\
\hline African-American & -0.003 & 0.683 \\
\hline Latino & $1.83 \times 10^{-4}$ & 0.758 \\
\hline Asian-American & $-7.42 \times 10^{-4}$ & 0.741 \\
\hline Native American & 0.002 & 0.721 \\
\hline Mixed Race & -0.014 & 0.435 \\
\hline International & -0.009 & 0.422 \\
\hline
\end{tabular}

$k=25$ 
Table 11: Funnel Plot of Alliance and Therapist Empathy Studies

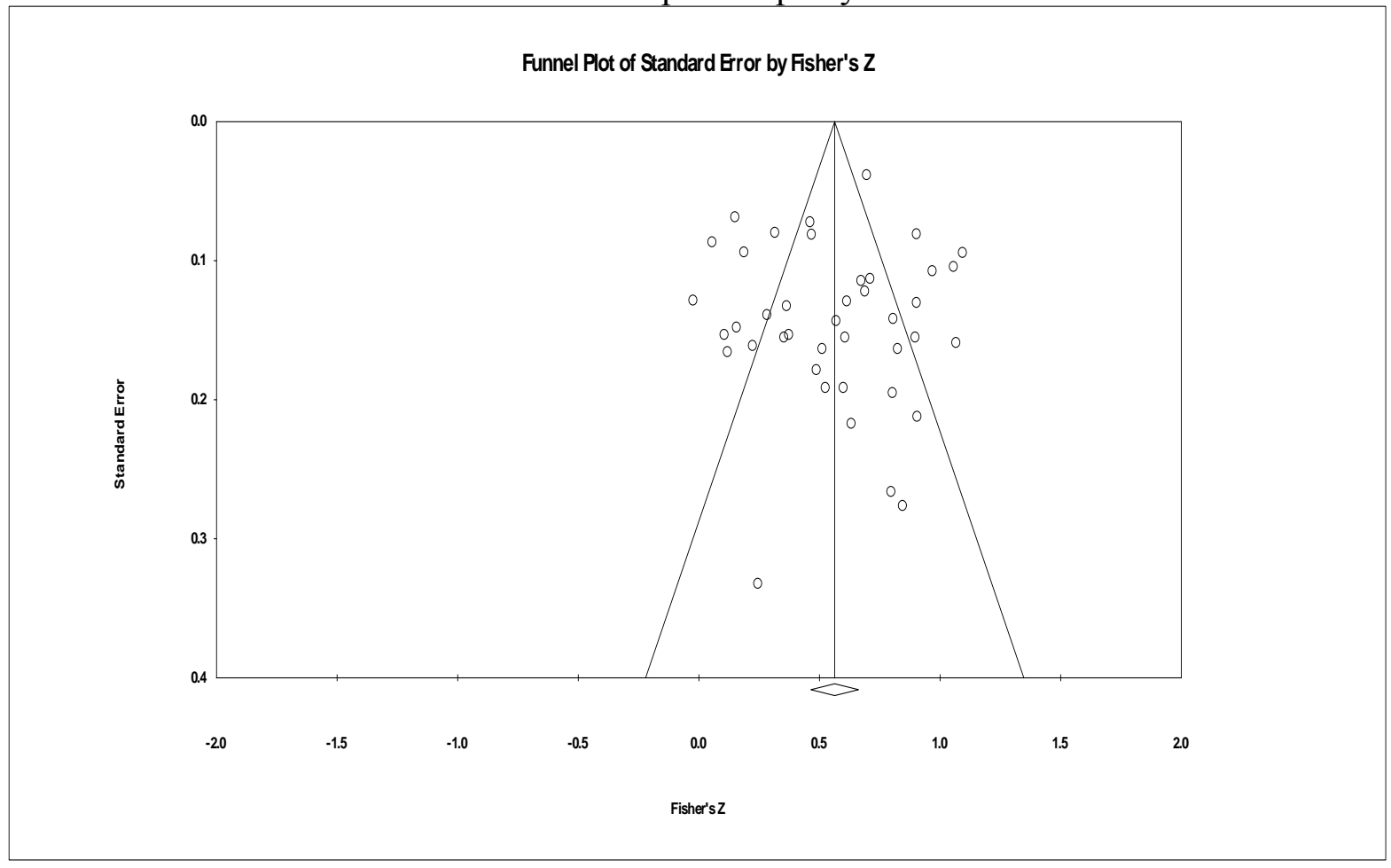


Table 12: Trim and Fill Analysis of Alliance Related to Therapist Empathy

Duval and Tweedie's trim and fill

\begin{tabular}{|c|c|c|c|c|c|c|c|c|c|}
\hline & \multirow[b]{2}{*}{$\begin{array}{l}\text { Studies } \\
\text { Trimmed }\end{array}$} & & \multicolumn{3}{|c|}{ Fixed Effects } & \multicolumn{3}{|c|}{ Random Effects } & \multirow[t]{2}{*}{ Q Value } \\
\hline & & & $\begin{array}{c}\text { Point } \\
\text { Estimate }\end{array}$ & $\begin{array}{l}\text { Lower } \\
\text { Limit }\end{array}$ & $\begin{array}{l}\text { Upper } \\
\text { Limit }\end{array}$ & $\begin{array}{c}\text { Point } \\
\text { Estimate }\end{array}$ & $\begin{array}{l}\text { Lower } \\
\text { Limit }\end{array}$ & $\begin{array}{l}\text { Upper } \\
\text { Limit }\end{array}$ & \\
\hline Observed values & & & 0.56449 & 0.53005 & 0.59892 & 0.56310 & 0.46453 & 0.66167 & 287.70593 \\
\hline Adjusted values & & 1 & 0.54582 & 0.51195 & 0.57969 & 0.54806 & 0.44722 & 0.64890 & 322.07425 \\
\hline
\end{tabular}

Duval and Tweedie's trim and fill

\begin{tabular}{|c|c|c|c|c|c|c|c|}
\hline \multirow[b]{2}{*}{$\begin{array}{l}\text { Studies } \\
\text { Trimmed }\end{array}$} & \multicolumn{3}{|c|}{ Fixed Effects } & \multicolumn{3}{|c|}{ Random Effects } & \multirow[t]{2}{*}{ Q Value } \\
\hline & $\begin{array}{c}\text { Point } \\
\text { Estimate }\end{array}$ & $\begin{array}{l}\text { Lower } \\
\text { Limit }\end{array}$ & $\begin{array}{l}\text { Upper } \\
\text { Limit }\end{array}$ & $\begin{array}{c}\text { Point } \\
\text { Estimate }\end{array}$ & $\begin{array}{l}\text { Lower } \\
\text { Limit }\end{array}$ & $\begin{array}{l}\text { Upper } \\
\text { Limit }\end{array}$ & \\
\hline & 0.56449 & 0.53005 & 0.59892 & 0.56310 & 0.46453 & 0.66167 & 287.70593 \\
\hline 0 & 0.56449 & 0.53005 & 0.59892 & 0.56310 & 0.46453 & 0.66167 & 287.70593 \\
\hline
\end{tabular}


Table 13: Alliance and Therapist Genuineness Overall Analysis

\section{Alliance and Genuineness}

\begin{tabular}{|c|c|c|c|c|c|c|c|}
\hline \multirow[t]{2}{*}{ Strifymame } & \multicolumn{7}{|c|}{ Strisfics for exch shody } \\
\hline & $\begin{array}{c}\text { Asher's } \\
Z\end{array}$ & $\begin{array}{l}\text { Standard } \\
\text { crror }\end{array}$ & Variance & $\begin{array}{l}\text { Lover } \\
\text { limit }\end{array}$ & $\begin{array}{l}\text { Upper } \\
\text { limit }\end{array}$ & ZValus & pValus \\
\hline Fitch 2007 & 0.592 & 0.074 & 0.005 & 0.449 & 0.736 & 8062 & 0,000 \\
\hline Fuetes ef al 2007 & 0.420 & 0.134 & 0.018 & 0.158 & 0.682 & 3.143 & 0.008 \\
\hline Calso, Kelley, Fuates ef a 2005 & 0.618 & 0.106 & 0.011 & 0.411 & 0.826 & 5.834 & 0.000 \\
\hline Kelley 2002 & 0.854 & 0.074 & 0.005 & 0.710 & 0.998 & 11.584 & 0.000 \\
\hline LoCo00 ot al 2011 & 0.479 & 0.127 & 0.016 & 0230 & 0.728 & 3772 & 0.000 \\
\hline Nemaosh et a 2009 & 0.526 & $0.1 \% 9$ & 0.022 & 0234 & 0.818 & 3.529 & 0.000 \\
\hline Oven, Tao, Leach, \& Foddla 2011 & 0.829 & 0.076 & 0.006 & 0.680 & 0.978 & 10.905 & 0.000 \\
\hline Rotrmen 2007 & 0.978 & 0.156 & 0.024 & 0.672 & 1.284 & 6.262 & 0.000 \\
\hline Spigdmen 2011 & 0.497 & 0.198 & 0.037 & 0.120 & 0.875 & 2.584 & 0.010 \\
\hline Znư \& Blat 2006 & 0.167 & 0000 & 0.005 & 0.030 & 0.304 & 2397 & 0.017 \\
\hline & 0.596 & 0.089 & 0.008 & 0.422 & $0.7 \pi 0$ & 6.714 & 0.000 \\
\hline
\end{tabular}

Fishr's Zand $96 \%$ a

$-1.00$

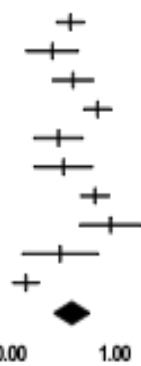

200 
Table 14: Additional Information Regarding the Individual Alliance and Therapist Genuineness Studies

\begin{tabular}{|c|c|c|c|c|c|c|c|c|}
\hline & & & & Alliance & & Empathy & & come \\
\hline Study & Sessions & Type & Rater & Measure & Rater & Measure & $\mathrm{N}$ & ES \\
\hline Fitch 2007 & $7 \mathrm{nr}$ & $\begin{array}{l}\text { Counselors as } \\
\text { caregivers }\end{array}$ & $T$ & WAI & $\mathrm{T}$ & RRI & 188 & .592 \\
\hline $\begin{array}{l}\text { Fuertes et } \\
\text { al. } 2007\end{array}$ & $\begin{array}{l}16 \\
\text { (median) }\end{array}$ & $\begin{array}{l}\text { Correlates of real } \\
\text { relationship }\end{array}$ & C, T & WAI & C & BLRI, RRI & 59 & .42 \\
\hline $\begin{array}{l}\text { Gelso et } \\
\text { al. } 2005\end{array}$ & $>5$ & $\begin{array}{l}\text { Validation of the } \\
\text { RRI-T }\end{array}$ & $T$ & WAI & $\mathrm{T}$ & RRI & 92 & .618 \\
\hline $\begin{array}{l}\text { Kelley } \\
2002\end{array}$ & $\begin{array}{l}28 \\
\text { months } \\
\text { (mean) }\end{array}$ & $\begin{array}{l}\text { Development of } \\
\text { RRI }\end{array}$ & $\mathrm{C}$ & WAI & $\mathrm{C}$ & BLRI, RRI & 187 & .854 \\
\hline $\begin{array}{l}\text { Lo Coco } \\
\text { et al. } 2011\end{array}$ & $\begin{array}{l}5.8 \\
(\text { mean) }\end{array}$ & $\begin{array}{l}\text { Real relationship } \\
\text { and alliance } \\
\text { related to } \\
\text { outcome }\end{array}$ & $\mathrm{C}, \mathrm{T}$ & WAI & C, T & RRI & 65 & .479 \\
\hline $\begin{array}{l}\text { Marmaros } \\
\text { h et al. } \\
2009\end{array}$ & 15 & $\begin{array}{l}\text { Real relationship } \\
\text { in psychotherapy }\end{array}$ & $\mathrm{C}, \mathrm{T}$ & WAI & C, T & RRI & 48 & .526 \\
\hline $\begin{array}{l}\text { Owen et } \\
\text { al. } 2005\end{array}$ & $\begin{array}{l}5 \\
\text { (median) }\end{array}$ & $\begin{array}{l}\text { Perceptions of } \\
\text { therapist } \\
\text { multicultural } \\
\text { orientation }\end{array}$ & C & WAI & C & RRI & 176 & .829 \\
\hline $\begin{array}{l}\text { Rothman } \\
2007\end{array}$ & $1-120$ & $\begin{array}{l}\text { Therapeutic } \\
\text { alliance with } \\
\text { sexual offenders }\end{array}$ & C & WAI & $\mathrm{C}$ & BLRI & 44 & .978 \\
\hline $\begin{array}{l}\text { Spigelman } \\
2011\end{array}$ & $16-20$ & $\begin{array}{l}\text { Contribution of } \\
\text { empathy to early } \\
\text { alliance }\end{array}$ & C & WAI & $\mathrm{O}$ & MEE & 30 & .497 \\
\hline \begin{tabular}{|l} 
Zuroff \& \\
Blatt 2006
\end{tabular} & 16 & $\begin{array}{l}\text { Therapist } \\
\text { contributions to } \\
\text { brief therapy for } \\
\text { depression }\end{array}$ & $\mathrm{O}$ & VTAS & C & BLRI & 209 & .167 \\
\hline
\end{tabular}

Abbreviations

Rater:

$\mathrm{C}=$ Client

$\mathrm{O}=$ Observer 
$\mathrm{T}=$ Therapist

Measures:

BLRI = Barrett-Lennard Relationship Inventory

MEE $=$ Measure of Expressed Empathy

RRI $=$ Real Relationship Inventory

VTAS $=$ Vanderbilt Therapeutic Alliance Scale

$\mathrm{WAI}=$ Working Alliance Inventory 
Table 15: Results of Moderator Tests for Therapist Genuineness and Alliance

Categorical

\begin{tabular}{|l|c|c|c|c|}
\hline Moderator & $k$ & $Q_{\mathrm{b}}$ & $p$ & $r$ \\
\hline Article Type & 10 & 2.111 & .146 & \\
\hline Published & 6 & & & .467 \\
\hline Unpublished & 4 & & & .628 \\
\hline Therapist Experience & 9 & 0.566 & .452 & \\
\hline Professional & 4 & & & .594 \\
\hline Mixed & 5 & & & .497 \\
\hline Alliance Rater & 12 & 1.311 & .252 & \\
\hline Client & 7 & & & .583 \\
\hline Therapist & 5 & & & .506 \\
\hline Genuineness Measure & 11 & .023 & .878 & \\
\hline BLRI & 4 & & & .539 \\
\hline RRI & 7 & & & .561 \\
\hline Genuineness Rater & 12 & .636 & .425 & \\
\hline Client & 7 & & & .559 \\
\hline Therapist & 5 & & & .471 \\
\hline Rater Constancy** & 19 & 29.898 & .000 & \\
\hline Rater Constant & & & & .628 \\
\hline Rater Not Constant & & & & .262 \\
\hline
\end{tabular}

Continuous

\begin{tabular}{|l|c|c|c|c|}
\hline Moderator & $\mathrm{k}$ & Coefficient Value & $Q_{\text {model }}$ & $p_{\text {model }}$ \\
\hline Publication/Defense Year & 10 & -0.01 & 0.125 & 0.723 \\
\hline Male/Female Ratio & 8 & -0.005 & 1.087 & 0.297 \\
\hline Number of Clients & 10 & $-1.18 \times 10^{-4}$ & 0.02 & 0.886 \\
\hline White/Nonwhite Client Ratio* & 6 & -0.013 & 5.423 & 0.02 \\
\hline Client Mean Age & 7 & $-2.07 \times 10^{-4}$ & 0.0001 & 0.992 \\
\hline Male/Female Therapist Ratio & 5 & -0.005 & 2.178 & 0.14 \\
\hline Number of Therapists & 8 & $1.04 \times 10^{-4}$ & 0.014 & 0.903 \\
\hline White/Nonwhite Therapist Ratio & 7 & 0.003 & 0.184 & 0.67 \\
\hline Average Number of Sessions & 9 & 0.007 & 1.76 & 0.184 \\
\hline
\end{tabular}

Note: $\mathrm{k}=$ number of studies

$Q_{\mathrm{b}}=$ Heterogeneity between categorical variables 
$Q_{\text {model }}=$ Model fit $Q$ statistic

$P_{\text {model }}=$ p-value (significance level) of model

*Significant at the $p<.05$ level

$* *$ Significant at the $p<.01$ level 
Table 16: Funnel Plot of Alliance and Therapist Genuineness Studies

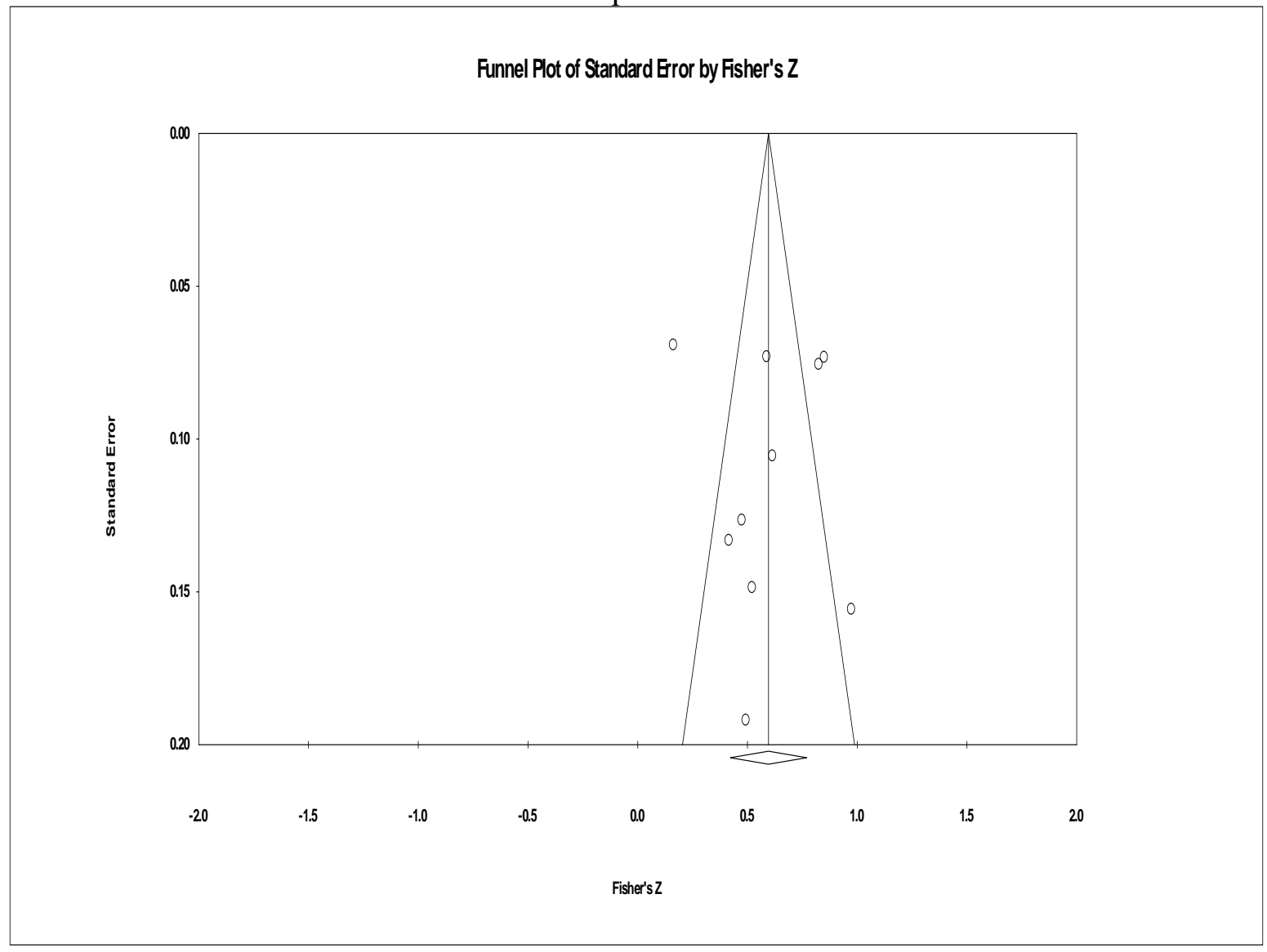


Table 17: Trim and Fill Analysis of Alliance Related to Therapist Genuineness

Duval and Tweedie's trim and fill

\begin{tabular}{|c|c|c|c|c|c|c|c|c|c|}
\hline & \multirow[b]{2}{*}{$\begin{array}{l}\text { Studies } \\
\text { Trimmed }\end{array}$} & & \multicolumn{3}{|c|}{ Fixed Effects } & \multicolumn{3}{|c|}{ Random Effects } & \multirow[t]{2}{*}{ Q Value } \\
\hline & & & $\begin{array}{c}\text { Point } \\
\text { Estimate }\end{array}$ & $\begin{array}{l}\text { Lower } \\
\text { Limit }\end{array}$ & $\begin{array}{l}\text { Upper } \\
\text { Limit }\end{array}$ & $\begin{array}{l}\text { Point } \\
\text { Estimate }\end{array}$ & $\begin{array}{l}\text { Lower } \\
\text { Limit }\end{array}$ & $\begin{array}{l}\text { Upper } \\
\text { Limit }\end{array}$ & \\
\hline Observed values & & & 0.58984 & 0.52986 & 0.64981 & 0.59591 & 0.42196 & 0.76987 & 68.61809 \\
\hline Adjusted values & & 0 & 0.58984 & 0.52986 & 0.64981 & 0.59591 & 0.42196 & 0.76987 & 68.61809 \\
\hline
\end{tabular}

Duval and Tweedie's trim and fill

\begin{tabular}{|c|c|c|c|c|c|c|c|}
\hline \multirow[b]{2}{*}{$\begin{array}{l}\text { Studies } \\
\text { Trimmed }\end{array}$} & \multicolumn{3}{|c|}{ Fixed Effects } & \multicolumn{3}{|c|}{ Random Effects } & \multirow[t]{2}{*}{ Q Value } \\
\hline & $\begin{array}{c}\text { Point } \\
\text { Estimate }\end{array}$ & $\begin{array}{l}\text { Lower } \\
\text { Limit }\end{array}$ & $\begin{array}{l}\text { Upper } \\
\text { Limit }\end{array}$ & $\begin{array}{c}\text { Point } \\
\text { Estimate }\end{array}$ & $\begin{array}{l}\text { Lower } \\
\text { Limit }\end{array}$ & $\begin{array}{l}\text { Upper } \\
\text { Limit }\end{array}$ & \\
\hline & 0.58984 & 0.52986 & 0.64 & 0.59591 & 0.42196 & 0.76987 & \\
\hline & 0.58984 & 0.52986 & 0.64981 & 0.59591 & 0.42196 & 0.76987 & 68.61809 \\
\hline
\end{tabular}


CURRICULUM VITAE

\section{Jacob Nienhuis \\ 616-856-0294}

Jake.Nienhuis@gmail.com

nienhuja@gvsu.edu

\section{Academic History}

July 2014 (expected)

The University of Louisville, Louisville, Kentucky

Doctor of Philosophy, Counseling Psychology

(APA Accredited)

Dissertation Title: A meta-analytic review of the relationships between the therapeutic alliance, empathy, and genuineness in individual adult psychotherapy.

Defended December 2013

Dec. 2011

The University of Louisville, Louisville, Kentucky

Masters of Education, Counseling Psychology

May 2007

Calvin College, Grand Rapids, Michigan

Bachelor of Arts, Psychology; Minor in International Relations

\section{Supervised Counseling Experiences}

July 2013 - July 2014 APA Accredited Doctoral Internship. Grand Valley State
University Counseling Center, Allendale, Michigan.

\section{Clinical}

- Provided individual, group, and career counseling for university students. Presenting client concerns included: Depression, anxiety, relationships, sexual assault, childhood trauma, eating disorders, grief, identity development issues, family, and personality disorders. 
- Group therapy: General interpersonal process groups and a psychoeducational group on healthy relationships.

- Provided drop-in urgent care during the work day and provided on-call crisis intervention for after-hours emergencies. Trained in Crisis Intervention Stress Management for Individuals and Groups.

- Conducted personality and career assessments. Wrote integrative reports following the assessments and discussed these reports with clients. Wrote letters to clients summarizing the therapeutic process and how this related to the assessment results.

- $\quad$ Participated in trainings on crisis intervention, multicultural psychology, group therapy, career counseling, assessment, existential psychology, and substance abuse education.

- Presented cases and psychology topics to the counseling center staff.

\section{Consultation and Outreach}

- Provided outreach to different campus groups (e.g. Housing, Greek organizations, student-led initiatives, etc.) on: Depression and anxiety management, relaxation, communication and conflict resolution, study strategies, and alcohol education.

- Assisted in the training of new graduate assistants and resident assistants in the campus Housing Department.

\section{Supervision and Administration}

- Supervised campus Peer Educators on a weekly basis.

- Assisted with the training and certification of the campus Peer Educators

- Collaborated on the selection committee for future interns.

- Collaborated on an intern-led research project on cultural make-up of students seeking counseling center services as representative of total student body.

Aug. 2011 - May 2012

Practicum. Fort Knox, Department of Behavioral Health, Fort Knox, Kentucky. Provided individual therapy for active duty soldiers and military reserve members. Co-facilitated group therapy for soldiers suffering from extreme PTSD. Conducted walk-in interviews and mental status exams for 
Aug. 2010 - Aug. 2011

May - Oct. 2010

Aug. 2009 - May 2010

May - Sept. 2009 soldiers seeking advanced training. Staffed cases with different care team members. Conducted an assessment for ADHD and compiled a full report. Participated in trainings regarding military culture and new treatments.

Practicum. Indiana University Southeast Center for Counseling and Personal Services, New Albany, Indiana. Provided brief and long-term therapies for traditional and nontraditional undergraduate university students. Administered, scored, and interpreted comprehensive assessment batteries, wrote reports, and conducted feedback sessions. Participated in and facilitated outreach programming.

Practicum. The Archdiocese of Louisville, Louisville, Kentucky. Assessment practicum experience which involved working in the Catholic school system, assessing students for learning and cognitive disabilities, and writing assessment reports. Conducted a variety of intelligence and personality tests (e.g. WISC-IV, WAIS-IV, WIAT-IV, Incomplete Sentences, TAT, etc.). Wrote psychological assessment reports and recommendations for implementation in school.

Practicum. The University of Louisville Counseling Center, Louisville, Kentucky. Provided brief and long-term individual therapies for traditional and non-traditional undergraduate and graduate university students. Participated in outreach programming. Presented cases to case conference team including psychologists, social workers, nurse practitioners, and psychiatrists. Worked as a member of a care team.

Practicum. Kentucky State Reformatory, La Grange, Kentucky. Conducted individual therapy with adult male members of the general inmate population. Assisted in group therapy classes on basic life skills and symptom management for inmates in the psychiatric unit of the prison. Collaborated with colleagues at different levels of the care team.

\title{
Professional Experiences
}

Aug. 2013 - Dec. 2013

\author{
Grand Valley State University, Department of University \\ Studies, Allendale, MI \\ US 102 instructor. Taught a one-credit class on career \\ exploration to undecided university students. Responsibilities \\ included teaching and interpreting the Myers-Briggs Type \\ Indicator, Strong Interest Inventory, and Strengthsquest,
}


Aug. 2012 - June 2013

July 2011 - Aug. 2012

July 2010 - June 2011

July 2009 - June 2010

Aug. 2008 - June 2009

Jan. 2006 - July 2008

Jan - May 2006 assigning and grading student work, and introducing students to university resources.

Clinical Research Assistant, Leatherman Spine Center at Norton Healthcare, Louisville, KY

Clinical research assistant to Dr. Leah Carreon.

Responsibilities included data entry, patient enrollment, photography, and literature review.

Graduate Research Assistant, The National Research Center for Career and Technical Education, University of Louisville, College of Education and Human Development Graduate assistant to Dr. James Stone. Responsibilities included literature searching, report writing, data collection and entry, and communication with peer institutions.

Graduate Research Assistant, The University of Louisville, Department of Educational \& Counseling Psychology, Department of Education and Counseling Psychology Graduate assistant to Dr. Mark Leach and Dr. Nancy Cunningham. Responsibilities included teaching anti-bullying interventions, data entry \& collection, and assistance with the reaccreditation process.

Graduate Research Assistant, Department of Education and Counseling Psychology

Graduate assistant to Dr. Nancy Cunningham. Responsibilities included teaching anti-bullying interventions, data collection \& entry, and use of social network statistical programming.

Graduate Research Assistant, Department of Education and Counseling Psychology

Graduate assistant to Dr. Samuel Stringfield and Dr. Eileen Estes. Responsibilities included literature review, information gathering, and data entry.

Patient Care Provider, Pine Rest Christian Mental Health Services. Grand Rapids, MI.

Responsibilities involved providing a safe patient environment, leading group discussions and mental health classes, and interacting with patients in order to assess their current thoughts/feelings and give support.

Intern - Mary Free Bed Rehabilitation Hospital, Grand Rapids, MI. 
Activities were divided between observation of clinical testing and conducting original research. The site provided services for people with traumatic brain injury and other impairments. On-site Supervisor: Dr. Jacobus Donders

\section{Publications}

Budge, S. L., Moore, J. T., Del Re, A. C., Wampold, B. E., Baardseth, T. P., \& Nienhuis, J. B. (2013). The effectiveness of evidence-based treatments for personality disorders when comparing treatment-as-usual and bonafide treatment. Clinical Psychology Review 33(8), 1057-1066.

Carreon, L. Y., Bratcher, K. R., Das, N., Nienhuis, J., Glassman, S. D. (2013). Estimating EQ-5D values from the Oswestry Disability Index and Numeric Rating Scales for Back and Leg Pain. The Spine Journal, 13(9), S40.

Carreon, L. Y., Mueller, B., Bratcher, K. R., Das, N., Nienhuis, J., Glassman, S. D. (2013). Correlation of EQ-5D and NDI In an adult spine patient population with degenerative cervical disease. The Spine Journal, 13(9), S39.

Das, N., Glassman, S. D., Djurasovic, M., Bratcher, K. R., Nienhuis, J., \& Carreon, L. Y. (2013). Effect of comorbidities and psychosocial conditions in clinical outcomes after lumbar spinal fusion. The Spine Journal, 13(9), S40-S41.

Das, N., Glassman, S. D., Djurasovic, M., Bratcher, K. R., Nienhuis, J. B., \& Carreon, L. Y. (2013). Effect of comorbidities and psychosocial conditions in HRQOL after lumbar spinal fusion. Annals of Epidemiology, 23(9), 585.

Stone, J., Nienhuis, J. B., \& Aliaga, O. A. (2012). The strategic value of social capital: How firms capitalize on social assets. European Journal of Training and Development 36(7), 766-768.

Donders, J., \& Nienhuis, J. B. (2007). Utility of California Verbal Learning Test, Second Edition, recall discriminability indices in the evaluation of traumatic brain injury. Journal of the International Neuropsychological Society, 13, 354-358.

\section{Presentations}

Nienhuis, J. N. (2012, February). Meta-analysis of therapist empathy and genuineness related to the alliance. Oral presentation at the University of Louisville Doctoral Student Organization monthly meeting, Louisville, KY. 
Cunningham, N. J., Hopkins, K. L., \& Nienhuis, J. B. (2011, August). A study of indicators of sexual harassment in early adolescence. Poster session presented at the meeting of the American Psychological Association, Washington, DC.

Cunningham, N. J., Nienhuis, J. B., Hesler, B. N., \& Hopkins, K. L. (2010, August). Examining participant roles in early adolescent bullying. Poster session presented at the meeting of the American Psychological Association, San Diego, CA.

Cunningham, N. J., Hesler, B. N., Nienhuis, J. B., \& Hopkins, K. L. (2010, August). Using social network analysis to examine victims of bullying. Poster session presented at the meeting of the American Psychological Association, San Diego, CA.

Nienhuis, J. B., Hesler, B. N., \& Hopkins, K. L. (2010, March). Participant roles in bullying during early adolescence. Oral paper presentation at the meeting of the Kentucky Psychological Association, Louisville, KY.

Cunningham, N. J., Nienhuis, J. B., Whitten, M. E., Goodwin, S., Lanham, J., Eder, K. M., \& Taylor, M. P. (2009, August). Social networks and bulling in early adolescence. Poster session presented at the meeting of the American Psychological Association, Toronto, ON.

Whitten, M., Nienhuis, J. B., Lanham, J. T., \& Goodwin, S. (2009, April). Node level analysis of a middle school peer network: Identifying the social relatedness and attributes of bullies, victims, and non-participants. Research data presented at the Annual Spring Research Conference, Louisville, KY.

\section{Committee and Volunteer Experiences}

March 2012 Volunteer, Brooklawn Hospital, Louisville, KY

March 2012 Cleanup Volunteer, Maryville, IN

Aug. 2009 - Present Volunteer Peer Mentor, University of Louisville, Louisville, KY

Oct. 2008 - May 2013 Web liaison and member of the Doctoral Student Organization, Department of Counseling Psychology, The University of Louisville

Sept. 2008 - Present American Psychological Association, Graduate Student Affiliate

Sept. 2008 - Present Kentucky Psychological Association, Graduate Student Affiliate 


\section{Professional References}

Dr. Amber Roberts, Ph. D.

Director, University Counseling Center

204 Student Services

1 Campus Drive

Allendale, MI 49401

(616) 331-3266

roberamb@gvsu.edu

Dr. Jesse Owen, Ph. D.

Associate Professor of Educational and Counseling Psychology

University of Louisville

2301 South $3^{\text {rd }} \mathrm{St}$

Louisville, KY 40208

(502) 852-0632

jesse.owen@louisville.edu

Dr. Pamela Miller, Ph. D.

Associate Director and Director of Training, University Counseling Center

204 Student Services

1 Campus Drive

Allendale, MI 49401

(616) 331-3266

millepam@gvsu.edu 